\title{
Solubilization of Hydrophobic Peptides by \\ Reversible Cysteine PEGylation
}

by

Neil Christopher Pomroy
A thesis submitted in conformity with the requirements for the degree of Master of Science Graduate Deparment of Biochemistry University of Toronto


Acquisitions and Bibliographic Services

395 Wellington Street Otlawa ON KIA ONA Canada
Bibliothèque nationale du Canada

Acquisitions et services bibliographiques

395, rue Wellington Ottawa ON KIA ON4 Canada
The author has granted a nonexclusive licence allowing the National Library of Canada to reproduce, loan, distribute or sell copies of this thesis in microform, paper or electronic formats.

The author retains ownership of the copyright in this thesis. Neither the thesis nor substantial extracts from it may be printed or otherwise reproduced without the author's permission.
L'auteur a accordé une licence non exclusive permettant à la Bibliothèque nationale du Canada de reproduire, prêter, distribuer ou vendre des copies de cette thèse sous la forme de microfiche/film, de reproduction sur papier ou sur format électronique.

L'auteur conserve la propriété du droit d'auteur qui protège cette thèse. $\mathrm{Ni}$ la thèse ni des extraits substantiels de celle-ci ne doivent être imprimés ou autrement reproduits sans son autorisation. 


\section{ABSTRACT}

'PEG-a-Cys' reagent, synthesized by the esterification of monomethoxy-poly(ethylene glycol) to Ellman's reagent [5,5'-dithiobis (2-nitrobenzoic acid)], is demonstrated to react to form a disulfide bond with the cysteine residue of ALC, a 25-residue synthetic peptide $\left(\mathrm{H}_{2} \mathrm{~N}-\mathrm{REAAALAAAAALAAWAALCPARRRR}-\mathrm{CO}_{2} \mathrm{H}\right)$ designed to model a fusion protein of a membrane protein transmembrane segment. Enzymatic digestion of the four charged residues at the carboxyl terminus of the peptide - which mimics the enzymatic cleavage of a TM segment from the fusion protein - releases a hydrophobic peptide which precipitates from aqueous solution within 24 hours. The PEG-a-Cysmodified peptide remains soluble for at least 7 days following identical enzymatic digestion, as measured by amino acid analysis of ultracentrifuged samples. Circular dichroism spectra reveal that neither PEG-a-Cys-modification nor digestion of ALC cause major changes in its primarily $\alpha$-helical secondary structure. Routine solubilization of hydrophobic peptides is expected to simplify the purification and structural characterization of membrane protein TM segments. 


\section{ACKNOWLEDGEMENTS}

I'd like to thank Dr. Charles M. Deber for his guidance and supervision, and Dr. Anders Bennick and Dr. James Rini for their support and helpful discussions. Thanks also to Dr. Nam Wang, Dr. Art Grey and Mr. Rey Interior for their willingness to lend their expertise in, respectively, peptide synthesis, nuclear magnetic resonance spectroscopy and amino acid analysis. Thanks as well to Natalie Goto, Dr. Liping Liu, Christopher Yuen, Chen Wang and all other members of the Deber lab, past and present, for their assistance and insightful discussions. Thanks also to Randall Willis for his technical expertise and his willingness to share it.

I am indebted to the University of Toronto, the Hospital for Sick Children and Dr.

Charles M. Deber for supporting me during my research via an Open scholarship, a Research Training Committee award and MRC grant funds respectively. I'd also like to thank the Medical Research Council of Canada and the Canadian Cystic Fibrosis Foundation for their support of this research.

In addition, I am grateful to my father Christopher, my mother Charlotte, my brother Ian, and my sisters Susan and Alison, for encouraging and stimulating my interest in learning in a variety of areas, including but not limited to science. Lastly I must thank my dear friends from the In: Gregory Downs, Krista Hearty, Dr. Matthew Naysmith, Joy Henderson, Rev. Michael Lightbody, Dana Wessell, Lindsay Richardson, Greg Clark, Kim Stanford, Paul Thompson, Janel Bascomb, Alison Pomroy, Becky Young, Kelly Fogg, Alexandra Longsworth, Ben Walsh, Dave Biasutti, Leela Holliman and Randall Willis; all of whose friendship and joie de vivre were greatly appreciated throughout my years of study. 


\section{TABLE OF CONTENTS}

Abstract......................................................... ii

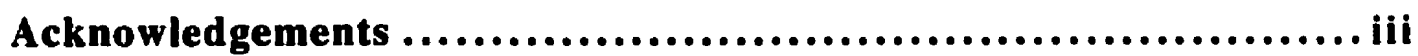

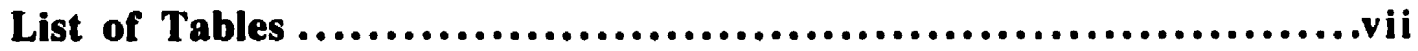

List of Figures $\ldots \ldots \ldots \ldots \ldots \ldots \ldots \ldots \ldots \ldots \ldots \ldots \ldots \ldots \ldots \ldots \ldots \ldots \ldots \ldots \ldots \ldots \ldots \ldots \ldots$

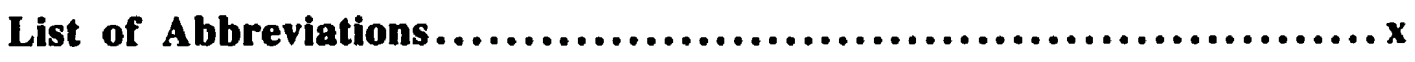

\section{INTRODUCTION $\ldots \ldots \ldots \ldots \ldots \ldots \ldots \ldots \ldots \ldots \ldots \ldots \ldots \ldots \ldots \ldots \ldots$}

1.1 Structural characterization of integral membrane protein transmembrane domains $. . \ldots \ldots \ldots \ldots \ldots \ldots \ldots \ldots \ldots \ldots \ldots \ldots \ldots \ldots \ldots . \ldots \ldots$

1.1.1 Hydrophobicity and polypeptide structure ...........................3

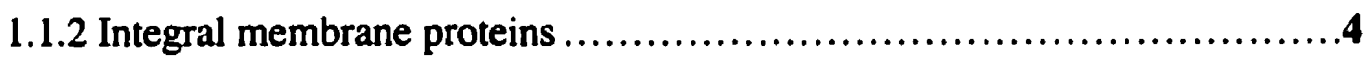

1.1.3 Structural characterization of transmembrane domains ...................5

1.1.4 Experimental models of transmembrane segments.......................6

1.1.4.1 The use of detergents to solubilize TM domains.....................8

1.2 Poly(ethylene glycol) and protein PEGylation.................10

1.2.1 Physical and chemical properties of PEG ..........................10

1.2.2 PEGylation of proteins .......................................... 2

1.2.3 Chemistries of PEG derivatization ................................... 14

1.2.3.1 Cys-PEGylation .............................................. 15

1.2.3.2 Ellman's reagent as a Cys-reactive molecule for $P E G$ derivatization. 16

1.3 Rationale.............................................. 9

1.3.1 Design of PEG-a-Cys reagent .....................................21

1.3.2 Design of ALC model peptide ....................................24

\section{MATERIALS AND METHODS $\ldots \ldots \ldots \ldots \ldots \ldots \ldots \ldots \ldots \ldots \ldots \ldots \ldots . \ldots$}

2.1 PEG-a-Cys reagent.................................. 7

2.1.1 Synthesis..................................................... 8

2.1.2 Purification............................................................. 9

2.1.2.1 Skoog PEG assay ........................................................ 30

2.1.2.2 TNB assay.......................................................... 1

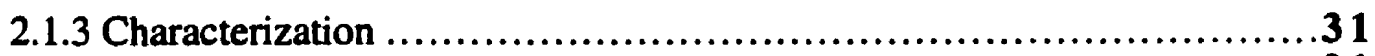

2.1.3.1 Nuclear magnetic resonance spectroscopy........................... 31

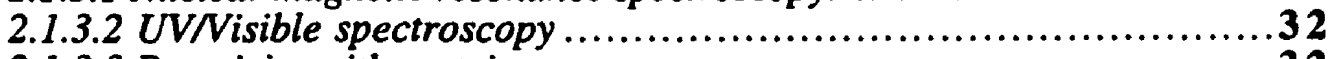

2.1.3.3 Reactivity with cysteine ..................................... 32 


\section{TABLE OF CONTENTS (continued)}

2.2 ALC model peptide.........................................33

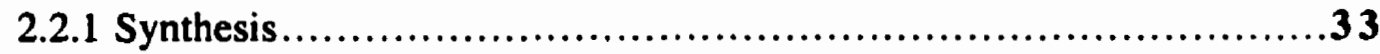

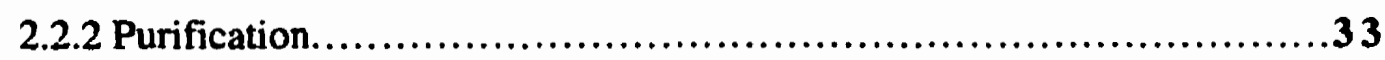

2.2.3 Characterization ...................................................34

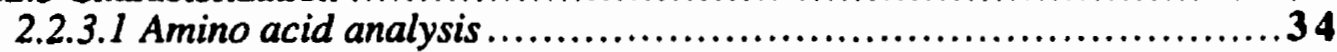

2.3 PEGylation and enzyme digestion of ALC ...................35

2.3.1 PEGylation of ALC with PEG-a-Cys ................................35

2.3.1.I Native basic PAGE................................................35

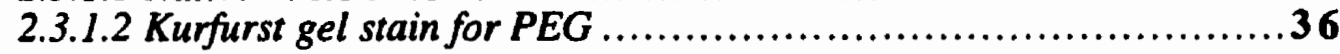

2.3.2 Enzyme digestion of C-terminal Arg residues ........................36

2.3.3 Solubility effects of PEGylation and digestion ........................37

2.3.3.1 Ultracentrifugation..............................................37

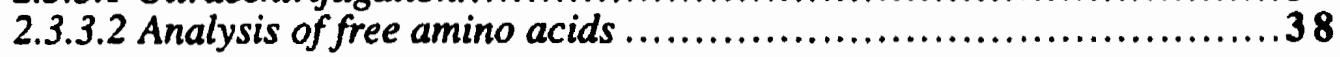

2.3.4 Structural effects of PEGylation and digestion...........................38

2.3.4.1 Circular dichroism spectroscopy....................................... 39

3. RESULTS....................................................40

3.1 PEG-a-Cys reagent........................................41

3.1.1 Synthesis.......................................................41

3.1.2 Purification..........................................................4 4

3.1.2.1 FPLC gel filtration...........................................43

3.1.3 Characterization ................................................46

3.1.3.1 NMR spectroscopy.......................................46

3.1.3.2 UVNVisible spectroscopy ........................................50

3.1.3.3 Reactivity with cysteine .......................................50

3.2 ALC model peptide.........................................53

3.2.1 Purification....................................................53

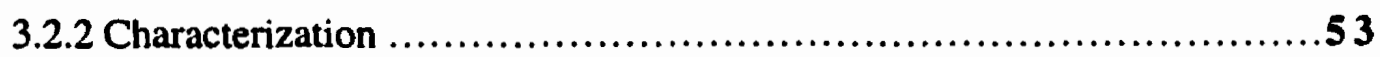

3.3 PEGylation and enzyme digestion of ALC ..................55

3.3.1 PEGylation.........................................................55

3.3.1.1 Reversibility of PEGylation ....................................57

3.3.2 Enzyme digestion ..............................................5 7

3.3.3 Solubility effects of PEGylation and digestion .......................61

3.3.3.1 Ultracentrifugation...........................................6 61

3.3.3.2 NB-PAGE analysis of supernatants..............................63

3.3.3.3 Free amino acid analysis of digested samples.....................66

3.3.4 Structural effects of PEGylation and digestion........................67

3.3.4.1 Structural stability at 1 day ........................................67

3.3.4.2 Structural stability over eight day incubation......................6 7 


\section{TABLE OF CONTENTS (continued)}

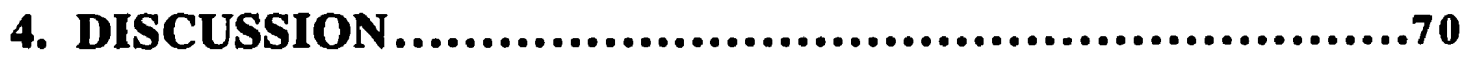

4.1 PEG-a-Cys reagent....................................72

4.1.1 Design considerations: Bis- vs. mono-esterification of PEG to Ellman's

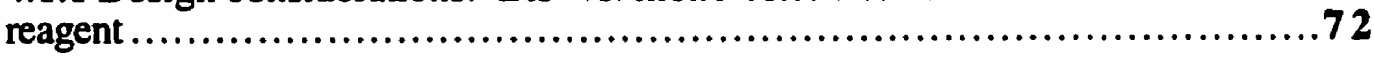

4.1.2 Synthesis................................................... 75

4.1.3 Purification.......................................................... 76

4.1.4 Characterization ..................................................... 78

4.1.4.1 NMR spectroscopy..........................................78

4.1.4.2 UV/Vis spectroscopy..........................................79

4.1.4.3 Reactivity with cysteine......................................8 80

4.2 PEGylation and enzyme digestion of ALC ................. 1

4.2.1 Native basic PAGE analysis of proteins...........................8 1

4.2.2 PEGylation.....................................................82

4.2.2.1 Reversibility of PEGylation ..................................... 83

4.2.3 Enzyme digestion of C-terminal Arg residues $\ldots \ldots \ldots \ldots \ldots \ldots \ldots \ldots \ldots \ldots . . .64$

4.2.4 Solubility effects of PEGylation...................................85

4.2.5 Structural effects of PEGylation...................................87

4.3 Conclusion..........................................91

4.4 Future perspectives $. . \ldots \ldots \ldots \ldots \ldots \ldots \ldots \ldots \ldots \ldots \ldots \ldots \ldots \ldots . \ldots \ldots$

5. REFERENCES $\ldots \ldots \ldots \ldots \ldots \ldots \ldots \ldots \ldots \ldots \ldots \ldots \ldots \ldots \ldots \ldots \ldots \ldots \ldots \ldots \ldots$ 


\section{LIST OF TABLES}

Page

Table 1: Yields of PEG-a-Cys synthesis

Table 2: Free [Arg] and \% digestion of ultracentrifugation supernatants 66

Table 3: Hydrophobicity of digested states of ALC peptide as determined by the method of Kyte and Doolittle 84 


\section{LIST OF FIGURES}

Page

Figure 1: PEG and MPEG ___

Figure 2: Ellman's reagent_______

Figure 3: PEG-a-Cys reagent_____ 1

Figure 4: PEGylation of peptides________

Figure 5: ALC peptide

Figure 6: Synthesis of PEG-a-Cys reagent _-__- 28

Figure 7: Gel filtration of PEG-a-Cys on Sephadex G100 resin _-__-_44

Figure 8: Purification of PEG-a-Cys by Superdex 75 FPLC gel

filtration

Figure 9: 1D- ${ }^{1} \mathrm{H}-\mathrm{NMR}$ spectrum of PEG-a-Cys in $d_{6}-\mathrm{DMSO}$ at

500 MHz.

Figure 10: HMBC-2D- ${ }^{13} \mathrm{C} /{ }^{1} \mathrm{H}-\mathrm{NMR}$ spectrum of PEG-a-Cys in $\mathrm{d}_{6}-\mathrm{DMSO}$ at $500 \mathrm{MHz}$

Figure 11: UV/Visible spectroscopic characterization of reduced PEG-aCys

Figure 12: Reactivity of PEG-a-Cys with amino acids 52

Figure 13: Purification of ALC peptide by RP-HPLC 54

Figure 14: PEGylation of ALC: NB-PAGE analysis 56

Figure 15: Reversibility of ALC PEGylation: NB-PAGE analysis ___58

Figure 16: Carboxypeptidase B digestion of ALC: NB-PAGE analysis. 60

Figure 17: ALC concentrations of ultracentrifugation supernatants: amino acid analysis

Figure 18: Ultracentrifugation supernatants at 0.1 days: NB-PAGE analysis 


\section{LIST OF FIGURES (continued)}

Page

Figure 19: Ultracentrifugation supernatants at 7 days: NB-PAGE analysis 65

Figure 20: Structural effects of PEGylation and digestion of ALC peptide over 1 day: CD spectroscopy 68

Figure 21: Structural effects of PEGylation of ALC peptide over 8 days: CD spectroscopy 69

Figure 22: Molecular weights of the reactants, products and byproducts of PEG-a-Cys synthesis 


\section{LIST OF ABBREVIATIONS}

ALC

Ala

Arg

$\mathrm{CD}$

Cys

DCC

DCU

DMAP

$\mathrm{d}_{6}$-DMSO

DTNB

FPLC

Glu

HPLC

HMBC

Leu

MPEG

MPEGyl-DTNB

Ala/Lew/Cys model hydrophobic peptide

Alanine

Arginine

Circular dichroism spectroscopy

Cysteine

Dicyclohexylcarbodiimide

Dicyclohexylurea

Dimethylaminopyridine

All-deuterated dimethylsulfoxide

Ellman's reagent: 5,5'-dithiobis (2-nitrobenzoic acid)

Fast purification liquid chromatography

Glutamate

High performance liquid chromatography

Heteronuclear multiple bond correlation NMR

Leucine

Monomethoxypoly(ethylene glycol)

Monomethoxypoly(ethylene glycol)yl-5,5'-dithiobis (2-nitrobenzoate)

bis -MPEGyl-DTNB PEG-a-Cys; bis -monomethoxypoly(ethylene glycol)yl5,5'-dithiobis (2-nitrobenzoate)

MPEGyl-TNB

MPEG $^{5000}$

m.w.

NB-PAGE

NMR

PEG

PEG-a-Cys

PEGylate

PITC

Pro

PTH
Monomethoxypoly(ethylene glycol)yl thionitrobenzoate

Monomethoxypoly(ethylene glycol); average m.w. $=5 \mathrm{kDa}$

Molecular weight

Native basic polyacrylamide gel electrophoresis

Nuclear magnetic resonance spectroscopy

Poly(ethylene glycol)

bis -MPEGyl-DTNB or bis -monomethoxypoly(ethylene-

$$
\text { glycol)yl-5,5'-dithiobis (2-nitrobenzoate) }
$$

To conjugate PEG to a substrate via a covalent bond

Phenylisothiocyanate

Proline

Phenylthiohydantoin 


\section{LIST OF ABBREVIATIONS (continued)}

RP-HPLC

Ser

TFA

TNB

UV/Vis

Reverse-phase high performance liquid chromatography

Serine

Trifluoroacetic acid

Thionitrobenzoic acid and/or thionitrobenzoate

Ultraviolet and visible wavelength spectroscopy 
Chapter 1

\section{Introduction}




\subsection{Structural characterization of integral membrane protein transmembrane domains}

Integral membrane proteins are responsible for many essential functions within the cell; genes that code for integral membrane proteins are predicted to constitute fully one third of the human genome (Frishman \& Mewes, 1997). In addition to other roles, membrane proteins control the traffic of both physical substances (via channels and other transporter proteins) and information (via receptors and signaling proteins) between individual cells and between various subcompartments within each cell (Marsh, 1996; Shai, 1995). A detailed understanding of the mechanisms of normal and abnormal function of integral membrane proteins is important for the treatment of diseases and conditions in which abnormally functioning integral membrane proteins are implicated. In order to achieve such a degree of understanding, it is necessary to determine the three-dimensional structure of integral membrane proteins to high (atomic) resolution (Opella, 1997).

However, very few integral membrane proteins have had their complete structures determined to atomic resolution (Preusch et al., 1998; Doyle et al., 1998). The principal hurdles lie with the extremely hydrophobic transmembrane or ' $T M$ ' domains of integral membrane proteins, which in vivo associate directly with the interior of lipid bilayer membranes. The hydrophobicity of these domains and their resultant insolubility in aqueous solution provides serious challenges to the structural biologist (Opella, 1997). The standard techniques of atomic resolution protein structure determination, $\mathrm{X}$-ray crystallography and nuclear magnetic resonance ('NMR') spectroscopy, have been optimized for the study of water-soluble proteins. Both the low solubility of TM domains and the current technical limitations of NMR and X-ray crystallography have hindered the elucidation of high resolution structures of TM domains (Clore \& Gronenborn, 1998; Garavito et al., 1996). 


\subsubsection{Hydrophobicity and polypeptide structure}

The concepts of hydrophobicity and hydrophilicity of amino acid side chains are essential to understanding protein secondary and tertiary structures. Hydrophobicity is simply a measure of the tendency of a molecule to be excluded from aqueous solvent; the tendency of oil to separate from water into discrete droplets can be attributed to its hydrophobicity. It is an indication that the association of the hydrophobic molecule with other like molecules is energetically favorable compared with its solvation by water molecules (Jencks, 1969). For a 'hydrophilic' molecule, on the other hand, it would be energetically unfavorable for water molecules to be stripped from its solvation shell in order to remove it from the aqueous solvent.

Hydrophilic side chains have polar groups such as - $\mathrm{OH}$ (serine and threonine), $\mathrm{SH}$ (cysteine), $-\mathrm{CONH}_{2}$ (asparagine and glutamine); charged groups such as $-\mathrm{NH}_{3}^{+}$ (lysine), guanidinium (arginine), $-\mathrm{CO}_{2}{ }^{\circ}$ (aspartate and glutamate); or groups which are partially charged at physiological $\mathrm{pH}$ such as - $\mathrm{SH}$ (cysteine) and imidazole (histidine). These groups interact favorably with water molecules, through hydrogen bonding in the case of polar side chains and through ionic interactions with hydronium or hydroxide ions in the case of charged residues.

Hydrophobic side chains (e.g. alanine, valine, leucine, isoleucine, methionine), on the other hand, tend to be largely or entirely aliphatic and contain no chemical groups that can interact favorably with water molecules. Aromatic side chains (phenylalanine, tryptophan and tyrosine) are usually considered to be hydrophobic but can display a dual nature: the delocalized $\pi$ electrons of the aromatic rings can participate in interactions with water molecules; the hydroxyl oxygen of tyrosine and the aromatic nitrogens of tryptophan can form hydrogen bonds (Dougherty, 1996).

The hydrophobicities of the amino acids in the secondary structural elements of a protein are thought to be critical determinants of the tertiary structure into which the protein folds. The 'hydrophobic effect' drives the protein to assume a structure such that a greater part of its hydrophobic residues are buried or packed against one another, 
shielded from the aqueous solution by the hydrophilic residues that can form favorable associations with the water molecules (Dill, 1990).

\subsubsection{Integral membrane proteins}

The surfaces of soluble proteins consist largely of amino acids with hydrophilic side chains. Hydrophobic residues tend to dominate in the protein cores, which are isolated from the aqueous environment (Desjarlais \& Handel, 1995). The favorable energetics of the interaction of hydrophobic side chains with one another stabilize the protein core. The hydrophilic residues on the surface in effect 'protect' the hydrophobic amino acids in the interior from contact with the aqueous solvent. and in turn the hydrophobic residues that form a well-packed protein core stabilize the arrangement of hydrophilic amino acids at the surface (Fontana, 1991).

Integral membrane proteins, generally referred to simply as membrane proteins, are distinct from other proteins in that portions of their structures traverse a biological membrane. These portions are termed transmembrane or 'TM' domains. TM domains are rich in hydrophobic residues that are not shielded from aqueous solvent by hydrophilic residues. Membrane proteins usually possess soluble cytosolic or extracellular domains in addition to their TM domains. However, it is the exposed hydrophobic side chains of the amino acids in their TM domains that serve to anchor such proteins in the phospholipid bilayer, as the interaction of hydrophobic side chains with the hydrophobic interior of the membrane is energetically favored over the interaction of those side chains with water (Deber \& Goto, 1997).

Transmembrane domains are composed of one or more secondary structural elements called 'TM segments', each of which spans the bilayer once. A TM segment is composed of a stretch of amino acids which are contiguous in the primary sequence of the protein. The most common form of TM segment assumes an $\alpha$-helical conformation and is $\mathbf{2 0 - 2 3}$ amino acids in length in order to span the bilayer (Marsh, 1996). The TM domains of some membrane proteins have only a single, $\alpha$-helical TM 
segment which anchors the protein in the membrane. These single-spanning TM segments tend to be composed largely or entirely of hydrophobic residues, which project peripherally to the axis of the helix and interact with the hydrophobic interior of the membrane (Cserhati \& Szogyi, 1994). The TM segments of single-spanning membrane proteins can serve merely to localize and anchor the protein in the membrane, as in the case of some cell adhesion molecules (Jones, 1996). A single-spanning TM segment can however be directly involved in function, as in the TM dimerization of certain proteins involved in signal transduction (Kelly et al., 1994).

Other membrane proteins contain multiple TM segments. These segments are separated in the primary sequence by extracellular and intracellular loops which range in size from a few amino acids to multiple domains. The TM segments of these multispanning or polytopic membrane proteins are often directly implicated in protein functions, such as in the case of membrane transporter proteins in which the TM segments are thought to form a pore through which substrates are transported (Montal, 1990; Akabas et al., 1997). The TM domains of many multispanning membrane proteins are $\alpha$-helical; the helices are thought to pack against one another such that the amino acid side chains exposed to the lipid are largely hydrophobic (Popot \& Saraste, 1995). Some integral membrane proteins, notably bacterial porins and some toxins, have been demonstrated to possess TM domains that are composed of the associated $\beta$ sheets of several protein monomers; in the oligomer, the sheets form a cylindrical ' $\beta$ barrel' in which hydrophobic side chains project out of the barrel to contact the lipid interior of the membrane (Cowan et al., 1992; Gouaux, 1998).

\subsubsection{Structural characterization of transmembrane domains}

The presence and boundaries of one or more TM segments can be estimated on the basis of a calculated hydropathy profile of the protein based on its primary structure (e.g., Kyte \& Doolittle, 1982). Topology studies, which use degree of accessibility to various enzymes or labels as an indicator of the location (cytoplasmic, extracellular, or 
transmembrane) of particular amino acid residues, can provide additional information which can aid in the assignment of TM segments, delineation of their boundaries and their orientations in the membrane (Traxler et al., 1993). Several methods are available for assessing the structure of TM segments and domains at low resolution, including various mutational analyses such as cysteine scanning (Mingarro et al., 1997).

However, while novel techniques such as solid-phase NMR or atomic force microscopy may eventually provide other avenues from which to obtain high resolution structures of the TM domains of integral membrane proteins (Wagner, 1997; Heymann et al., 1997), X-ray crystallography and solution phase NMR spectroscopy remain the methods of choice at this time. The feasibility of either of these methodologies is dependent upon certain characteristics of the target protein (Preusch et al., 1998; Doyle et al., 1998). Both require that the protein be prepared to a high level of purity and that conditions are found at which the protein is stable in solution at high concentrations for a period of time that can range from days to weeks (Clore \& Gronenborn, 1998; Garavito et al., 1996).

The exposure of the hydrophobic TM segments of integral membrane proteins to aqueous solvent can result in their association with one another and with segments from the TM domains of other membrane protein monomers in a nonspecific manner. This type of nonspecific association is termed 'aggregation' and is largely irreversible (Jahnig \& Surrey, 1997). Aggregated proteins typically precipitate from solution and cannot be characterized.

\subsubsection{Experimental models of transmembrane segments}

Most integral membrane proteins are present in only minute quantities in living organisms. This and the fact that they are prone to aggregate and lose activity during purification necessitates the use of methods other than isolation from natural sources in order to arrive at sufficient quantities of pure protein for structural characterization (Grisshammer \& Tate, 1995). However, the extreme hydrophobicity of their TM 
domains creates technical problems for both chemical synthesis and bacterial expression of integral membrane proteins (Tomich et al., 1988; Grisshammer \& Tate, 1995). Chemical synthesis becomes impractical for entire transmembrane domains of multispanning membrane proteins, as a synthesis of such a long sequence would require hundreds of reaction steps. Even if the yield for each individual step was $95 \%$, the final yield would be significantly lower than $1 \%$ after more than 100 steps. Single spanning membrane protein TM segments are short enough to be chemically synthesized in reasonable yields, although the hydrophobicity of such peptides often results in their irreversible aggregation either during synthesis or upon post-synthetic cleavage from the support (Tomich et al., 1988).

Bacterial expression systems can produce large amounts of isotopically labeled proteins appropriate for study by NMR spectroscopy, but these systems have been developed and optimized for the production of soluble proteins. Attempts to express membrane proteins at high levels often leads to the death of the bacteria, which tends to bring protein expression to an abrupt halt (Grisshammer \& Tate, 1995). While certain optimizations are possible, including the use of specific bacterial mutants (Miroux \& Walker, 1996), no method has been demonstrated to be general for all membrane proteins.

The difficulty of expressing or synthesizing entire transmembrane domains of proteins has forced a reductionist approach upon the researcher. Model systems of single or multiple TM segments are more likely to be amenable to expression and/or synthesis. The results of structural characterizations of several of these models, covering all of the TM segments in a TM domain and their interactions with one another could be combined to generate information on the structure of an entire TM domain.

Synthetic peptides have proven to be useful model systems to study single hydrophobic TM segments (Deber \& $\mathrm{Li}, 1995$ ). The techniques of automated peptide synthesis can be brought to bear on such short sequences. The aggregation of hydrophobic segments during synthesis and cleavage can be prevented by the addition 
of a sufficient number of similarly charged amino acids to one or both ends of the peptide (Chung \& Thompson, 1996). Multiple TM segments can then be modeled by mixtures of chemically synthesized single-spanning TM segments (Lemmon \& Engelman, 1994), or by bacterial expression of the multiple TM segments as a fusion with a soluble protein (Peng et al., 1998). A fusion protein consisting of the TM segments at the carboxyl terminus of a well-expressed soluble carrier protein can allow bacterial expression where the segments on their own would be inexpressible. Subsequent enzyme cleavage of the TM segments from the fusion protein would allow for the characterization of their structure without interference by the carrier protein. However, cleavage of the TM segments from the soluble carrier exposes the hydrophobic peptides to the aqueous solvent, at which point irreversible aggregation and precipitation can occur.

\subsubsection{The use of detergents to solubilize TM domains}

The standard method of preventing membrane protein or TM segment aggregation and precipitation is the addition of strong detergents to the solution. Detergents are amphiphilic molecules that can form micellar structures around hydrophobic molecules such as TM domains, associating via their hydrophobic tails and shielding the molecule from aqueous solvent by means of their hydrophilic head groups (Moroi, 1992). Certain detergents are capable of solubilizing TM domains or segments in aqueous solution.

However, the detergent micelle can increase the mass and the time required to reorient in a magnetic field of even a small TM domain such that even multidimensional heteronuclear solution NMR is insufficient to produce interpretable spectra (Henry \& Sykes, 1994). For X-ray crystallography, selection of both initial (delipidating) and final (crystallizing) detergents requires an extensive search for compounds that are compatible with crystallization of a particular protein or protein fragment, as no detergent has emerged which is suitable for all or even most membrane proteins (Garavito et al., 1996). 
In the case of TM segment fusion protein isolation, the detergent is customarily added at the step of recovery of a fusion protein from the bacterial cell lysate in order to enhance the solubility of the fusion protein, which in some cases can themselves aggregate and precipitate. In any case, it must be added prior to enzyme cleavage of the TM segments from the fusion protein in order that the hydrophobic peptides are not exposed to detergent-free aqueous solution (Kiefer et al., 1996). The cleavage of TM segments from a carrier protein cannot always be performed in strong detergent solutions, as many protease enzymes are subject to denaturation by strong detergents (Lantz \& Ciborowski, 1994). It is possible to exchange a strong solubilizing detergent such as sodium dodecyl sulfate for a weaker 'non-denaturing' detergent such as Triton $X-100$, but while these solutions support protease activity they do not always ensure hydrophobic peptide solubility.

TM domains and segments are characterized in membrane-mimetic environments such as micelles, organic solvents or liposomes in order to obtain structures that are biologically relevant (Henry \& Sykes, 1994). Detergent contamination can cause heterogeneity of the membrane-mimetic environment and complicate the interpretation of the structural data acquired. Detergents can be challenging to remove from the TM domain or segment due to the strong interaction between the hydrophobic tail of the detergent and the hydrophobic surface of the TM domain/segment (Dong et al., 1997).

A general method of temporarily solubilizing the TM segments of bacterially expressed fusion proteins so that they could be cleaved from the soluble carrier protein in the absence of detergents, purified, and transferred into one of several membranemimetic environments would thus be extremely useful to the structural biologist. 


\subsection{Poly(ethylene glycol) and protein PEGylation}

a)

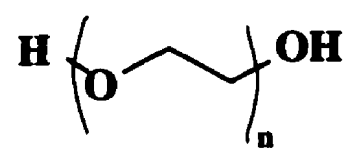

b)<smiles>CC(O)CCC(C)(C)C</smiles>

Figure 1: PEG and MPEG. The molecules are linear polymers of ethylene oxide (- $\mathrm{CH}_{2}-\mathrm{CH}_{2}-\mathrm{O}$-) units. (a) Poly (ethylene glycol) 'PEG' bears two hydroxyl groups, one at each end of the linear molecule. (b) Monomethoxypoly(ethylene glycol) 'MPEG' is blocked at one end by a methyl group and bears only one hydroxyl group per molecule.

\subsubsection{Physical and chemical properties of PEG}

Poly(ethylene glycol), abbreviated as 'PEG' (Figure la) is a linear molecule formed by the polymerization of ethylene oxide molecules to a water or ethylene glycol initiator molecule (Powell, 1980). The resulting chain of $-\mathrm{CH}_{2}-\mathrm{CH}_{2}-\mathrm{O}$ - units is capped at either end by a hydroxyl (-OH) group. PEG differs from similar polymers, such as polypropylene oxide and polymethylene oxide, in one important respect: water solubility. PEG is soluble in water at concentrations of up to $60 \%(\mathrm{w} / \mathrm{v})$ (Powell, 1980). PEG has been demonstrated to bind between 2 and 3 water molecules per ethylene oxide unit, and is thought to form a hydrated coil in solution (Antonsen \& Hoffman, 1992). The hydration shell adds significantly to the effective molecular size of the polymer. The ability of PEG to bind water is instrumental in its use in crystallization of proteins; by sequestering a large proportion of the water in a protein solution, the effective concentration of the protein can be raised to supersaturation, encouraging crystal formation (Ray, 1992).

PEGs of greater than 4 ethylene oxide units are available only as heterogeneous mixtures of various chain lengths and therefore of various molecular weights. The molecular weights of PEGs in such mixtures assume a Poisson distribution about the 
average molecular weight, which can be determined by calculation based on the number of reaction steps (Flory, 1940). This molecular weight distribution is relatively narrow, when compared with other types of polymers (Powell, 1980). However, the existence of even such a narrow distribution causes variances in the physical properties of PEG and PEG derivatives of which the chemical properties are constant.

PEG is largely inert, aside from the hydroxyl group at either end of the linear polyether backbone chain. While the backbone is subject to very slow peroxidation when exposed to air or other oxidizing conditions, and chain breakage thereby, it is otherwise extremely stable and unreactive. The primary alcohols at either end can be activated by the covalent attachment of reactive small molecules (Zalipsky \& Lee, 1992). Since each PEG molecule contains two of these hydroxyl groups, activation of both would result in a bifunctional molecule that would be capable of crosslinking multiple substrates with which it is reacted. PEG can be synthesized with one hydroxyl group blocked by methoxylation to yield monomethoxypoly(ethylene glycol), 'MPEG' (Figure Ib) (Powell, 1980). This is accomplished by using methanol as an initiator molecule for the polymerization reaction instead of water or ethylene glycol. MPEG can be subsequently activated at its single remaining hydroxyl group to yield a monofunctional PEG derivative, which can attach to substrates without crosslinking them (Delgado et al., 1992).

PEG, in aqueous solution, is capable of repelling proteins from surfaces to which the polymer is attached (Osterberg et al., 1995). Since all of the covalent bonds down the length of PEG's backbone are single bonds, the molecule has free rotation about each one, subject only to steric interference by other units of the PEG chain. The resulting high mobility, combined with the strongly bound hydration shell, are thought to be the source of PEG's protein repulsion ability. The approach of a protein to a PEGylated surface necessitates either the compression or the spatial displacement of the PEG molecule, both of which restrict its rotational freedom and are therefore entropically unfavorable (Bergstrom et al., 1994). Close approach would involve 
displacing the water molecules bound in PEG's hydration shell, which is energetically unfavorable (Gombotz et al., 1991).

\subsubsection{PEGylation of proteins}

PEG and derivatives of PEG have been covalently linked or 'PEGylated' to many different types of substrates. PEG-coated surfaces are used in applications where adsorption of protein is problematic, such as capillary electrophoresis (Bruin et al., 1989). PEGylated lipids have been used to construct 'stealth' liposomes that take advantage of the protein repulsion ability of PEG to evade the immune system and deliver drugs more efficiently (Wu et al., 1993). However, the most extensive and interesting work has been performed on PEGylated proteins.

The attachment of PEG to proteins was first performed in 1976 in order to modify a glucose-6-phosphate dehydrogenase for the purpose of altering the phase partitioning constant of the enzyme in a two-phase bioreactor (Pollack \& Whitesides, 1976). Shortly thereafter the conjugation of PEG to bovine serum albumin was demonstrated to reduce the protein's immunogenicity (Abuchowski et al., 1977). This second application has proven to be the primary focus of protein PEGylation. However, PEGylation is still performed for phase partitioning and for the alteration of enzyme solubilities.

The predominant use of protein PEGylation has been concerned with decreasing the immunogenicity and increasing the biological half-life of protein drugs (Delgado et al., 1992). The attachment of PEG to a protein is thought to repel other proteins in much the same way that PEG repels proteins from surfaces to which it is attached. As the human immune system is based largely on interactions with proteins (receptors and antibodies), the ability of a PEGylated protein to repel other proteins explains the reduction in immunogenicity observed (Delgado et al., 1992). Clearance from the bloodstream is dependent upon protein interactions as well as the size of the substrate. PEGylation increases the size of a protein considerably more than the molecular weight 
increase, due to the high mobility and hydration shell of the polymer chains. This leads to slower clearance from the bloodstream of PEGylated proteins. Slower clearance and lower immunogenicity lead to longer biological half-lives for PEGylated drugs, which in turn lowers the doses needed for effective treatment and thus reduces systemic toxicity (Delgado et al., 1992). Increased circulation times and lower immunogenicity in the case of PEGylated 'stealth' liposomes lead to the passive targeting of such liposomes to tumours and other areas of damaged or 'leaky' vasculature such as sites of inflammation and infection (Wu et al., 1993); similar behaviour may be expected of PEGylated proteins.

PEGylated proteins are also used for two-phase extraction of proteinaceous ligands. PEG and dextran, a polymer of glucose, form a two-phase system in aqueous solution at sufficient concentrations (Flanagan \& Barondes, 1975). Proteins partition into the dextran phase of such a system, but PEGylated proteins partition rather into the PEG phase. By PEGylation of antibodies or other proteins that bind specific ligands, and mixing them with a solution containing the target protein in such a two-phase PEGdextran system, it is possible to purify a specific ligand (Tjerneld \& Johansson, 1990). However, despite advances in counter-current distribution technologies, this method of purification has yet to become widely employed (Johansson, 1992).

In addition, PEG has been used to modify water-soluble proteins to solubilize them in organic solvents. For example, PEGylation of the enzyme subtilisin was demonstrated to confer solubility in 1,4-dioxane, without loss of activity (Pasta et al., 1988). It has been theorized that water bound to the PEG chains creates a highly hydrogen bonded micro-environment in the vicinity of the surface of modified proteins that stabilize them when they are placed in organic solvents (Gaertner \& Puigserver, 1992). The most exciting property of enzymes so modified is that, in the water-poor environment of an organic solvent, the hydrolase activities of some enzymes are converted to synthase activities (Matsushima et al., 1984; Mori et al., 1992). 
PEGylation of enzymes thus opens the door for stereospecific synthetic enzyme chemistry involving water-insoluble substrates.

PEGylation has also been performed on hydrophobic proteins in order to solubilize them in water. Two bacterial membrane proteins, bacteriorhodopsin and porin, have been made water-soluble by PEGylation (Sirokman \& Fasman, 1993; Wei \& Fasman, 1995). It is possible that the PEG was able to confer its property of high aqueous solubility upon the membrane proteins by protecting the hydrophobic side chains of the TM domains from the aqueous solvent. Also, the protein-repellent properties of PEG may have prevented the close approach of protein molecules to one another, preventing aggregation and precipitation.

\subsubsection{Chemistries of PEG derivatization}

A wide variety of chemistries have been developed with which to derivatize PEG for attachment to proteins (Zalipsky \& Lee, 1992). Most of this development has focused on different ways to synthesize PEG derivatives that can be conjugated with free amino groups to form amide bonds. This method is preferred for most applications due to the abundance of free amino groups in proteins in the form of Lys residues and the stability of the amide bond formed (Zalipsky \& Lee, 1992).

The original method of derivatization involved reaction of the alkoxide of MPEG with cyanuric chloride (Abuchowski et al., 1977). A large excess of reagent was required due to the tendency for the chlorines of cyanuric chloride to spontaneously hydrolyze under the conditions required for PEGylation of proteins (Abuchowski et al., 1977). This as well as the toxicity of the derivative and its promiscuous reactivity with the side chains of Cys and Tyr (Zalipsky et al., 1992) provided the impetus for the discovery of new chemistries of PEG derivatization.

MPEG-carbonyldiimidazole (Beauchamp et al., 1983) and MPEGphenylcarbonate (Veronese et al., 1985) were less promiscuous than the cyanuric chloride derivative, but suffered from poor reactivity and reagent toxicity, respectively. 
MPEG-succinimidyl succinate (Abuchowski et al., 1984) and MPEG-succinimidyl carbonate (Zalipsky et al., 1992) exhibit high reactivity and specificity. However, the ester bond between the succinate and the MPEG in the former is subject to degradation in aqueous solution, and the synthesis of the latter requires the use of the extremely toxic reagent phosgene.

All of the above reagents were designed to PEGylate at Lys residues of proteins, as most proteins contain many accessible Lys residues on their surfaces and extensive modification was considered to be important in order to maximize the effects of PEGylation. However, reaction with Lys results in irreversible amide and urethane bonds (Zalipsky \& Lee, 1992). This is useful when stability is an asset, but is unsuitable for any application that requires transient PEGylation. Also, the multitude of surface accessible Lys residues in the targets tended to result in heterogeneously PEGylated proteins that were very difficult to separate from one another (Snider et al., 1992). Stringent characterization requires homogeneously PEGylated substrate. Lys PEGylation is therefore inappropriate for the construction of a homogeneous population of reversibly PEGylated protein or peptide, and alternate conjugation methodologies are required.

\subsubsection{Cys-PEGylation}

Attachment to Cys side chains by thiol-reactive PEGs has several advantages over the more common Lys PEGylation. PEGylation at Cys residues is highly targeted, since while most proteins have many Lys residues, they tend to have few, if any, free Cys -SH groups. The heterogeneity of PEGylation that has complicated the characterization of Lys-PEGylated proteins (Snider et al., 1992) is thus avoided. Should no free cysteines be present in a particular protein, a single Cys residue can be engineered into a synthetic or cloned protein at a prescribed position, as is accomplished routinely in cysteine-scanning topology studies (Akabas et al., 1997). Cys-PEGylation can be performed under mild reaction conditions (aqueous, neutral pH) without the need for highly reactive activating reagents such as the carbodiimides used in Lys- 
PEGylation (Zalipsky \& Lee, 1992). Another advantage of Cys-PEGylation is the reversibility of the reaction. The mixed disulfide bond formed between the thiolreactive PEG and the peptide is cleavable with suitable disulfide-reducing agents such as dithiothreitol (DTT) (Musu et al., 1996) or TCEP-HCl, in contrast to the amide bond formed during Lys-PEGylation, which can be cleaved chemically only under conditions which hydrolyze all of the peptide bonds in the polypeptide. The reversibility of CysPEGylation allows the ready removal of the PEG moiety under a variety of conditions.

A variety of Cys-PEGylation reagents have been synthesized to date: 4phenoxy-3,5-dinitrobenzoyl-PEG (Glass et al., 1979), maleimido-MPEG (Delgado et al., 1992), two different forms of dithiopyridyl-MPEG (Musu et al., 1996; Campbell et al., 1997), MPEG-thiol (Zalipsky \& Lee, 1992) and PEG vinyl sulfone (Morpurgo et al., 1996). Synthesis of any of the listed derivatives involves multiple reaction steps and can involve the use of hazardous chemicals. It would be an advantage for a PEG derivatization to minimize the number of reaction steps and the use of hazardous materials in order that it might be routinely carried out in laboratories whose focus is the study of proteins and peptides rather than synthetic organic chemistry.

\subsubsection{Ellman's reagent as a Cys-reactive molecule for PEG derivatization}

It has been convenient to include in the synthesis of PEG derivatives a small molecule that can be easily quantitated. Amino acids that do not occur in proteins, such as norleucine, can be quantitated by amino acid analysis upon hydrolysis of a PEGylated sample (Lu \& Felix, 1993). A more elegant if less sensitive method of quantitation involves the use of chromophores. The derivatization of PEG with a chromophore allows quantitation of the derivative and of the amount of PEG attached to the target, in a nondestructive manner (Ladd \& Snow, 1993). Nitrobenzoic acids contain a convenient carboxylic acid group for the attachment of PEG, while the chromophoric properties are provided by the nitrobenzene ring. MPEG has been esterified to 4-fluoronitrobenzoic acid, resulting in a chromophoric Lys-reactive PEG derivative (Ladd \& Snow, 1993). However, no PEG derivatives have previously been 
synthesized that combine the advantages of Cys-reactivity with the chromophoric activity of the nitrobenzoic acids.

Ellman's reagent is a chromophore-containing molecule also known as 5,5'dithiobis(2-nitrobenzoic acid) or DTNB (Figure 2). It was first synthesized in 1959 as a water-soluble form of bis(para-nitrophenyl) disulfide, which had been demonstrated to be useful in the colourimetric quantitation of aliphatic thiol compounds. Ellman's reagent reacts with aliphatic thiols at $\mathrm{pH} 8.0$ by a disulfide exchange mechanism, releasing a thionitrobenzoate or 'TNB' anion which, at neutral or basic $\mathrm{pH}$, is a chromophore that absorbs strongly in the visible range $\left(\varepsilon_{M}=13600\right.$ at $\left.412 \mathrm{~nm}\right)$ (Ellman, 1959). Reduction of Ellman's reagent with reducing agents specific for disulfide bonds also releases TNB (Riddles et al., 1979).

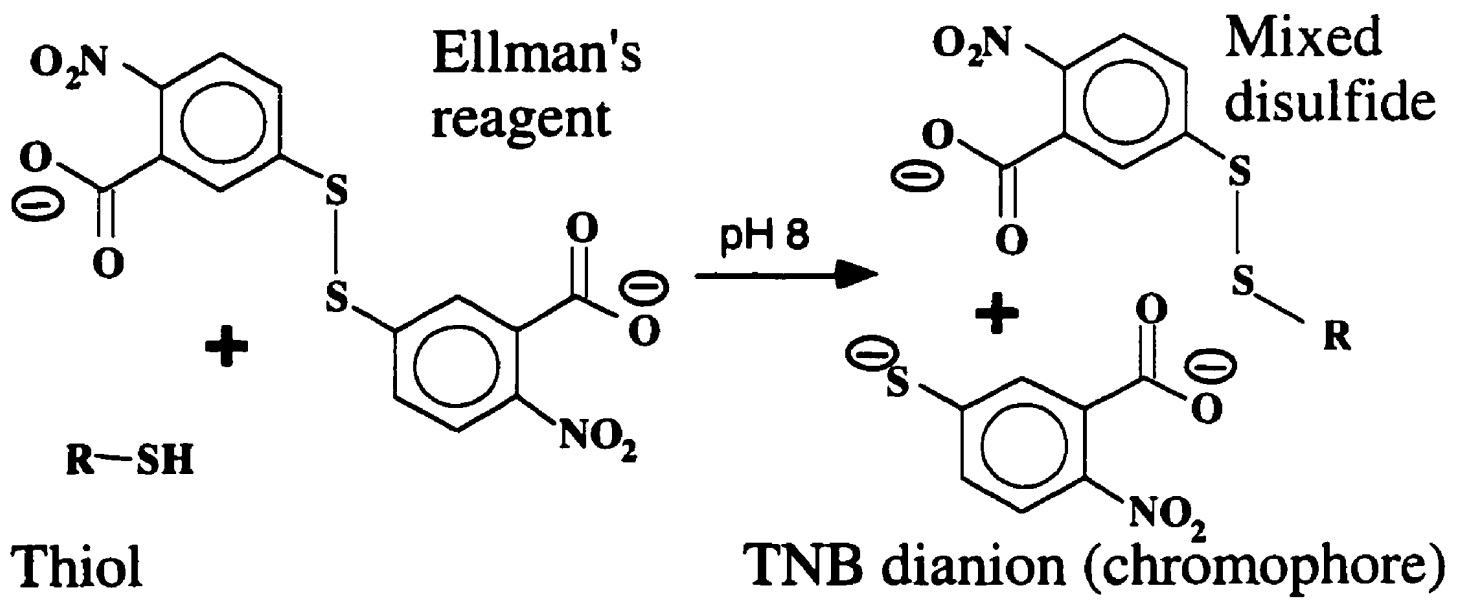

Figure 2: Ellman's reagent. The internal disulfide reacts specifically with thiol groups to form mixed disulfide bonds. The reaction produces a thionitrobenzoate 'TNB' dianion byproduct which is a chromophore at neutral or basic $\mathrm{pH}$.

Ellman's reagent has been used for analyses of proteins ranging from the simple quantitation of free thiols to crosslinking experiments which yielded structural information (Holtzer, 1986; Lehrer, 1975; Lehrer, 1978). It has also been used in order 
to label cysteine-containing peptides chromophorically (Sliwkowski \& Levine, 1985); labelled peptides displayed an absorbance at $328 \mathrm{~nm}$. However, as it has since been determined that Ellman's reagent is vulnerable to degradation by ultraviolet light near $325 \mathrm{~nm}$ (Walmsley et al., 1987), this measurement cannot be considered nondestructive. Measurement of the absorbance of the free TNB anion reaction and/or reduction product at $412 \mathrm{~nm}$ is therefore preferred (Takeda et al., 1992).

The disulfide of Ellman's reagent is useful synthetically. Activation of carboxylic acids in preparation for an esterification, for example with PEG, proceeds by reaction with an electrophilic carbodiimide (Gish, 1970). As the disulfide of Ellman's reagent is itself electrophilic due to the electron-withdrawing character of the adjacent nitroaromatic rings, it was not predicted to react with the electrophilic activator. The disulfide is thus effectively self-protecting for these types of activation reactions. By avoiding the protection and deprotection reactions usually required when derivatizing a reactive small molecule, the esterification of Ellman's reagent can be accomplished in a single step using carbodiimide chemistry. The alteration of a three step protocol to a single step has clear advantages in terms of both a higher product yield and lower potential for incomplete and/or side reactions. 


\subsection{Rationale}

It is clear from a review of the literature (section 1.1) that a major obstacle to the routine structural characterization of membrane proteins is the hydrophobicity and resultant insolubility in aqueous solution of membrane proteins in general and TM domains in particular. It has thus been necessary to take a reductionist approach and examine the structures and structural interactions of single or multiple TM segments as a step towards elucidation of TM domain structure (section 1.1.4). The use of fusions with soluble carrier proteins has made it possible to express in sufficient quantities single or multiple TM segments that are small enough to potentially be solved by solution NMR spectroscopy (Peng et al., 1998).

However, cleavage of the TM segments from their soluble carrier can and often does result in their immediate or eventual aggregation and precipitation from solution, as the released peptides are by their very nature hydrophobic. While certain detergents can enhance the solubility of hydrophobic peptides, such detergents can themselves interfere with protease cleavage, purification and characterization (section 1.1.4.1). Therefore, a method for the maintenance of aqueous solubility of the cleaved TM segments that does not involve the use of detergent solutions would be of great advantage to the structural biologist. The covalent attachment of a solubilizer, a molecule with high aqueous solubility, to one or more residues in the TM segments was anticipated to suit this purpose. Attachment of the solubilizer prior to enzyme cleavage of the TM segments from the soluble carrier protein would allow for that cleavage to take place in the absence of detergent. The solubilized cleaved TM segments could then be purified, stored, and otherwise treated in a manner identical to soluble proteins, without the use of detergents and without fear of aggregation and precipitation.

A non-proteinaceous solubilizer that could be attached and removed at will would have several advantages over simply leaving the TM segments fused to the soluble carrier protein. A chemical with a higher intrinsic aqueous solubility than that possessed by a carrier protein would enable a much smaller molecule to confer 
equivalent solubilization; small molecular size is critical for structural characterization by NMR spectroscopy. Also, a carrier protein would be detected by techniques used to characterize the structure of the TM segments. For example, circular dichroism spectroscopy detects optically active (chiral) species (Johnson, 1990). As both the TM segments and the carrier protein are composed of optically active peptide bonds, both would contribute to the $\mathrm{CD}$ spectrum. Proteins intended for structural characterization by NMR spectroscopy are isotopically labelled, and any isotopic labeling of TM segments expressed as fusion proteins would result in similar labeling of the carrier protein. In both of these cases the signal from the carrier protein could interfere with and obscure the signal from the TM segments. A non-proteinaceous solubilizer could be selected that was entirely or largely non-chiral, and so transparent to $C D$ spectroscopy. The solubilizer could be synthesized without the inclusion of an isotopic label, and so would be transparent to protein NMR spectruscopy.

It would also be possible to design the covalent attachment of the solubilizer to the peptides to be chemically reversible such that the solubilizing molecule could be removed from the TM segments at will. A chemically reversible bond such as a disulfide would be convenient in that the solubilizer could be removed in a variety of environments that are useful for structural characterization of TM segments, such as membrane-mimetic solutions or organic solvents. In contrast, a carrier protein can only be cleaved by proteolytic enzymes, which have strict environmental requirements for activity. A solubilizer with a chemically reversible covalent bond to the TM segments could thus serve as a temporary modifier, maintaining their solubility in aqueous solution for the purposes of purification, storage, and transfer between various environments.

The goal of this research was to design and characterize a non-proteinaceous solubilizing reagent capable of forming a chemically reversible covalent bond with a target peptide, and to test its ability to solubilize hydrophobic peptides in a system that models a TM segment fusion protein. 


\subsubsection{Design of PEG-a-Cys reagent}

The primary attributes desired of a covalent solubilizer for hydrophobic peptides included: high water solubility; specific reactivity with a single amino acid side chain; chemical reversibility of attachment; and simplicity of synthesis. The PEG-a-Cys reagent (Figure 3) was designed with these characteristics in mind.

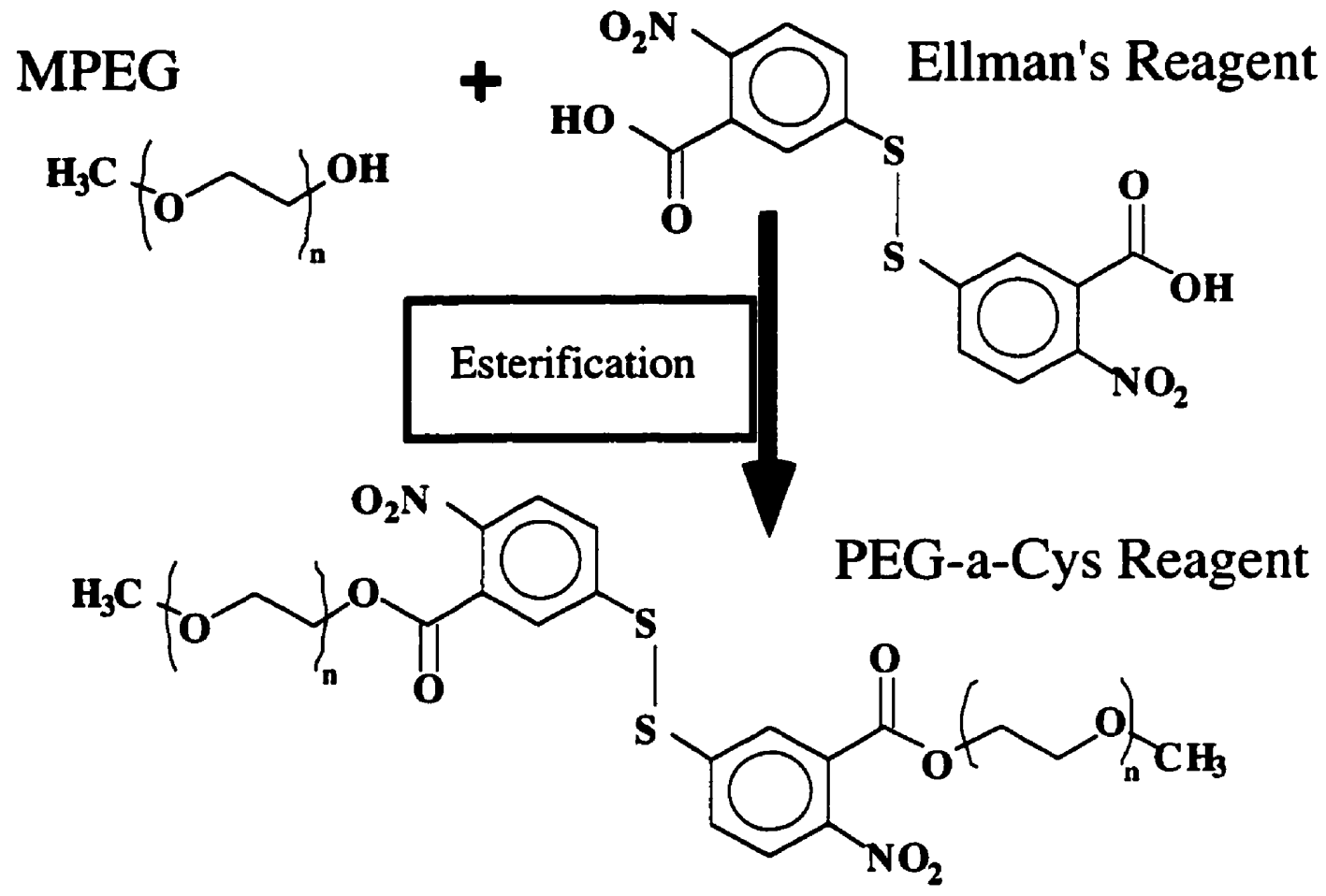

Figure 3: PEG-a-Cys reagent. The reagent was designed to combine the solubilizing properties of PEG with the reversible thiol reactivity of Ellman's reagent, fusing the two chemicals by esterification.

PEG was chosen for the role of solubilizer based on its physical properties (section 1.2.1). The high aqueous solubility of the polymer increased the likelihood that a hydrophobic peptide modified by the reagent would become water-soluble. PEG's ability to repel proteins from surfaces to which it is attached, which has been implicated in the effectiveness of PEGylation in reducing the immunogenicity of proteins (section 1.2.2), was anticipated to hinder the association of PEGylated hydrophobic peptides with one another and thus prevent aggregation. 
Use of MPEG, the monomethyl ether of PEG, was preferable to avoid crosslinking of peptide substrates. MPEG contains only one hydroxyl group per molecule and its derivatives are unable to crosslink their substrates. MPEGs of average molecular weights ranging from $0.75 \mathrm{kDa}$ to $8 \mathrm{kDa}$ were available. The usual average molecular weight of MPEG used for protein modification is $5 \mathrm{kDa}$ (Delgado et al., 1992). PEGylation with a derivative of this size of MPEG was sufficient to render the membrane proteins bacteriorhodopsin and porin soluble in aqueous solution (Sirokman \& Fasman, 1993; Wei \& Fasman, 1995). MPEG of average molecular weight $5 \mathrm{kDa}$, 'MPEG ${ }^{5000}$ ' was therefore chosen for the synthesis of the PEG-a-Cys reagent.

Establishment of a disulfide bond with cysteine residues (section 1.2.3.1) was chosen to suit the requirements of specific reactivity and chemical reversibility. Ellman's reagent (section 1.2.3.2) was chosen as the Cys-reactive small molecule for PEG derivatization. It reacts specifically with Cys residues to form a mixed disulfide bond. The chromophore released by reaction or reduction of Ellman's reagent was expected to allow for simple detection of the derivative, before and during attachment to the target as well as during release from the target. It possesses carboxylic acid groups to which the hydroxyl group of MPEG can be esterified, and its internally protected disulfide was expected to simplify the derivitization reaction.

The bis-ester of MPEG ${ }^{5000}$ and Ellman's reagent was named 'PEG-a-Cys' for its intended ability to PEGylate Cys residues. PEG-a-Cys was predicted to react spontaneously with free thiols, such as peptide Cys residues, in a manner similar to that of Ellman's reagent. PEG-a-Cys reaction with a Cys-containing peptide should result in the attachment of a single $5 \mathrm{kDa}$ MPEG moiety to the peptide by the formation of a mixed disulfide bond (Figure 4). The other half of the PEG-a-Cys reagent, released by the reaction, was predicted to be anionic at neutral $\mathrm{pH}$ and to absorb visible wavelengths of light near $412 \mathrm{~nm}$, the $\lambda_{\max }$ of Ellman's reagent. 


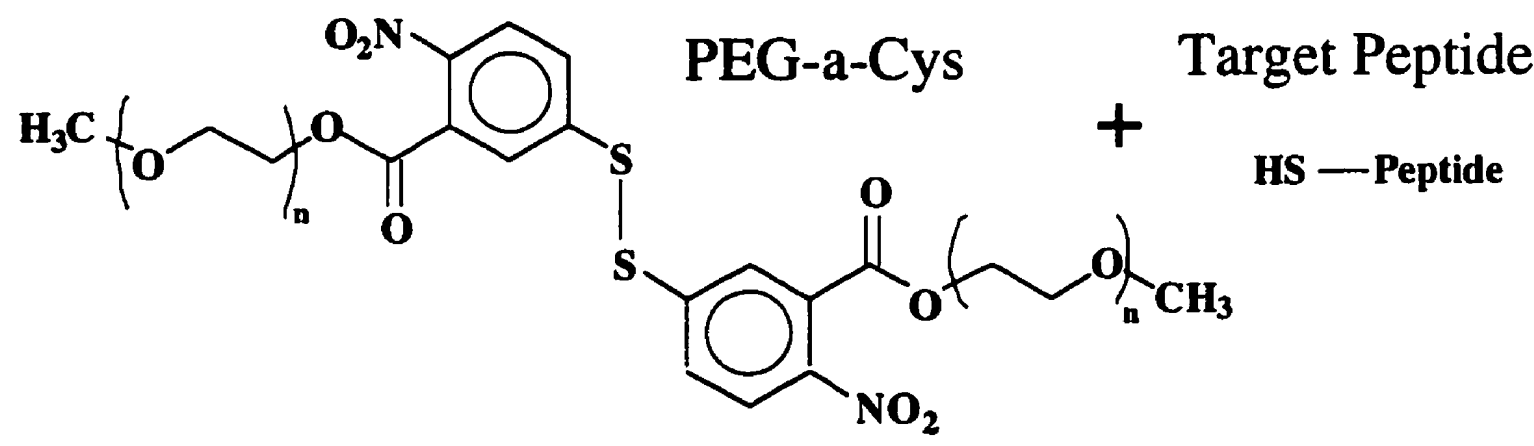

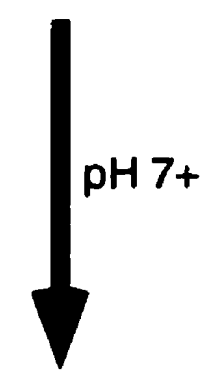

PEGylated Peptide

MPEGyl-TNB anion (chromophore)<smiles>CCCCOC(=O)c1cc(SSc2ccc([N+](=O)[O-])c(C(=O)OCCOC(C)(C)C)c2)ccc1[N+](=O)[O-]</smiles>

Figure 4: PEGylation of peptides. PEG-a-Cys was predicted to react in aqueous solution with free thiols such as peptide cysteine residues in a manner analogous to that of Ellman's reagent (Ellman, 1959). Half of the reagent was predicted to spontaneously form a mixed disulfide bond with the target peptide, 'PEGylating' it. The reaction was predicted to release the other half of the PEG-a-Cys reagent in the form of MPEGyl-TNB, which at neutral or basic $\mathrm{pH}$ would be an anion and a chromophore. 


\subsubsection{Design of ALC model peptide}

To test the effects of Cys PEGylation by PEG-a-Cys on a hydrophobic peptide, a synthetic peptide named 'ALC' was designed (Figure 5). The name is an acronym for 'Ala,Leu,Cys' and represents the major features of the peptide: an Ala/Leu hydrophobic core and a single Cys residue as a target for PEGylation. Design of the ALC sequence was based on a series of synthetic peptides that mimic generic TM segments (Liu et al., 1996).

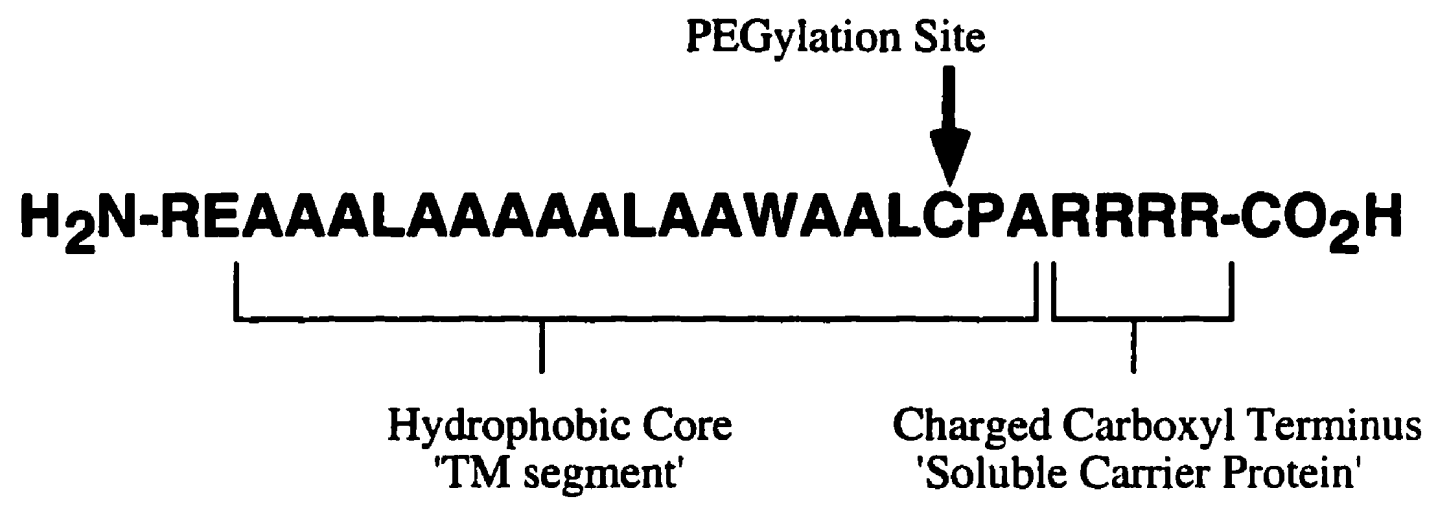

Figure 5: ALC peptide. The 'Ala/Leu/Cys' peptide was designed to model a fusion protein of a membrane protein TM segment. The hydrophobic Ala/Leu core contains a Cys residue for PEG-a-Cys attachment and models a generic TM segment. The charged carboxyl terminus models a soluble carrier protein and was designed to be cleaved enzymatically.

The peptide was designed to model a fusion protein of a membrane protein transmembrane (TM) segment with a soluble carrier protein (section 1.1.4). The hydrophobic core, intended to model a generic TM segment, was 19 amino acids (residues 3-21) in length, the approximate length of a genuine $\alpha$-helical transmembrane segment. The sequence of the core was based on polyalanine; Ala was chosen due to its high propensity to form $\alpha$-helical secondary structures (Chou \& Fasman, 1978). Leu $\mathrm{Leu}_{12}$ and $\mathrm{Leu}_{18}$ were included to increase the hydrophobicity of the core; the residues were spaced in the primary sequence such that they would be evenly spaced about the 
axis of an $\alpha$-helical structure, to encourage uniform hydrophobicity of the segment and avoid amphiphilicity. $\mathrm{Cys}_{19}$ was included as a target site for PEGylation by the PEG-aCys reagent.

The charged residues at the carboxyl terminus $\left(\operatorname{Arg}_{22}-\operatorname{Arg}_{25}\right)$ were intended to model a soluble carrier protein. The high positive charge was expected to keep the peptide soluble. The residues were susceptible to enzymatic digestion by carboxypeptidase B, an enzyme which sequentially hydrolyzes basic amino acids from the carboxyl terminus of peptides (Folk et al., 1960). Such digestion would release an the extremely hydrophobic core peptide. Thus, enzyme cleavage of a hydrophobic TM segment from a soluble carrier protein could be modeled.

Other residues were included for technical reasons. $\mathrm{Arg}_{1}$ and $\mathrm{Glu}_{2}$ were intended to aid in keeping the intact (undigested) peptide soluble. Pro $\mathrm{Pa}_{20}$ was included specifically to ensure that the progress of the carboxypeptidase B enzyme was halted prior to hydrolysis of $\mathrm{Cys}_{19}$ in order to protect the PEGylation site from nonspecific digestion; the enzyme is unable to digest peptide bonds of which Pro is the amino-side (earlier in the primary sequence) residue and should therefore remove only the 4 carboxyl terminal Arg residues, halting before hydrolysis of $\mathrm{Ala}_{21}$. $\operatorname{Trp}_{15}$ was a standard feature of the model peptide series on which ALC was based (Liu et al., 1996), and was included to provide the opportunity to allow investigations into the environment of the hydrophobic core via fluorescence studies, which were not included within the scope of this research. 


\section{Chapter 2}

\section{Materials and Methods}




\subsection{PEG-a-Cys reagent}

The novel reagent PEG-a-Cys, or 'bis(monomethoxypoly(ethylene glycol)yl) dithionitrobenzoate' was synthesized via nucleophilic substitution by the hydroxyl oxygen of monomethoxypoly(ethylene glycol) at the dicyclohexylcarbodiimide-activated carboxylic acid moieties of Ellman's reagent, 5-5'-dithiobis(2-nitrobenzoic acid). A gel filtration chromatography protocol was developed to purify the reagent. Assays based on the chemical properties of PEG and Ellman's reagent were adapted to analyze the chromatographic fractions. The reaction product was characterized by nuclear magnetic resonance and ultraviolet/visible spectroscopies. The reactivity of PEG-a-Cys with cysteine residues was established.

\subsubsection{Synthesis}

The procedure was broadly based on an analogous synthesis of an MPEGyl ester of 4-fluoro-3-nitrobenzoic acid (Ladd \& Snow, 1993). Dithionitrobenzoic acid $(1.0 \mathrm{mmol}, 0.40 \mathrm{~g})$ and dicyclohexylcarbodiimide $(2.00 \mathrm{mmol}, 2.00 \mathrm{~mL}$ of a $1.00 \mathrm{M}$ solution in dichloromethane) were dissolved in $20 \mathrm{~mL}$ of dichloromethane. Monomethoxypoly(ethylene glycol) $(2.00 \mathrm{mmol}, 10.0 \mathrm{~g}$, average m.w. $=5.0 \mathrm{kDa})$ and dimethylaminopyridine $(0.22 \mathrm{mmol}, 0.2 \mathrm{~mL}$ of a $1.10 \mathrm{M}$ solution in dichloromethane) were added, and the volume was brought to $40 \mathrm{~mL}$ with dichloromethane. Two molar equivalents of MPEG and DCC were used in order to favor formation of the desired bis-ester (Figure 6).

The mixture was blanketed with nitrogen and stirred at room temperature for 22 hours. The mixture was filtered and the filtrate was washed sequentially with water, $5 \%$ acetic acid, and water. The water washes served to remove dicyclohexylurea and any unreacted Ellman's reagent; the acetic acid wash served to remove the dimethylaminopyridine base and any remaining dicyclohexylurea. The organic phase was then dried over magnesium sulfate, filtered, and evaporated to dryness with reduced pressure using a Rotavapor- $R$ (Büchi) apparatus. The resulting solid was then 


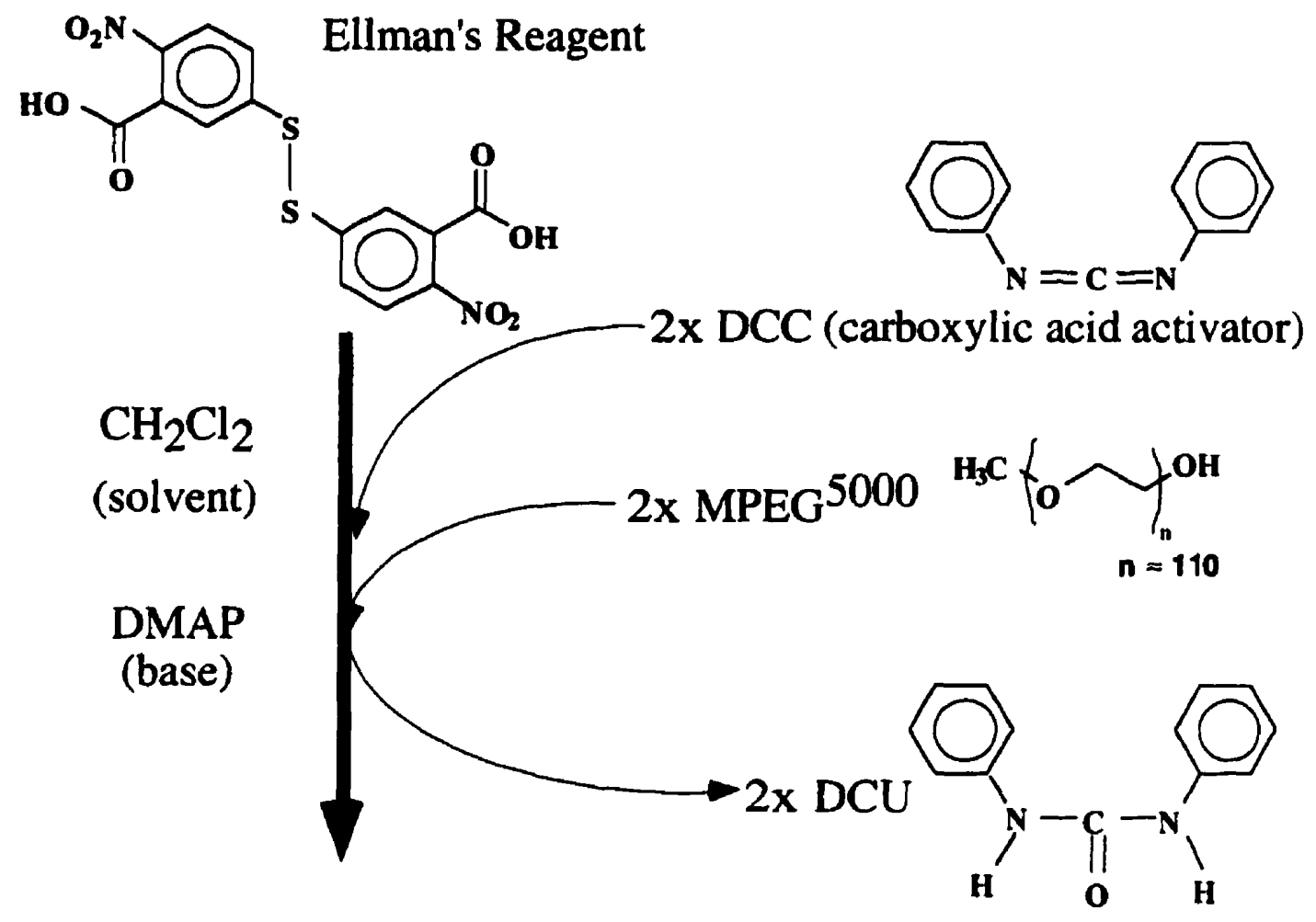<smiles>CC(C)OCCCOC(=O)c1cc(SSc2ccc([N+](=O)[O-])c(C(=O)OCCOC(C)(C)C)c2)ccc1[N+](=O)[O-]</smiles>

Figure 6: Synthesis of PEG-a-Cys reagent. Two molar equivalents of dicyclohexylcarbodiimide (DCC) activator and two molar equivalents of MPEG ${ }^{5000}$ were reacted with Ellman's reagent to produce the bis-ester 'PEG-a-Cys' in a single reaction step. Also produced were two molar equivalents of dicyclohexylurea (DCU). Dimethylaminopyridine (DMAP) was used as a catalytic base in the reaction. 
dried in a vacuum desiccator over calcium sulfate and weighed every morning and evening until the mass varied by less than $1 \mathrm{mg}$ between weighings. This was termed the 'crude product'.

The crude product was dissolved in hot $\left(50^{\circ} \mathrm{C}\right)$ ethanol and then cooled in dry ice $\left(-70^{\circ} \mathrm{C}\right)$. The precipitate was recovered by filtration, and washed with cold $\left(-70^{\circ} \mathrm{C}\right)$ diethyl ether. The solid was dried in a vacuum desiccator over calcium sulfate and weighed every morning and evening until the mass varied by less than $1 \mathrm{mg}$ between weighings. This ethanol-precipitated product was termed 'PEG-a-Cys'.

\subsubsection{Purification}

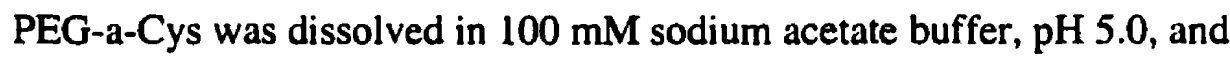
applied to columns $(24-28 \mathrm{~cm} \times 1.0-1.5 \mathrm{~cm})$ of a series of gel filtration resins (Sephadex G10, G50, G100 and Sephacryl G200). Sodium acetate $100 \mathrm{mM}$, pH 5.0 was used as the eluant. Samples $(1.0 \mathrm{~mL}$ of $10 \mathrm{mg} / \mathrm{mL}$ PEG-a-Cys in $100 \mathrm{mM}$ pH 5.0 sodium acetate buffer) were applied to the top of the column bed and allowed to enter the column under gravity. The walls of the column immediately above the bed were washed with $1.0 \mathrm{~mL}$ of eluant, and this liquid was allowed to enter the column under gravity. The headspace of the column was then filled with eluant and the column was eluted under positive pressure at a flow rate of $0.2-0.4 \mathrm{~mL} / \mathrm{min}$. applied by means of a peristaltic pump.

Fractions were collected every 5 minutes. Fraction volumes ranged from 0.9 to $2.3 \mathrm{~mL}(0.02-0.06$ column bed volumes) depending on the flow rate, which varied with the resin. Fractions were assayed for the presence of both PEG and thionitrobenzoate activity. The presence of PEG (including unreacted MPEG ${ }^{5000}$ and/or PEG-a-Cys) was determined by performing a Skoog assay (see section 2.1.2.1) (Skoog, 1979) on a $10 \mu \mathrm{L}$ sample of each fraction in a final assay volume of $1.0 \mathrm{~mL}$. The presence of thionitrobenzoate (PEG-a-Cys and/or Ellman's reagent) was determined by an TNB assay (see section 2.1 .2 .2 ) on a $100 \mu \mathrm{L}$ sample of each fraction 
in a final assay volume of $1.0 \mathrm{~mL}$. Absorbances were measured on an LKB Biochrom Ultrospec II spectrophotometer.

For preparative purification, PEG-a-Cys was dissolved in ultrapure (Milli-Q) water and purified by FPLC using a Superdex 75HR 10/30 gel filtration column (10 $\mathrm{mm}$ x $300 \mathrm{~mm}, 24 \mathrm{~mL}$ bed volume; Pharmacia Biotech, Montreal, Quebec). Ultrapure (Milli-Q) water was used as the eluant. Samples $(0.1 \mathrm{~mL}$ of $10 \mathrm{mg} / \mathrm{mL}$ PEG-a-Cys) were loaded at a flow rate of $0.1 \mathrm{~mL} / \mathrm{min}$; t the purification was performed at a flow rate of $0.5 \mathrm{~mL} / \mathrm{min}$. Fractions were collected every 0.5 minutes $(250 \mu \mathrm{L}, 0.01$ bed volumes) and were assayed for the presence of PEG and for thionitrobenzoate activity as above.

Normalized absorbance values for the assays were calculated by dividing the absorbance recorded for each fraction by the largest absorbance recorded for that assay in that particular column run. Each assay was then plotted in terms of normalized absorbance (range: 0.0 to 1.0 ) vs. mid-fraction bed volume. Mid-fraction bed volume can be understood as the total volume of solvent eluted by the midpoint of the fraction in question, expressed as a proportion of the volume of the resin bed. Mid-fraction bed volume for each fraction, $F_{n}$ was calculated using the following formula:

mid-fraction bed volume $=\frac{\frac{V_{F_{n}}}{2}+\sum_{i=1}^{n-1} V_{F_{i}}}{V_{c}}$

where: $\quad V_{F_{n}}=$ volume of the nth fraction

$V_{c}=$ total volume of the resin bed

\subsubsection{Skoog PEG assay}

Poly(ethylene glycol) forms a red-brown precipitate when reacted with barium chloride and iodine under acidic conditions. The precipitate is thought to be a complex of barium and iodide with the backbone oxygen atoms of PEG. The assay, originally developed for detecting PEGylated proteins in blood samples, is of sufficient sensitivity to detect PEG at concentrations below $10 \mu \mathrm{g} / \mathrm{mL}$ (Skoog, 1979). 
The sample, 20-200 $\mu \mathrm{L}$, was diluted with $1.0 \mathrm{~mL}$ perchloric acid $\left(\mathrm{HClO}_{4}, 1.0\right.$ M). After a 15 minute incubation at $20^{\circ} \mathrm{C}, 250 \mu \mathrm{L}$ barium chloride $\left(\mathrm{BaCl}_{2}, 5 \% \mathrm{w} / \mathrm{v}\right.$ in $\mathrm{H}_{2} \mathrm{O}$ ) was added, followed immediately by $125 \mu \mathrm{L}$ iodine $\left(\mathrm{I}_{2} / \mathrm{KI}, 0.1 \mathrm{M}\right)$. After a second 15 minute incubation at $20^{\circ} \mathrm{C}$, the sample was mixed vigorously and the absorbance was measured at $535 \mathrm{~nm}$ on an LKB Biochrom Ultrospec II 4050 UV/Visible Spectrophotometer.

\subsubsection{TNB assay}

The well-characterized absorbance of Ellman's reagent at $412 \mathrm{~nm}$ (Ellman, 1959; Riddles et al., 1979; Riddles et al., 1983), upon reaction with either free thiol or a thiol-reducing agent, allowed for a convenient assay for levels of Ellman's reagent and/or PEG-a-Cys based on thionitrobenzoate, or 'TNB', content. Due to the results of the UV/Visible spectroscopic characterization of PEG-a-Cys (see section 3.1.3.2), the absorbance was measured at $420 \mathrm{~nm}$ rather than at $412 \mathrm{~nm}$.

The sample, $100 \mu \mathrm{L}$, was diluted in $1780 \mu \mathrm{L} \mathrm{H}_{2} \mathrm{O}$, to which $100 \mu \mathrm{L}$ sodium acetate $\left(\mathrm{NaO}_{2} \mathrm{C}_{2} \mathrm{H}_{3}, 0.1 \mathrm{M}, \mathrm{pH} 5.0\right)$ and $20 \mu \mathrm{L}$ tricarboxyethylphosphine hydrochloride (TCEP- $\mathrm{HCl}, 0.1 \mathrm{M}$ ) were added. The absorbance at $420 \mathrm{~nm}$ was measured immediately.

\subsubsection{Characterization}

\subsubsection{Nuclear magnetic resonance spectroscopy}

PEG-a-Cys was dissolved in all-deutero dimethylsulfoxide ( $\mathrm{d}_{6} \mathrm{DMSO}$ ), analyzed by $1 \mathrm{D}-{ }^{1} \mathrm{H}$ and $\mathrm{ID}-{ }^{13} \mathrm{C}$ NMR for assignment of resonances, and examined by $2 \mathrm{D}-{ }^{13} \mathrm{C} /{ }^{1} \mathrm{H}$ heteronuclear multiple bond correlation (HMBC) NMR. MPEG ${ }^{5000}$ and Ellman's reagent, the starting materials from PEG-a-Cys synthesis, were also dissolved in $\mathrm{d}_{6}-\mathrm{DMSO}$ and subjected to $1 \mathrm{D}-{ }^{-} \mathrm{H}$ NMR analysis to aid in peak assignments for PEG-a-Cys. Experiments were performed on a $500 \mathrm{MHz}$ NMR spectrometer. We are pleased to acknowledge the assistance of Dr. Art Grey of the University of Toronto 
Department of Biochemistry NMR Centre for the analysis and interpretation of the NMR data in addition to performing the experiments.

\subsubsection{UV/Visible spectroscopy}

PEG-a-Cys was dissolved to $0.05 \mathrm{mM}$ in sodium phosphate buffer $(100 \mathrm{mM}$, $\mathrm{pH} 7.0$ ) and the absorbance spectrum was measured from 350 to $550 \mathrm{~nm}$ using a $\mathrm{U}$ 3210 spectrophotometer (Hitachi). The region between 400 and $450 \mathrm{~nm}$ was sampled at $1 \mathrm{~nm}$ intervals; the remainder of the spectrum was sampled at $10 \mathrm{~nm}$ intervals. PEGa-Cys dissolved to $0.5 \mathrm{mM}$ in sodium phosphate buffer (100 mM, $\mathrm{pH} 7.0)$ and reduced with tricarboxyethylphosphine hydrochloride 'TCEP-HCl' was examined in an identical manner. The absorbance values of PEG-a-Cys were subtracted from the absorbance values of reduced PEG-a-Cys to obtain a difference spectrum. An identical set of analyses were carried out on Ellman's reagent, dissolved to $0.05 \mathrm{mM}$ in sodium phosphate buffer (100 mM, pH 7.0).

\subsubsection{Reactivity with cysteine}

PEG-a-Cys dissolved to $0.05 \mathrm{mM}$ in sodium phosphate buffer $(100 \mathrm{mM}, \mathrm{pH}$ 7.0) was reacted with cysteine solutions of $0.01,0.05,0.1,0.2,0.3,0.4$ and $0.5 \mathrm{mM}$ concentrations. Control reactions with serine at $0.1,0.2,0.3,0.4$ and $0.5 \mathrm{mM}$ concentrations were also performed. The absorbance at $420 \mathrm{~nm}$ was recorded for each reaction after a 5 minute incubation at $20^{\circ} \mathrm{C}$. 


\subsection{ALC model peptide}

\subsubsection{Synthesis}

The ALC peptide (Sequence: $\mathrm{H}_{2} \mathrm{~N}$-REAAALAAAAALAAWAALCPARRRR$\left.\mathrm{CO}_{2} \mathrm{H}\right)$ was synthesized on an LKB-Biolynx 4170 Automated Peptide Synthesizer (Pharmacia Biotech., Montreal, Quebec). Fmoc-protected amino acids were purchased from the Calbiochem-Novabiochem Group in San Diego, California. The peptide was deprotected and cleaved in a mixture of TFA/water/anisole/ethanedithiol (95/1/2/2). The resulting solution was desalted on a Sephadex G-10 column, eluted with $20 \mathrm{mM}$ ammonium bicarbonate and lyophilized. We acknowledge the assistance of Dr. Nam Wang of the Hospital for Sick Children Biotechnology Service Center in the syntheses and preparation of the peptide.

Two batches of ALC were synthesized. The first batch was used for initial characterization of PEGylation conditions (not shown) and optimization of polyacrylamide gel electrophoresis methods, as well as for the circular dichroism experiments (section 2.3.4.1). A second batch was synthesized to provide sufficient material for the optimization of PEGylation (section 2.3.1), digestion using FPLCpurified PEG-a-Cys (section 2.3.2) and for the ultracentrifugation experiments (section 2.3.3.1).

\subsubsection{Purification}

Crude ALC was dissolved in an aqueous solution of $10 \%$ acetonitrile and purified by high performance liquid chromatography (HPLC) on a Waters 600 system. Aliquots $(100 \mu \mathrm{L})$ of a $10 \mathrm{mg} / \mathrm{mL}$ solution of crude ALC were injected on a Vydac reverse-phase $C 4$ semi-preparative column $(10 \times 250 \mathrm{~mm}, 300 \AA \AA$ pore size $)$ and eluted at a flow rate of $3.0 \mathrm{~mL} / \mathrm{min}$. with an aqueous acetonitrile gradient. The initial concentrations in the mobile phase were $10 \%$ acetonitrile, $90 \%$ water, $0.1 \%$ TFA. The concentration of acetonitrile was raised to $40 \%$ in 20 minutes and held at $40 \%$ for 10 
minutes to elute the peptide. Subsequently, the acetonitrile concentration was raised to $70 \%$ in 10 minutes and held for 5 minutes to ensure that hydrophobic species were eliminated from the column. The concentration of acetonitrile was then lowered to $10 \%$ over 15 minutes and held for 5 minutes to re-equilibrate the column in preparation for the next injection.

Peptides were detected by absorbance at $215 \mathrm{~nm}$ on a Lambda-Max Model 480 LC Spectrophotometer. Collected peaks from multiple runs were pooled, diluted with water to reduce the acetonitrile concentration to less than $15 \%$, frozen in dry ice for 1-2 hours and lyophilized on a Unitrap II Lyophilizer or a Freezemobile 25XI Lyophilizer (both from Virtis, New York). Lyophilized pure ALC was injected onto the same HPLC column and eluted under identical conditions to assess purity. The identity of the lyophilized peptide was established using electrospray mass spectrometry (predicted m.w. $=2577.4$ Da; measured m.w. $=2578 \mathrm{Da})$.

\subsubsection{Characterization}

\subsubsection{Amino acid analysis}

ALC was analyzed for total amino acid content to confirm the identity of the peptide and to determine concentrations. The peptide was hydrolyzed with hydrochloric acid $(6 \mathrm{M})$ for 48 hours and the amino acids were reacted with phenylisothiocyanate to form phenylthiohydantoin derivatives. The PTH derivatives were analyzed and quantitated by HPLC in comparison with a standard mixture of PTH-derivatized amino acids (Smith, 1997). Peptide concentrations were determined by dividing the concentrations of PTH-Glu, PTH-Ala and PTH-Leu by one, thirteen and three respectively (corresponding to the molar amounts of each residue present in the ALC peptide) and calculating the mean of the values obtained.

Many thanks to Rey Interior of the Biotech Service Center at the University of Toronto for performing the amino acid analyses. 


\subsection{PEGylation and enzyme digestion of ALC}

\subsubsection{PEGylation of ALC with PEG-a-Cys}

ALC ( $1 \mathrm{mM})$ in deionized water was treated with FPLC-purified PEG-a-Cys at concentrations of $0.5,1.0,1.5,2.0$ and $2.5 \mathrm{mM}$. The $\mathrm{pH}$ of the solutions were assessed using $\mathrm{pH}$ test strips (Sigma). The reactions were incubated for $\mathbf{3 0}$ minutes at $20^{\circ} \mathrm{C}$. In order to test the reversibility of PEGylation, samples of unmodified and PEGylated ALC were incubated with tricarboxyethylphosphine hydrochloride 'TCEP$\mathrm{HCl}^{\prime}(300 \mu \mathrm{M}$; Boehringer-Mannheim) at a concentration of $30 \mathrm{mM}$, for 30 minutes at $20^{\circ} \mathrm{C}$. The samples were analyzed by NB-PAGE.

\subsubsection{Native basic PAGE}

NB-PAGE is similar to the more familiar SDS-PAGE, differing in that the electric field is reversed in polarity, no detergent is used, and the $\mathrm{pH}$ of the buffer system is 4.2 instead of 8.0 in order to enhance the solubility and native charges of basic proteins.

The Phastsystem (Pharmacia Biotech) PAGE apparatus was used to run the gels. Each sample ( $4 \mu \mathrm{L}$ ) was mixed with $1 \mu \mathrm{L}$ of $5 \mathrm{X}$ sample buffer $(100 \mathrm{mM}$ sodium phosphate $\mathrm{pH} 6.0,50 \%$ glycerol, $3 \mathrm{mM}$ pyronin $\mathrm{Y}$ as tracking dye) before loading onto a precast high density PhastGel (20\% crosslinking, 30\% ethylene glycol) under constant voltage with the following settings: $200 \mathrm{~V}, 10 \mathrm{~mA}, 2.5 \mathrm{~W}, 15^{\circ} \mathrm{C}, 10 \mathrm{Vh}$. After sample loading, the polarity of the electrodes was reversed, and electrophoresis was carried out under constant voltage with the following settings: $200 \mathrm{~V}, 10 \mathrm{~mA}, 2.5$ $\mathrm{W}, 15^{\circ} \mathrm{C}, 250 \mathrm{Vh}$. The gels were placed in the PhastGel development chamber and fixed with $2.5 \%$ glutaraldehyde for 5 minutes before being stained with Coomassie brilliant blue for 8 minutes and destained 3 times with water/methanol/acetic acid (6/3/1) for 5, 8 and 10 minute periods. Fixing, staining and destaining were all performed at $50^{\circ} \mathrm{C}$. Following Coomassie staining the gels were imaged using a White/UV 
Transilluminator (UVP Inc.) and the image captured with GRAB-IT'TM v1.57b (UVP Inc.). Gels were subsequently stained for PEG using the Kurfurst technique and imaged a second time.

\subsubsection{Kurfurst gel stain for PEG}

The Kurfurst method consists of the application of the Skoog assay (section 2.1.2.1) to gel-immobilized PEGylated polypeptides. The procedure was performed subsequent to Coomassie staining of the gel. The procedure visualizes all species of PEG present in the gel. The intensity of Coomassie-stained bands is not diminished by the Kurfurst stain; PEGylated peptides and proteins can be identified by the fact that they are stained by both Coomassie and the Kurfurst stain (Kurfurst, 1992).

PhastGels, after Coomassie staining and imaging, were immersed in $20 \mathrm{~mL}$ perchloric acid $\left(\mathrm{HClO}_{4}, 1.0 \mathrm{M}\right)$ for 15 minutes with agitation. To this solution, $5 \mathrm{~mL}$ barium chloride $\left(\mathrm{BaCl}_{2}, 5 \% \mathrm{w} / \mathrm{v}\right)$ was added, followed immediately by the addition of 2 $\mathrm{mL}$ iodine $\left(\mathrm{I}_{2} / \mathrm{KI}, 0.1 \mathrm{M}\right)$. After 5-15 minutes with agitation, the gels were destained in $\mathrm{H}_{2} \mathrm{O}$ for 2-5x 15 minutes, until the background staining had subsided to a clarity suitable for imaging.

\subsubsection{Enzyme digestion of C-terminal Arg residues}

Sodium phosphate buffer (pH 7.0) was added to unmodified and PEGylated ALC samples to a final concentration of $10 \mathrm{mM}$.

Carboxypeptidase B (Sigma-Aldrich, lyophilized powder with buffer salts) was dissolved in water to a concentration of $1 \mathrm{mg} / \mathrm{mL}$ no longer than one hour before use. Dilutions of this stock solution were added to the peptide solutions to final enzyme concentrations of 4 and $10 \mu \mathrm{g}$ enzyme $/ \mathrm{mL}$. The final concentration of ALC in each sample was $1 \mathrm{mM}$. These solutions were incubated for 2 hours at $20^{\circ} \mathrm{C}$. The samples were analyzed by NB-PAGE (section 2.3.1.1). 


\subsubsection{Solubility effects of PEGylation and digestion}

Four equal portions of lyophilized ALC were dissolved in deionized water to 5 $\mathrm{mM}$ concentration. Two of these samples were PEGylated by the addition of equal volumes of 5 mM FPLC-purified PEG-a-Cys; an equivalent volume of deionized water was added to the two unmodified samples. All were incubated for 30 minutes at room temperature. Buffer (sodium phosphate $\mathrm{pH} 7.0$ ) was then added to all samples, to a final concentration of $10 \mathrm{mM}$. Carboxypeptidase $B$ was added to one each of PEGylated and unmodified samples, to a final concentration of $10 \mu \mathrm{g}$ enzyme / $\mathrm{mL}$. These samples were termed 'digested'; the samples which received no enzyme were termed 'intact'. The putative final ALC concentration in all samples was $1 \mathrm{mM}$, as was the final concentration of PEG-a-Cys in the two PEGylated samples. Final concentrations were achieved by addition of deionized water in appropriate amounts to each sample.

\subsubsection{Ultracentrifugation}

The samples were incubated for 7 days at $20^{\circ} \mathrm{C}$. At time points of $0.1,1,2,3$, 5 and 7 days, each sample was mixed thoroughly and an aliquot $(150 \mu \mathrm{L})$ was removed for ultracentrifugation. The aliquots were immediately placed in $250 \mu \mathrm{L}$ polycarbonate tubes and centrifuged at $100000 \mathrm{xg}$ for 60 minutes at $4^{\circ} \mathrm{C}$ in a $42.2-\mathrm{Ti}$ rotor using a L8-55 ultracentrifuge (Beckman). The greater part ( $90 \mu \mathrm{L})$ of each supernatant was removed by pipette with care to not disturb any pellet. Each supernatant was mixed thoroughly and from each 3 aliquots were removed. One aliquot $(8 \mu \mathrm{L})$ from each supernatant was analyzed by NB-PAGE (section 2.3.1.1) for quick but qualitative estimate of ALC PEGylation and digestion states. A second aliquot ( $20 \mu \mathrm{L})$ from each supernatant was analyzed for total amino acid content (section 2.2.3.1) to determine ALC concentration. The third aliquot $(20 \mu \mathrm{L})$ of each of the digested samples and of the 0.1 day samples of each of the intact samples (as controls) was analyzed for free amino acids. 


\subsubsection{Analysis of free amino acids}

Analysis of free amino acids was performed to determine the extent of enzymatic removal of C-terminal arginine residues from ALC by carboxypeptidase B. Before derivitization, the samples were acidified and treated with diethyl ether in order to precipitate the peptides so that they would not interfere with the analyses. Samples (20 $\mu \mathrm{L})$ were added to trifluoroacetic acid $(99 \%, 60 \mu \mathrm{L})$ resulting in a TFA concentration of 75\%. Diethyl ether $\left(150 \mu \mathrm{L}, 4^{\circ} \mathrm{C}\right)$ was added and the samples were held on ice for one hour. Centrifugation $\left(14000 \times \mathrm{g}, 4^{\circ} \mathrm{C}\right)$ was followed by immediate decanting of supernatants, which were let stand ovemight in the fumehood to evaporate excess diethyl ether. The samples were then derivatized and analyzed as in section 2.2.3.1, omitting the hydrolysis step.

\subsubsection{Structural effects of PEGylation and digestion}

ALC was dissolved in sodium phosphate buffer ( $10 \mathrm{mM}, \mathrm{pH} 7.0)$ to a concentration of $375 \mu \mathrm{M}$ and treated with $750 \mu \mathrm{M}$ TCEP- $\mathrm{HCl}$ for 30 minutes in order to reduce interpeptide disulfide bonds. Pre-PEGylation reduction was necessary due to the sample history of this particular batch of ALC. The solution was then divided into four equal samples. PEG-a-Cys was then added to two of the samples and water was added to the remaining two, bringing the concentrations of $\mathrm{ALC}$ to $150 \mu \mathrm{M}, \mathrm{TCEP}-\mathrm{HCl}$ to $300 \mu \mathrm{M}$ and PEG-a-Cys to $750 \mu \mathrm{M}$ in each sample. The samples were incubated for 30 minutes at $20^{\circ} \mathrm{C}$ in order to ensure complete PEGylation. Carboxypeptidase B, diluted from freshly prepared $1 \mathrm{mg} / \mathrm{mL}$ stock solution, was added to one unmodified and one PEGylated sample to a final concentration of $0.02 \mu \mathrm{g}$ enzyme / $\mathrm{mL}$. This low

concentration of $\mathrm{CpB}$ was used as the batch of enzyme used for this experiment was of higher activity than that used for other digestions. The samples were incubated for 24 hours at $20^{\circ} \mathrm{C}$. Each sample was then examined by CD spectroscopy. The initial ALC concentration of $150 \mu \mathrm{M}$ as determined by amino acid analysis was used for the calculation of mean residue ellipticity. 
Unmodified and PEGylated ALC samples were prepared as above and were incubated for 8 days at $20^{\circ} \mathrm{C}$. Fach sample was centrifuged for 5 minutes at $14000 \times \mathrm{g}$ after $3,6,24,49,75,96$ and 192 hours of incubation and the supernatants were examined by $C D$ spectroscopy. The ellipticity data were reported in absolute terms (millidegrees) and were not converted to mean residue ellipiticity.

\subsubsection{Circular dichroism spectroscopy}

All samples were centrifuged at $14000 \times \mathrm{g}$ for 5 minutes immediately before the supernatants were transferred to a $0.1 \mathrm{~cm}$ path length quartz cell. The circular dichroism (in millidegrees) was recorded at each $0.2 \mathrm{~nm}$ wavelength interval between $190 \mathrm{~nm}$ and $250 \mathrm{~nm}$, on a J720-A Spectropolarimeter with version 1.20a software (Jasco). Each spectrum was the average of 3 scans, with the appropriate blank spectrum subtracted before the Jasco version 1.20 a noise reduction routine was applied. The blank for each sample (containing identical constituents but no peptide) was carried through reaction procedures identical to those experienced by the sample itself.

The ellipticity data were converted to mean residue ellipticity $(\theta)$ by the following formula:

$$
\theta=\frac{q}{[\mathrm{ALC}] \oplus(\# \mathrm{aa} / \mathrm{ALC}) \boldsymbol{\ell}}
$$

where:

$$
\begin{aligned}
\theta & =\text { mean residue ellipticity }\left(\mathrm{deg}^{\bullet} \mathrm{cm}^{2} / \mathrm{dmol}\right) \\
\mathrm{q} & =\text { ellipticity }(\mathrm{mdeg}) \\
{[\mathrm{ALC}] } & =\text { concentration of ALC peptide }(\mu \mathrm{M}) \\
\# \text { aalALC } & =\text { number of amino acids per ALC peptide }(=25) \\
\ell & =\text { path length }(\mathrm{cm})
\end{aligned}
$$

The mean residue ellipticity values were then normalized by, at each wavelength, subtracting the value of the mean residue ellipticity at $250 \mathrm{~nm}$. 
Chapter 3

Results 


\subsection{PEG-a-Cys reagent}

\subsubsection{Synthesis}

The crude product of PEG-a-Cys synthesis was recovered from the organic (methylene chloride) phase and appeared as a yellow-white solid. After dissolution in hot ethanol, PEG-a-Cys precipitated as a white solid. The theoretical ' $100 \%$ ' yield ( $10.36 \mathrm{~g})$ was calculated by assuming that all of the Ellman's reagent ( $1 \mathrm{mmole}, 0.40 \mathrm{~g}$ ) had been bis-esterified, incorporating all of the MPEG ( 2 mmoles, $10.00 \mathrm{~g}$ ) in the reaction and losing 2 equivalents of $\mathrm{H}_{2} \mathrm{O}$ per molecule of Ellman's reagent ( 2 mmoles, $0.036 \mathrm{~g})$.

The apparent high yield (Table 1) is debatable as any unreacted MPEG or monoesterified Ellman's reagent (MPEGyl-DTNB) was expected to have followed the PEGa-Cys during the wash steps, and would be expected to precipitate from ethanol along with PEG-a-Cys. Also, the unusual increase in yield between crude and final products suggested that the compound had adsorbed water during the precipitation step, and it must be assumed that water adsorption occurred during the aqueous washing steps prior to measurement of the crude product mass as well.

Table 1: Yields of PEG-a-Cys synthesis

\begin{tabular}{rcc}
\hline & Mass (g) & Yield (\%) \\
\hline Theoretical & 10.36 & $100^{\prime}$ \\
\hline Crude product & 9.77 & 94.5 \\
\hline PEG-a-Cys & 10.33 & 99.7 \\
\hline
\end{tabular}

\subsubsection{Purification}

Columns of several different gel filtration resins were tested for their ability to purify PEG-a-Cys. This allowed for the selection of an appropriate resin with which to perform preparative purification using an automated FPLC system. The eluted fractions from the column runs were examined by two chemical assays: the Skoog assay for PEG and the TNB assay for thionitrobenzoates. The Skoog assay detected any and all 
compounds containing PEG; in addition to PEG-a-Cys, any unreacted MPEG ${ }^{5000}$ and/or MPEGyl-DTNB would register. The TNB assay measured only thionitrobenzoates; in addition to PEG-a-Cys, any MPEGyl-DTNB and/or Ellman's reagent would be detected. MPEG, however, was not detectable with the TNB assay.

The first resin tested (G10 Sephadex) had an exclusion limit of $10 \mathrm{kDa}$. The results of the Skoog and TNB assays on the eluted fractions from this column were superimposable (not shown) revealing a single peak which eluted in the void volume, indicating that it was larger than the exclusion limit. This indicated PEG-a-Cys contained no contaminating unesterified Ellman's reagent, as this small molecule ( 0.4 $\mathrm{kDa}$ ) would not have eluted in the void; a second TNB assay peak eluting later would have been expected.

Several resins with higher exclusion limits (G50 Sephadex, G100 Sephadex and S200HR Sephacryl) were tested and each displayed two peaks with regards to the Skoog (total PEG) assay, indicating that two species of PEG of significantly different sizes were present. The second peak eluted $0.06(\mathrm{G} 50)$ to 0.15 (G100) bed volumes later than the first, and showed no correlation with TNB activity, indicating that the peak was due to a compound containing PEG but not Ellman's reagent. The elution volume of this second peak corresponded to that of a control run of pure MPEG ${ }^{5000}$. The second peak was therefore concluded to be unreacted MPEG ${ }^{5000}$.

The first Skoog assay peak superimposed exactly upon the single TNB assay peak, indicating that the first peak was due to a compound containing both PEG and Ellman's reagent, such as PEG-a-Cys, MPEGyl-DTNB or both. The fact that it was separable from the MPEG ${ }^{5000}$ peak suggested that the compound was of significantly greater molecular weight than MPEG ${ }^{5000}$. The first peak was therefore concluded to be PEG-a-Cys. Fractions eluting up to 1.1 bed volumes were assayed but no other peaks were detected, suggesting that no species other than PEG-a-Cys and MPEG ${ }^{5000}$ were present in significant amounts. 
The G100 resin provided the best resolution (Figure 7). PEG-a-Cys, represented by the congruent TNB assay and Skoog peak, eluted with a maximum at 0.53 bed volumes. The MPEG ${ }^{5000}$ peak was not completely resolved from the PEG-aCys peak as demonstrated by the tailing of the TNB assay trace. The tailing of the PEG-a-Cys peak was corrected for by subtraction of the normalized TNB assay results from the Skoog assay results. This gave an MPEG trace which reached a maximum at 0.68 bed volumes. It was estimated from the peak areas that approximately two-thirds of the original MPEG ${ }^{5000}$ had been esterified to Ellman's reagent to form PEG-a-Cys, leaving one-third unreacted MPEG $^{5000}$.

\subsubsection{FPLC gel filtration}

It was predicted that greater resolution would be gained from using a pressurized LC system such as fast purification liquid chromatography (FPLC). The Superdex 75 HR 10/6 column was chosen as the nearest in material composition and exclusion limit (75 kDa) to G100 Sephadex.

While sodium acetate buffer ( $\mathrm{pH} 5$ ) had been used as eluant to prevent alkaline hydrolysis of PEG-a-Cys, it was discovered that the use of $\mathrm{pH} 5$ unbuffered water as an eluant increased the resolution of the peaks and did not lead to alkaline hydrolysis of the reagent. All sections of the injection system, column, and fraction collection were shielded from light to prevent degradation of the Ellman's reagent portion of PEG-aCys by ultraviolet light (Walmsley et al., 1987). The optimized elution resulted in nearbaseline resolution (Figure 8a) of the two peaks. The PEG-a-Cys peak (congruent portions of the normalized TNB and Skoog assay traces) reached its maximum at 0.43 bed volumes. The MPEG ${ }^{5000}$ peak (Skoog assay with normalized TNB assay subtracted) reached its maximum at 0.51 bed volumes. A sample of pure $\mathrm{MPEG}^{5000}$ was loaded and eluted under identical conditions as a control and was demonstrated to elute with a maximum at 0.52 bed volumes (Figure $8 \mathrm{~b}$ ) as expected.

The effective yield of PEG-a-Cys synthesis, defined as the proportion of MPEG converted to PEG-a-Cys and measured by relative peak areas on FPLC, was $64 \%$. 


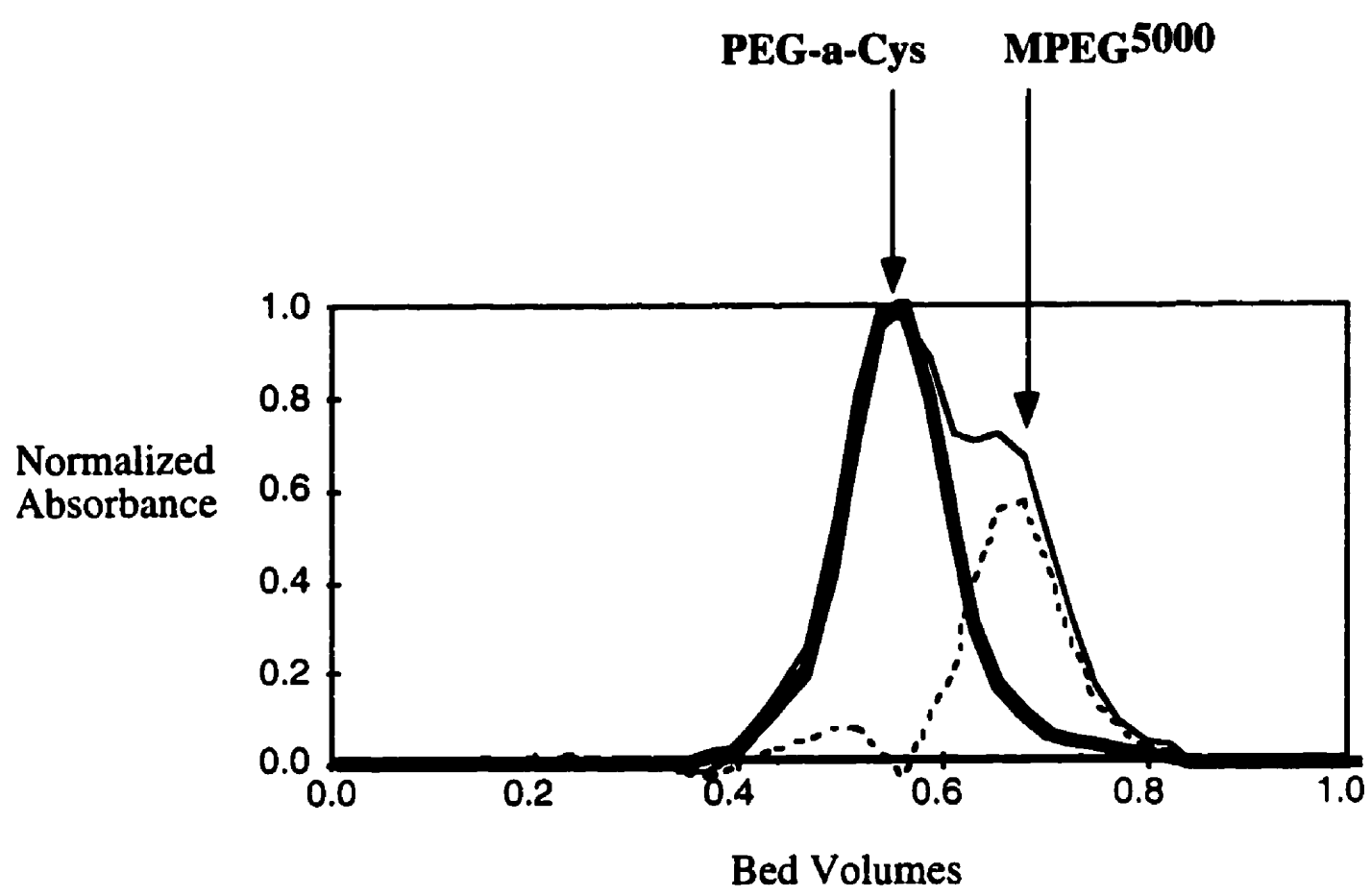

__ Skoog Assay (Total PEG)

TNB Assay (compounds containing Ellman's reagent)

-.... calculated MPEG (Skoog - TNB)

Figure 7: Gel filtration of PEG-a-Cys on Sephadex G100 resin. The first peak, in which the Skoog and TNB assay values overlap, was identified as PEG-a-Cys (avg. m.w. = $10.4 \mathrm{kDa}$ ). The second peak, calculated by the subtraction of the normalized TNB assay values from the Skoog assay values, was identified as MPEG $^{5000}$ (avg. m.w. $=5 \mathrm{kDa}$ ). 


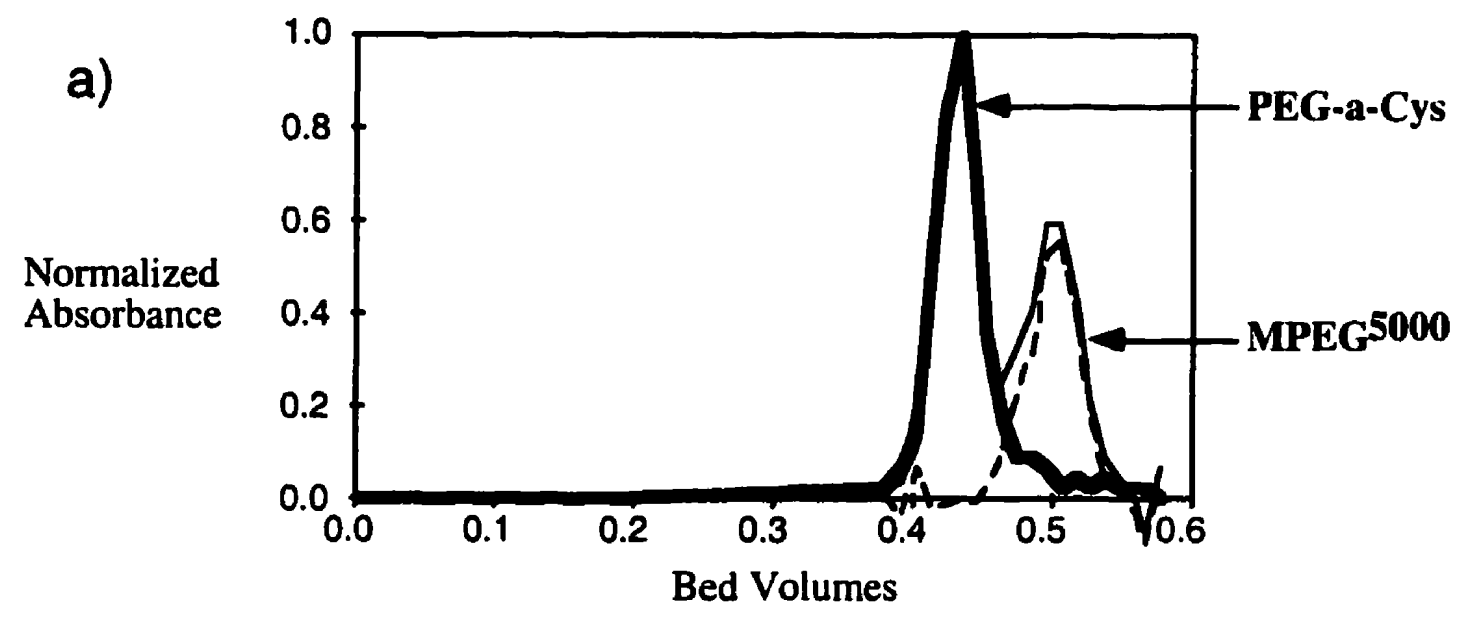

b)

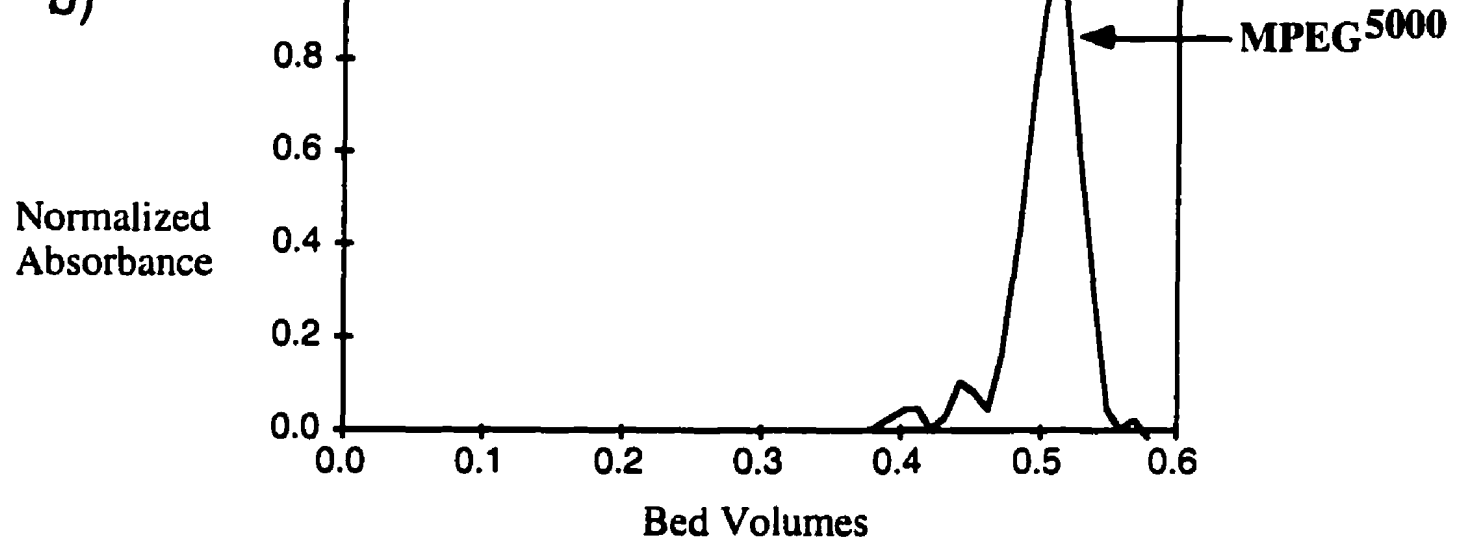

- Skoog Assay (Total PEG)

- TNB Assay (compounds containing Ellman's reagent)

....-. calculated MPEG (Skoog - TNB)

Figure 8: Purification of PEG-a-Cys by Superdex 75 FPLC gel filtration. (a) PEG-a-Cys (congruent portions of the TNB and Skoog assay traces) eluting at 0.43 bed volumes was almost completely resolved from MPEG ${ }^{5000}$ (calculated Skoog - TNB assays) which eluted at 0.51 bed volumes (b) A control run of pure MPEG $^{5000}$ eluted at 0.52 bed volumes. 


\subsubsection{Characterization}

\subsubsection{NMR spectroscopy}

In order to confirm that the synthesis had resulted in the formation of an ester bond between Ellman's reagent and MPEG ${ }^{5000}$, PEG-a-Cys was examined by NMR spectroscopy. The chemical shifts of the atoms of interest were first assigned using one dimensional NMR. These atoms were designated as follows: H2, H5 and H6 represent the aromatic hydrogens of the Ellman's reagent moiety; $\mathrm{H}_{\mathrm{p}}$ represents the 'carbonyl-proximal' protons of the PEG moiety ethoxy carbon closest to the putative ester bond; and $C_{c}$ represents the carbonyl carbon of the Ellman's reagent moiety. See Figure 9 for a diagram of PEG-a-Cys indicating proton designations, and Figure 10 for a similar diagram also indicating the carbon designation.

The ID.'H-NMR experiment revealed a complex, highly intense group of resonances between 3.2 and 3.7 ppm (Figure 9). A ID- ${ }^{1} \mathrm{H}-\mathrm{NMR}$ analysis of PEG ${ }^{5000}$ (not shown) revealed a similar group of resonances in that region, and they were attributed to the aliphatic hydrogen atoms of the ethoxy carbons in the PEG chain. A resonance at $4.36 \mathrm{ppm}$ of the PEG-a-Cys spectrum (Figure 9) was assigned to the $\mathrm{H}_{\mathrm{p}}$ protons. Three protons in PEG-a-Cys resonated at 7.94, 7.99 and 8.12 ppm and were assigned to aromatic hydrogen atoms $\mathrm{H} 5, \mathrm{H} 2$ and $\mathrm{H} 6$ respectively. These were near to but not superimposable with the aromatic resonances found at $7.88,7.95$ and 8.03 in a ID-'H-NMR analysis of Ellman's reagent (not shown). The small increases in the chemical shifts of the PEG-a-Cys aromatic hydrogens suggested that a minor chemical change in the vicinity of the aromatic rings of Ellman's reagent had occurred. This was consistent with the hypothesis that esterification of MPEG to the carbonyl carbon of Ellman's reagent had occurred.

PEG-a-Cys was also examined using $1 D-{ }^{13} \mathrm{C}-\mathrm{NMR}$ (data not shown). A complex, intense group of resonances between 60 and $75 \mathrm{ppm}$ were attributed to the ethoxy carbons of the PEG backbone. A resonance at $58 \mathrm{ppm}$ was assigned to the terminal methoxy carbon of MPEG. Six resonances at 125.6, 126.7, 127.8, 129.3, 
<smiles>Cc1c(SI)c(C(C)I)c(C(C)I)c([N+](=O)[O-])c1C(=O)OC(C)(C)COCCCOC(C)(C)C</smiles>
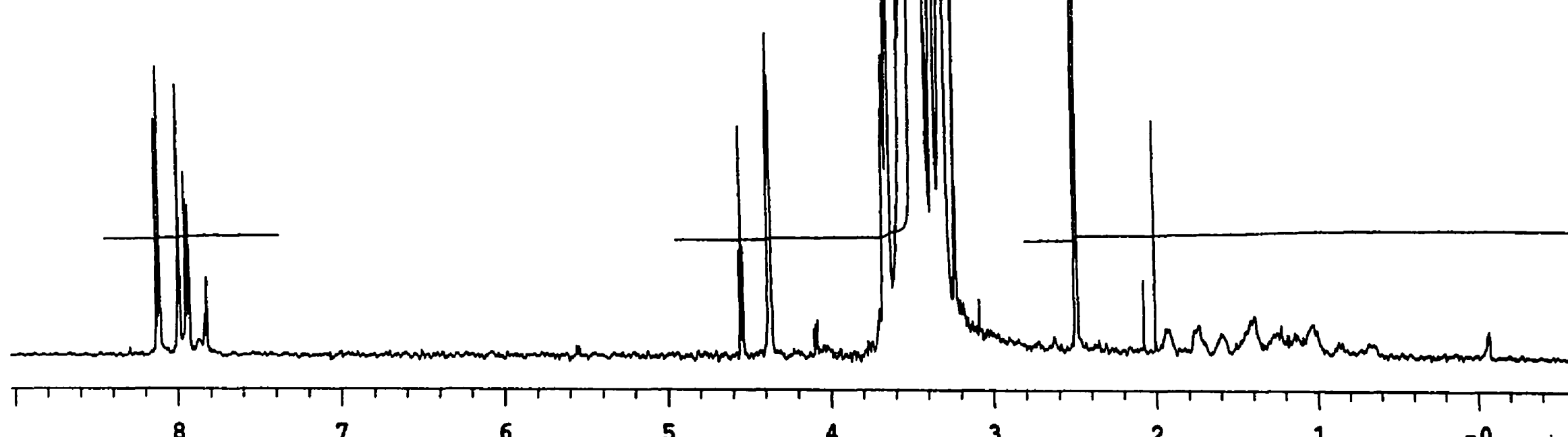

8

7

6

5

4

3

H6

H5

H2

$7.94 \mathrm{ppm}$

$\mathrm{H}_{\mathrm{p}}$

$8.12 \mathrm{ppm} \quad 7.99 \mathrm{ppm} \quad 7.94 \mathrm{ppm} \quad 4.36 \mathrm{ppm}$

Figure 9: 1D-1H-NMR spectrum of PEG-a-Cys in d -DMSO at 500 MHz. The assignment of the proton resonances of PEG-a-Cys was based on a comparison of the spectrum with those of starting materials MPEG ${ }^{5000}$ and Ellman's reagent (not shown). Resonances at 7.94, 7.99 and 8.12 ppm were assigned to aromatic protons H6, H2, and H5 respectively. The resonance at 4.37 ppm was assigned to the ' $\mathrm{H}_{\mathrm{p}}$ ' protons of the $\mathrm{CH}_{2}$ group of PEG proximal to the putative ester linkage. The putative structure of PEG-a-Cys with the assigned hydrogen atoms labelled is given above the spectrum. 
142.3 and $146.0 \mathrm{ppm}$ were assigned to the aromatic carbons of the nitrobenzyl rings. A resonance at $164.0 \mathrm{ppm}$ was assigned to the carbonyl carbon $\mathrm{C}_{\mathrm{c}}$ of the Ellman's reagent moiety. As a resonance in that range of the ${ }^{13} \mathrm{C}$ spectrum could be due to either a carboxylic acid or the putative ester carbonyl, a heteronuclear multiple bond correlation (HMBC) experiment was necessary to establish that the carbonyl was covalently linked to atoms of the PEG chain.

The HMBC spectrum was dense with overlapping resonances from the carbon and hydrogen atoms of the backbone of PEG, in the region encompassed by hydrogen chemical shifts of 3-4 ppm and carbon chemical shifts spanning the entire range measured (35-175 ppm). However, the aromatic and carbonyl resonances were detected in a different region of the spectrum bounded by ${ }^{13} \mathrm{C}$ chemical shifts of 120 $165 \mathrm{ppm}$ and ${ }^{1} \mathrm{H}$ chemical shifts of 4.3-8.5 ppm, and were well resolved (Figure 10).

Peaks were detected between the $C_{c}$ resonance of the Ellman's reagent moiety at ${ }^{13} \mathrm{C} 164.0 \mathrm{ppm}$ and several aromatic proton resonances: ${ }^{~} \mathrm{H} 7.94(\mathrm{H} 6), 7.99(\mathrm{H} 2)$ and 8.12 ppm (H5). The $\mathrm{C}_{c}-\mathrm{H} 2$ peak was more intense than either of the $\mathrm{C}_{c}-\mathrm{H} 5$ or $\mathrm{C}_{c}-\mathrm{H} 6$ peaks. A peak was also detected between the $C_{c}$ at ${ }^{13} \mathrm{C} 164.0 \mathrm{ppm}$ and the $\mathrm{H}_{\mathrm{p}}$ proton resonance at ' $\mathrm{H} 4.36 \mathrm{ppm}$. This peak was of similar intensity to that of $\mathrm{C}_{\mathrm{c}}-\mathrm{H} 2$. The $\mathrm{C}_{\mathrm{c}}$ $\mathrm{H}_{\mathrm{p}}$ peak indicated that PEG and Ellman's reagent were covalently linked in PEG-a-Cys via the carbonyl carbon, confirming that the esterification reaction was successful. 


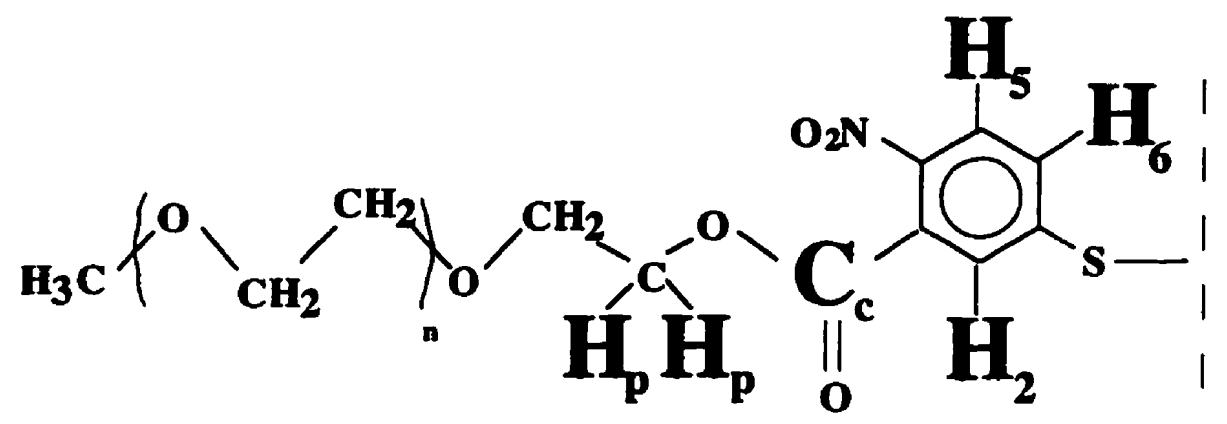

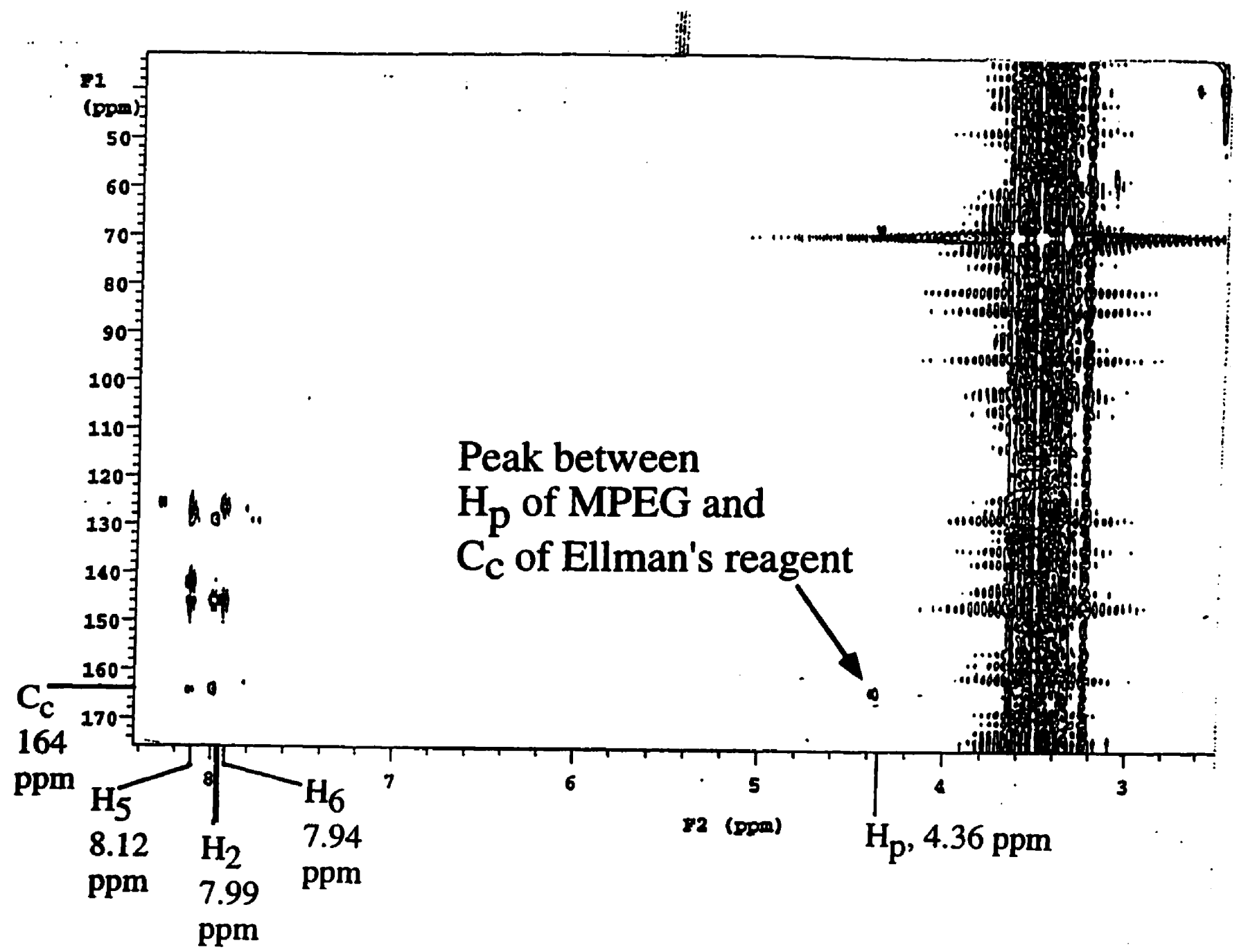

Figure 10: HMBC-2D- ${ }^{13} \mathrm{C} /{ }^{1} \mathrm{H}-\mathrm{NMR}$ spectrum of PEG-a-Cys in $d_{6}$ DMSO at $500 \mathrm{MHz}$. The peak between the carbonyl carbon $\mathrm{C}_{\mathrm{c}}$ at $164 \mathrm{ppm}$ and the carbonyl-proximal $\mathrm{CH}_{2}$ protons $\mathrm{H}_{\mathrm{p}}$ at $4.36 \mathrm{ppm}$ displayed an intensity similar to that of the $\mathrm{C}_{\mathrm{c}} /$ aromatic $\mathrm{H} 2$ peak at $164 \mathrm{ppm} / 7.99 \mathrm{ppm}$. $\mathrm{C}_{\mathrm{c}}$ and $\mathrm{H}_{\mathrm{p}}$ were separated by 3 covalent bonds in the putative structure of PEG-a-Cys. $\mathrm{C}_{\mathrm{c}}$ and $\mathrm{H} 2$ were separated by 3 covalent bonds in both the known structure of Ellman's reagent and the putative structure of PEG-a-Cys. 


\subsubsection{UVNisible spectroscopy}

PEG-a-Cys formed a clear solution upon dissolution in sodium phosphate buffer ( $\mathrm{pH}$ 7.0). Upon reduction with the disulfide-specific reducing agent tricarboxyethylphosphine 'TCEP', the solution became bright yellow within seconds, with no visible increase in turbidity. Reduced difference spectra between $\mathbf{3 5 0}$ and $\mathbf{5 5 0}$ nm were constructed for PEG-a-Cys and Ellman's reagent (Figure 11). MPEG ${ }^{5000}$ showed no appreciable absorbance in the range measured (data not shown). It was noted that the absorbance maximum of reduced PEG-a-Cys was $423 \mathrm{~nm}$ (Figure 11a), whereas reduced Ellman's reagent absorbed maximally at $412 \mathrm{~nm}$ (Figure $1 \mathrm{lb}$ ) consistent with the literature value (Ellman, 1959). The molar extinction coefficient of PEG-a-Cys was calculated to be $14000 \mathrm{M}^{-1} \mathrm{~cm}^{-1}$. The amplitude of the Ellman's reagent spectrum was lower than that of PEG-a-Cys, but this was an effect of the limited solubility of Ellman's reagent at $\mathrm{pH} 7$.

\subsubsection{Reactivity with cysteine}

To test the reactivity of PEG-a-Cys with compounds containing thiol groups, the final synthetic product was mixed with the amino acid cysteine, 'Cys'. The absorbance was measured at $420 \mathrm{~nm}$, near the $\lambda_{\max }$ of PEG-a-Cys. The solutions immediately changed colour from clear to yellow, and the absorbances at $420 \mathrm{~nm}$ increased dramatically, proving that the compound had reacted spontaneously with Cys. The $A_{420}$ values of the solutions increased with the concentration of Cys until a plateau was reached at a concentration of Cys twice that of the PEG-a-Cys used. The absorbance at $420 \mathrm{~nm}$ of a control reaction with the amino acid serine, 'Ser', remained unchanged from that of a solution of PEG-a-Cys alone (Figure 12). 
a)

b)

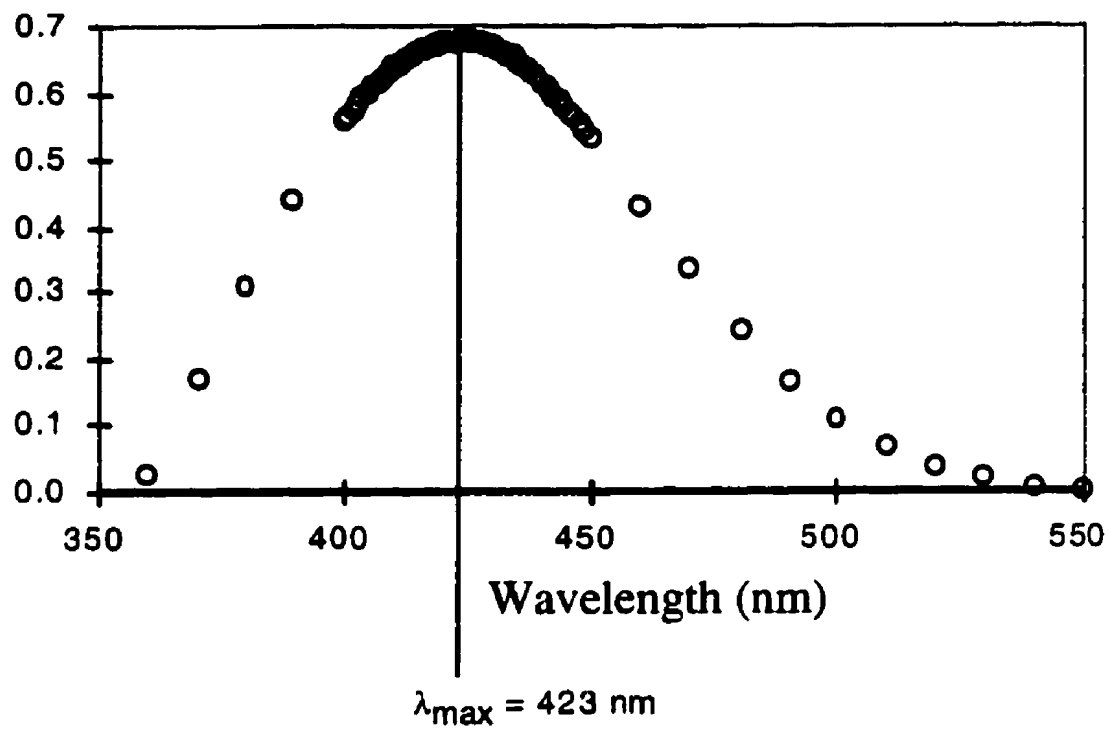

Absorbance

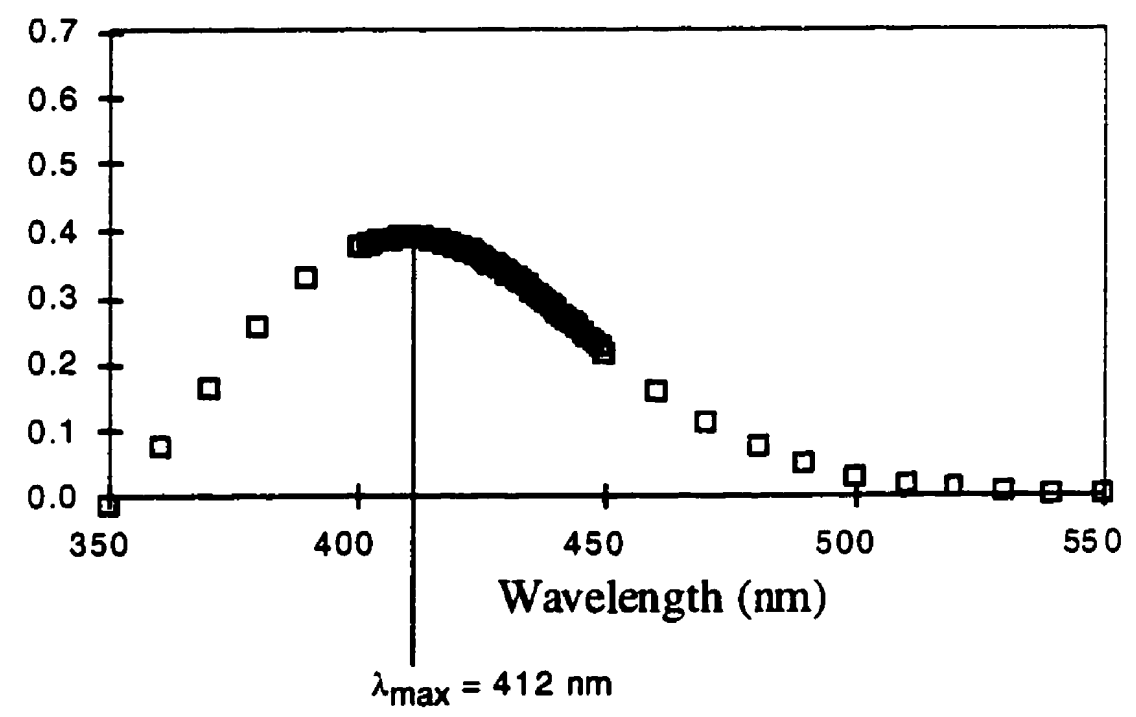

Figure 11: UV/Visible spectroscopic characterization of reduced PEG-a-Cys. (a) PEG-a-Cys $(0.05 \mathrm{mM})$ treated with the disulfide specific reducing agent TCEP-HCl absorbs maximally at $423 \mathrm{~nm}$. (b) Ellman's reagent $(0.05 \mathrm{mM})$ treated with TCEP- $\mathrm{HCl}$ absorbs maximally at $412 \mathrm{~nm}$. 


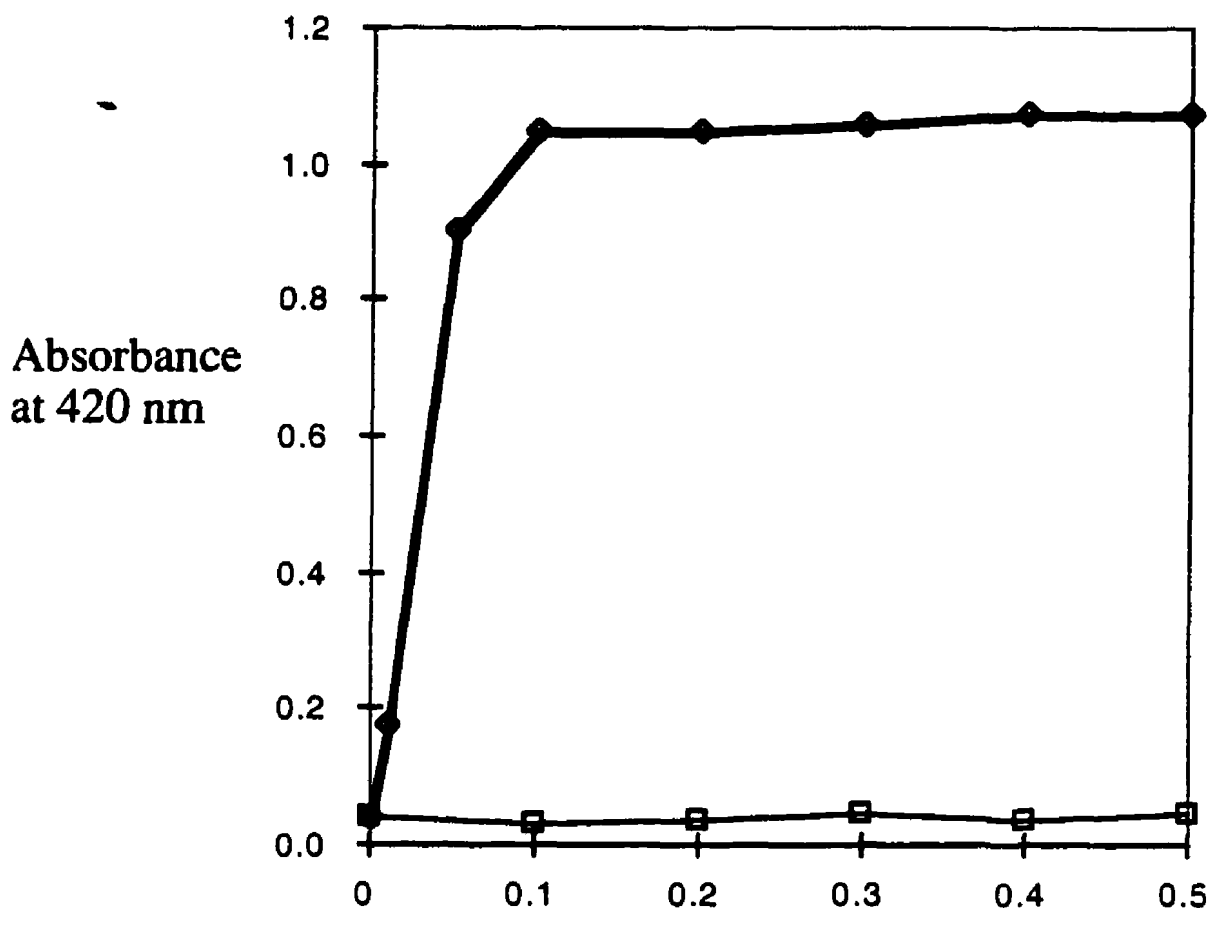

Amino acid concentration (mM)

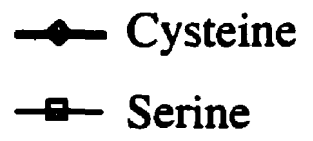

Figure 12: Reactivity of PEG-a-Cys with amino acids. The absorbance increase at $420 \mathrm{~nm}$ of PEG-a-Cys $(0.05 \mathrm{mM})$ upon incubation with cysteine demonstrated that PEG-a-Cys spontaneously reacted with the amino acid at $\mathrm{pH} 7.0$, releasing a chromophore. The absence of such an increase upon incubation with the serine control suggested that PEG-a-Cys reactivity is specific for thiols. 


\subsection{ALC model peptide}

\subsubsection{Purification}

Crude ALC was first eluted on a semi-preparative scale C4 (butyl-silica) column with a linear gradient of aqueous acetonitrile that rose from $10 \%$ to $70 \%$ acetonitrile over the course of one hour. A major peak was noted that eluted at approximately 50\% acetonitrile. Several other peaks were noted that were poorly resolved from the major peak. The gradient was adjusted to increase the resolution near the major peak: it was raised from $10 \%$ to $40 \%$ relatively quickly and then held at $40 \%$ until the major peak eluted at 19 minutes $(58 \mathrm{~mL})$. This gradient resulted in sufficient resolution of the major peak for its collection (Figure 13a). After lyophilization, the collected peptide was injected on the same column and eluted under identical conditions. The single peak suggested that the peptide was pure (Figure 13b).

\subsubsection{Characterization}

Electrospray mass spectrometry established the identity of the peptide (expected m.w. $=2577.4$; measured m.w. $=2578$ ). The amino acid analysis (not shown) revealed that the ratios of amino acids were identical to those in the designed sequence $\mathrm{H}_{2} \mathrm{~N}$-REAAALAAAAALAAWAALCPARRRR- $\mathrm{CO}_{2} \mathrm{H}$. It was concluded that the ALC peptide had been correctly synthesized and purified. 

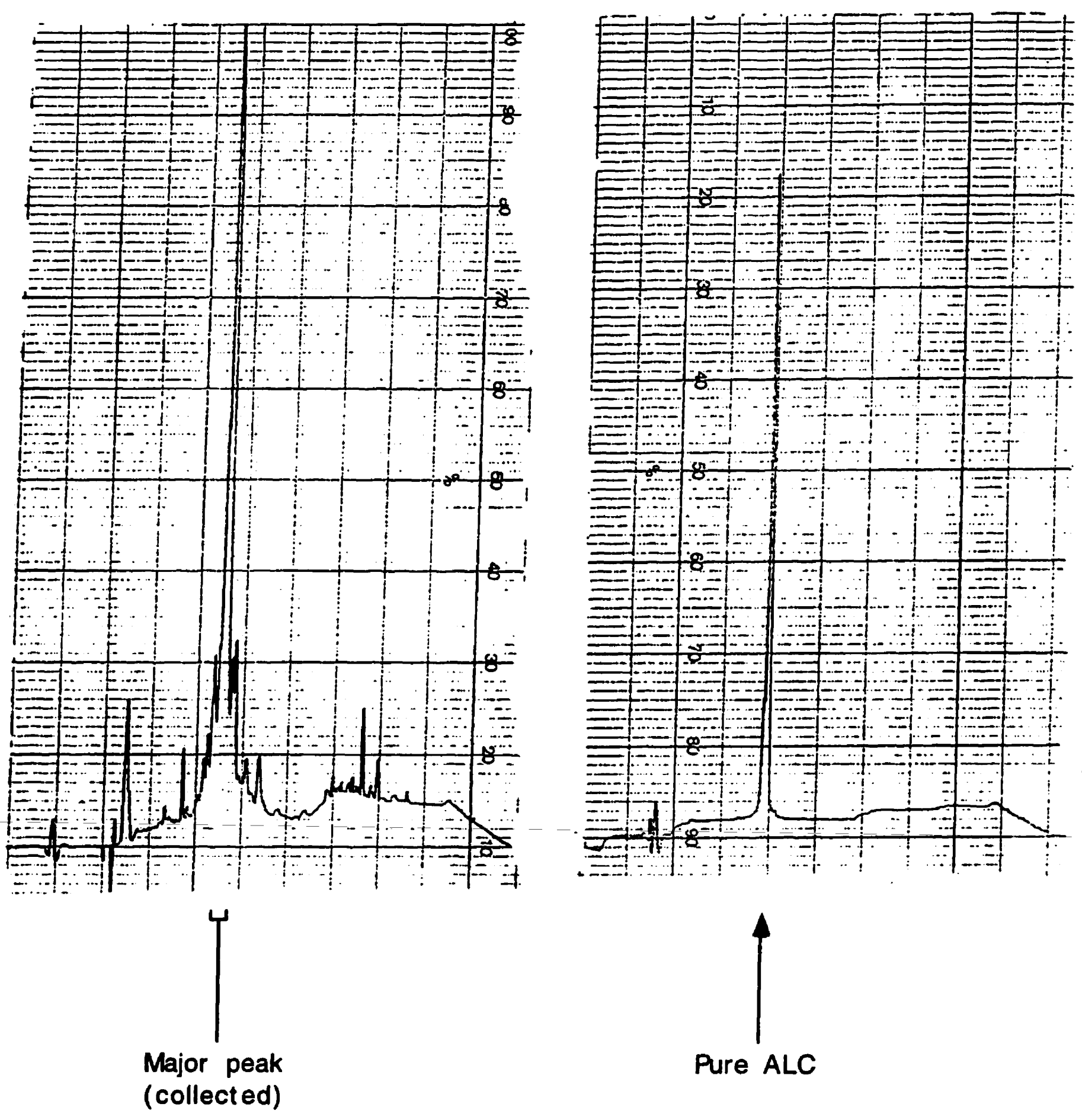

Figure 13: Purification of ALC peptide by RP-HPLC. (a) The major peak eluted at 19 minutes ( $58 \mathrm{~mL}$ ), during an isocratic ( $40 \%$ acetonitrile) step of an otherwise increasing acetonitrile : water gradient. (b) The collected peak was reinjected onto the RP-HPLC column and eluted as a single peak. 


\subsection{PEGylation and enzyme digestion of ALC}

\subsubsection{PEGylation}

The mixing of PEG-a-Cys with ALC peptide at $\mathrm{pH} 7.0$ caused a yellow colour to evolve, indicating the presence of the MPEGyl-TNB anionic chromophore (PEG-aCys reaction product). This colour evolution was not evident when PEG-a-Cys was mixed with a control solution containing buffer at $\mathrm{pH} 7.0$ and no peptide. Optimization of the PEGylation reaction as examined by native basic PAGE led to performing the reaction with FPLC-purified PEG-a-Cys at pH 5 in the absence of buffer. This allowed PEGylation at a 1:1 molar ratio of reagent to peptide but no colour evolution was observed at this $\mathrm{pH}$.

Native basic PAGE analysis of unmodified and PEGylated ALC revealed that PEGylation caused a mobility shift. Unmodified ALC ran as a pair of high mobility bands, appearing near the bottom of the gel (Figure 14, lane 1). The unmodified ALC bands were visualized with Coomassie (Figure 14a) and were not enhanced by the Kurfurst stain for PEG (Figure 14b). The two bands of roughly equal intensity were assigned to monomer and cystine dimer forms of ALC (see section 3.3.1.1). PEGylated ALC ran as a broad low mobility band, appearing near the top of the gel (Figure 14, lanes 2-6). The shifted PEGylated ALC band was stained by Coomassie (Figure 14a) but its visualization was greatly enhanced by a subsequent application of the Kurfurst stain (Figure 14b).

A band appeared in the stacking gel that was visualized only by the Kurfurst stain (Figure 14b) and the intensity of which was proportional to the amount of PEG-aCys in the reaction (Figure 14, lanes 3-6). This band was attributed to the reaction product MPEGyl-TNB and/or excess PEG-a-Cys.

Complete PEGylation as evidenced by the shifting of all of the peptide from the high mobility Coomassie-staining band to the low mobility Kurfurst-enhanced band 


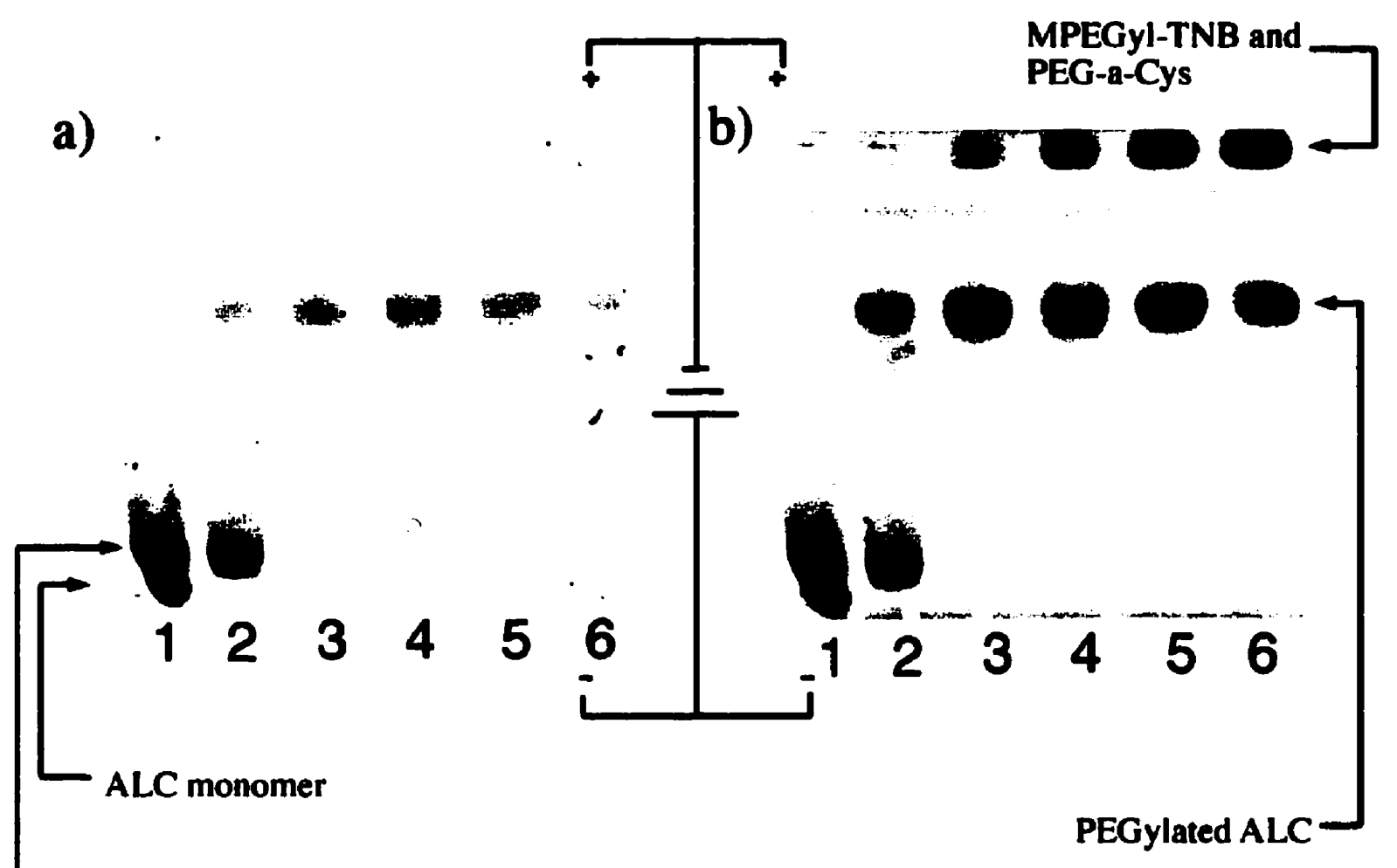

ALC cystine dimer

Figure 14: PEGylation of ALC: NB-PAGE analysis. (a) Coomassie (peptide) stain. (b) Coomassie + subsequent Kurfurst (PEG) stain. The Kurfurst stain enhanced the visibility of PEGylated peptides and allowed visualization of non-proteinaceous PEG species such as MPEGyI-TNB and/or unreacted PEG-a-Cys. Complete PEGylation of ALC peptide was achieved (lane 3).

Lane 1: ALC peptide (1 $\mathrm{mM})$

Lane 2: PEG-a-Cys $(0.5 \mathrm{mM})+$ ALC peptide (1 mM)

Lane 3: PEG-a-Cys (1 mM) + ALC peptide (1 mM)

Lane 4: PEG-a-Cys (2 mM) + ALC peptide ( $1 \mathrm{mM}$ )

Lane 5: PEG-a-Cys (3 mM) + ALC peptide (1 mM)

Lane 6: PEG-a-Cys (5 mM) + ALC peptide (1 mM)

Original gels could not be shown due to the temporary nature of the Kurfurst stain. 
was accomplished at a 1:1 molar ratio of PEG-a-Cys to ALC peptide (Figure 14, lane 3). The intensity of this PEGylated ALC peptide band remained constant as the molar ratio was raised to 2.5:1 (Figure 14, lanes 4-6). A 0.5:1 molar ratio of PEG-a-Cys to ALC peptide resulted in partial PEGylation, evidenced by two bands (Figure 14, lane 2): a low mobility Kurfurst-enhanced band of relatively low intensity corresponding to PEGylated ALC peptide; and a high mobility Coomassie-staining band of moderate intensity corresponding to ALC dimer.

\subsubsection{Reversibility of PEGylation}

Reduction of the mixed disulfide bond formed between PEG and the ALC peptide was accomplished by incubation with the disulfide-specific reducing agent TCEP-HCl. The unmodified ALC (Figure 15, lane 1) and PEGylated ALC controls

(Figure 15, lane 2) ran as discussed in the previous section. Unmodified ALC reduced with TCEP ran as a single high mobility band and was identified as monomer (Figure 15, lane 3). PEGylated ALC reduced with TCEP ran as a single high mobility band (Figure 15, lane 4) indistinguishable from reduced unmodified ALC. It was concluded that TCEP reduction cleaved the disulfide bond between the peptide and PEG, effectively reversing the PEGylation reaction. The identification of the single band of the TCEP-reduced ALC sample as monomer (Figure 15, lanes 3 and 4) indicated that the second band displayed by the ALC samples (lane 1 of both Figure 14 and Figure 15) corresponded to a cystine dimer of the peptide.

\subsubsection{Enzyme digestion}

The enzyme carboxypeptidase B was employed to remove the 4 C-terminal Arg residues from unmodified and PEGylated ALC, in order to mimic protease cleavage of a hydrophobic TM segment from a fusion protein. The enzyme-digested peptides were examined by native basic PAGE, on which digested peptides were expected to display decreasing mobility as Arg residues were removed. 


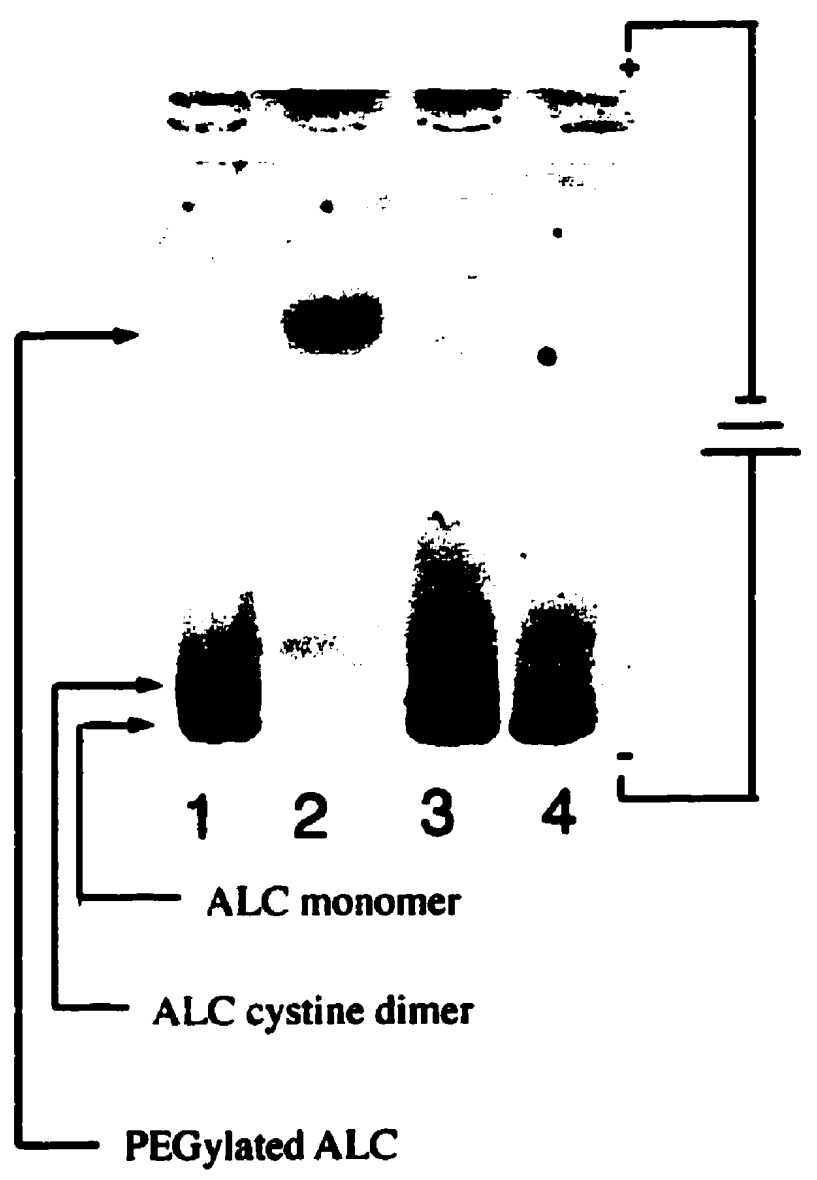

Figure 15: Reversibility of ALC PEGylation: NB-PAGE analysis.

The gel was stained with Coomassie only. Reduction of either ALC peptide or PEGylated peptide with TCEP-HCl resulted in a single high mobility band.

Lane 1: ALC peptide

Lane 2: PEGylated ALC peptide

Lane 3: ALC peptide + TCEP-HCl (30 mM)

Lane 4: PEGylated ALC + TCEP-HCl (30 mM) 
It was discovered that carboxypeptidase $B$ at a concentration of $10 \mu \mathrm{g} / \mathrm{mL}$ was sufficient for complete digestion of both unmodified and PEGylated ALC at peptide concentrations of $1 \mathrm{mM}$ by the end of a 2 hour incubation at $20^{\circ} \mathrm{C}$. Unmodified ALC samples (Figure 16, lanes 1-3) gave rise to bands that were well visualized by Coomassie (Figure 16a) and were not enhanced by the Kurfurst stain (Figure 16b). The PEGylated ALC samples (Figure 16, lanes 4-6) gave rise to bands whose intensity was enhanced by the Kurfurst stain (Figure 16b).

Intact (no enzyme) unmodified ALC (Figure 16, lane 1) and intact PEGylated ALC (Figure 16, lane 4) ran as previously described. Low $(4 \mu \mathrm{g} / \mathrm{mL})$ concentrations of enzyme resulted in the loss of the high mobility intact unmodified ALC band and the appearance of several bands of intermediate mobility (Figure 16, lane 2). The most intense band was of the lowest mobility, migrating only as far as the boundary of the stacking and running gels. Low $(4 \mu \mathrm{g} / \mathrm{mL})$ concentrations of enzyme resulted in the disappearance of the intact PEGylated ALC band and the appearance of several bands of lower mobility (Figure 16b, lane 5). Again, the most intense band migrated only as far as the stacking/running gel boundary. A high $(10 \mu \mathrm{g} / \mathrm{mL})$ concentration of enzyme resulted in each of unmodified and PEGylated ALC appearing as a single band at the boundary of the running and stacking gels (Figure 16, lanes 3 and 6).

As their intensity increased with increasing enzyme concentration, and no bands of lower mobility were observed at any enzyme concentration, it was postulated that the bands appearing at the stacking/running gel boundary represented completely digested peptide. The bands of intermediate mobility were assumed to represent partially digested peptide from which 1, 2 or 3 of the 4 C-terminal Arg residues had been removed. 


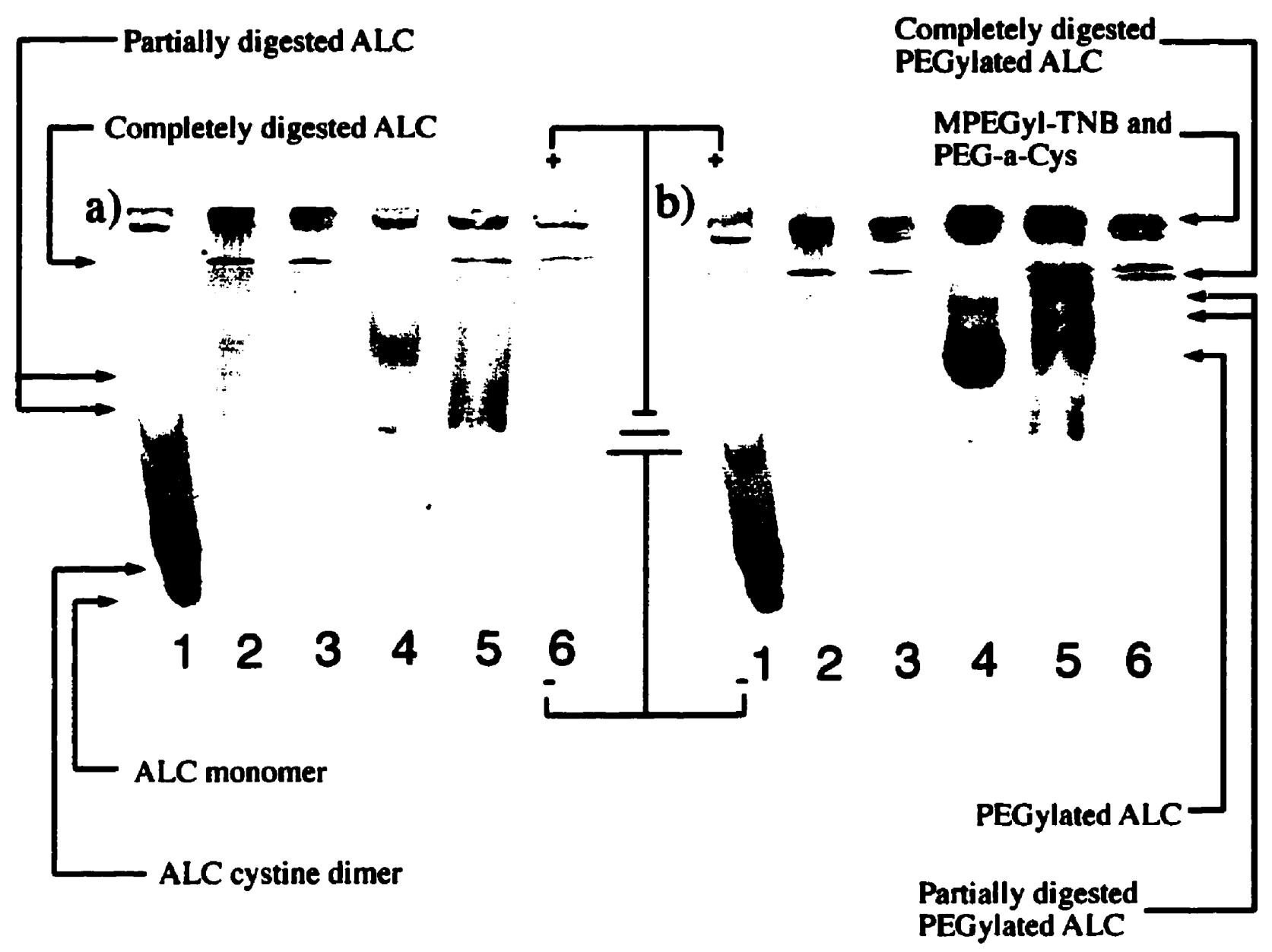

Figure 16: Carboxypeptidase B digestion of ALC: NB-PAGE analysis.

(a) Coomassie (peptide) stain. (b) Coomassie + subsequent Kurfurst (PEG) stain. Carboxypeptidase B at $10 \mathrm{mg} / \mathrm{mL}$ was sufficient to completely digest both ALC (lane 3) and PEGylated ALC (lane 6). Each appeared as a sharp band at the stacking / running gel interface but the PEGylated peptide was distinguishable by its enhancement upon application of the Kurfurst stain.

Lane 1: ALC peptide

Lane 2: ALC peptide + carboxypeptidase B (4 mg/mL)

Lane 3: ALC peptide + carboxypeptidase B $(10 \mathrm{mg} / \mathrm{mL})$

Lane 4: PEGylated ALC peptide

Lane 5: PEGylated ALC peptide + carboxypeptidase B (4 mg/ $\mathrm{mL})$

Lane 6: PEGylated ALC peptide + carboxypeptidase B $(10 \mathrm{mg} / \mathrm{mL})$ 


\subsubsection{Solubility effects of PEGylation and digestion}

\subsubsection{Ultracentrifugation}

To determine the amounts of peptide in solution, aliquots of intact and digested samples of both unmodified and PEGylated ALC were removed at several time points during a seven day incubation. Each aliquot was ultracentrifuged at $100000 \mathrm{xg}$ for 1 hour. The supernatants were analyzed for amino acid content to determine the concentrations of ALC in each (Figure 17).

Peptide concentrations in the intact unmodified ALC control as well as both intact and digested PEGylated ALC supernatants remained largely constant over the seven day incubation. A slight drop in the intact unmodified ALC concentration was noticeable by the 5 day time point. In contrast, the digested ALC sample experienced a significant drop in supernatant peptide concentration even at the first time point at 0.1 days. By the second time point at 1.0 days, it had dropped to less than $5 \%$ of its original value, where it remained throughout the course of the experiment. It was concluded that enzymatic removal of the C-terminal Arg residues resulted in precipitation of unmodified ALC, but not of PEGylated ALC. 
a)

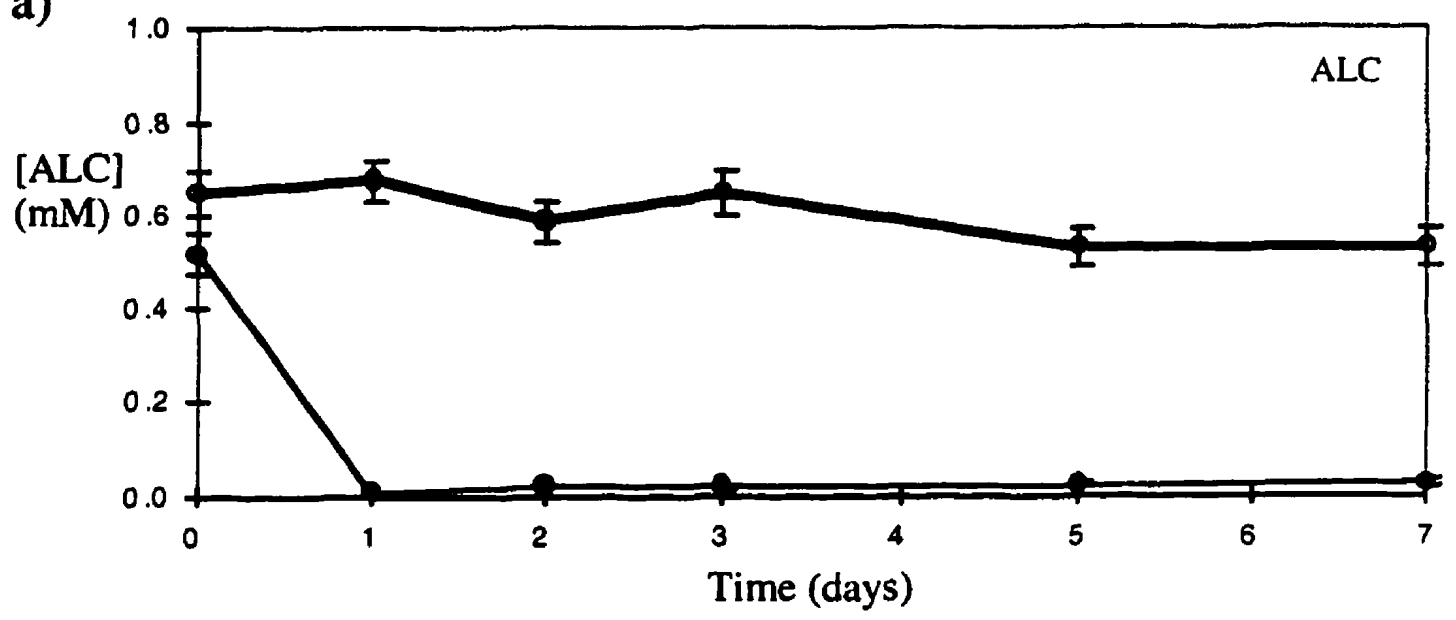

b)

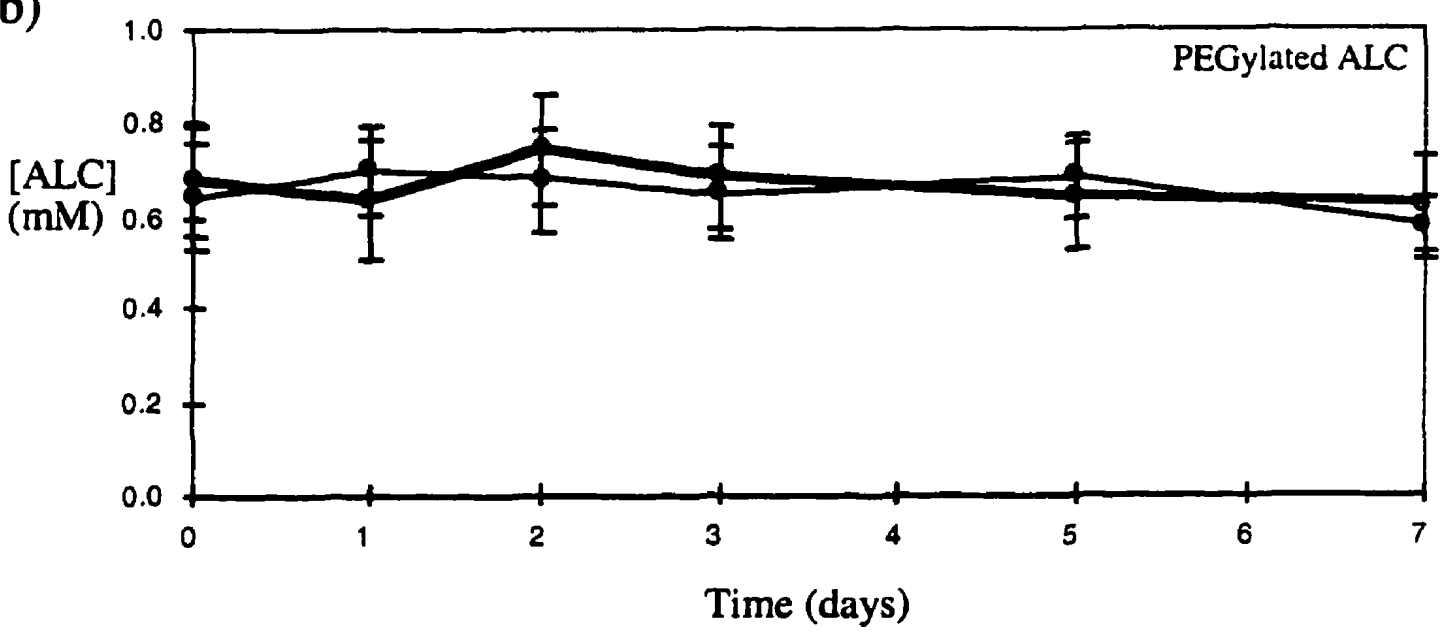

- Intact peptide

$\rightarrow$ Digested peptide

(C-terminal Arg residues removed)

\section{Figure 17: ALC concentrations of ultracentrifugation} supernatants: amino acid analysis. (a) Unmodified ALC: the concentration of the intact peptide remained constant for the first 5 days of incubation, dropping slightly at 7 days; digested ALC concentration fell to less than $5 \%$ of the original value within 1 day. (b) PEGylated ALC: both intact and digested PEGylated ALC concentrations remained constant over the course of the experiment. 


\subsubsection{NB-PAGE analysis of supematants}

Analysis of the supernatants from the ultracentrifugation was performed as a qualitative assessment of the samples. The gels of the first ( 0.1 days: Figure 18) and last (7 days: Figure 19) time points are shown. Unmodified ALC peptide was visualized by Coomassie (a) and was not enhanced by the Kurfurst stain, whereas the visualization of the PEGylated ALC peptide was enhanced by the Kurfurst stain (b).

Analysis of the supernatants from the 0.1 day ultracentrifugation suggested near-complete digestion of both enzyme-treated samples. The intact unmodified ALC peptide appeared as a pair of high mobility bands (Figure 18, lane 1) corresponding to monomer and cystine dimer. Digested unmodified ALC appeared as a sharp band at the interface of the stacking and running gels corresponding to completely digested ALC; however, an additional band appeared above that, at the point where the sample was applied to the gel (Figure 18, lane 2). This additional band may represent an aggregate of the digested ALC peptide. PEGylated ALC appeared as a low mobility band (Figure 18, lane 3). While most of the digested PEGylated ALC ran as a sharp band at the stacking/running gel interface corresponding to completely digested PEGylated ALC, several bands of intermediate mobility corresponding to partially digested PEGylated ALC were observed (Figure 18, lane 4). These intermediate bands were of such low intensity that they were only visible after Kurfurst staining of the gel (Figure 18b), and they were not visible on the gels of the 1 day samples or any of the later samples.

Analysis of supernatants from the 7 day ultracentrifugation suggested that no digested unmodified ALC remained in solution. Intact unmodified ALC ran as a pair of high mobility bands as usual (Figure 19, lane 1). No bands were visible for the digested unmodified ALC sample (Figure 19, lane 2), suggesting that there was no peptide present in the supernatant at this point in time. PEGylated ALC appeared at its characteristic low mobility position (Figure 19, lane 3). Digested PEGylated ALC appeared as a sharp band at the interface of the stacking and running gels (Figure 19, lane 4). 


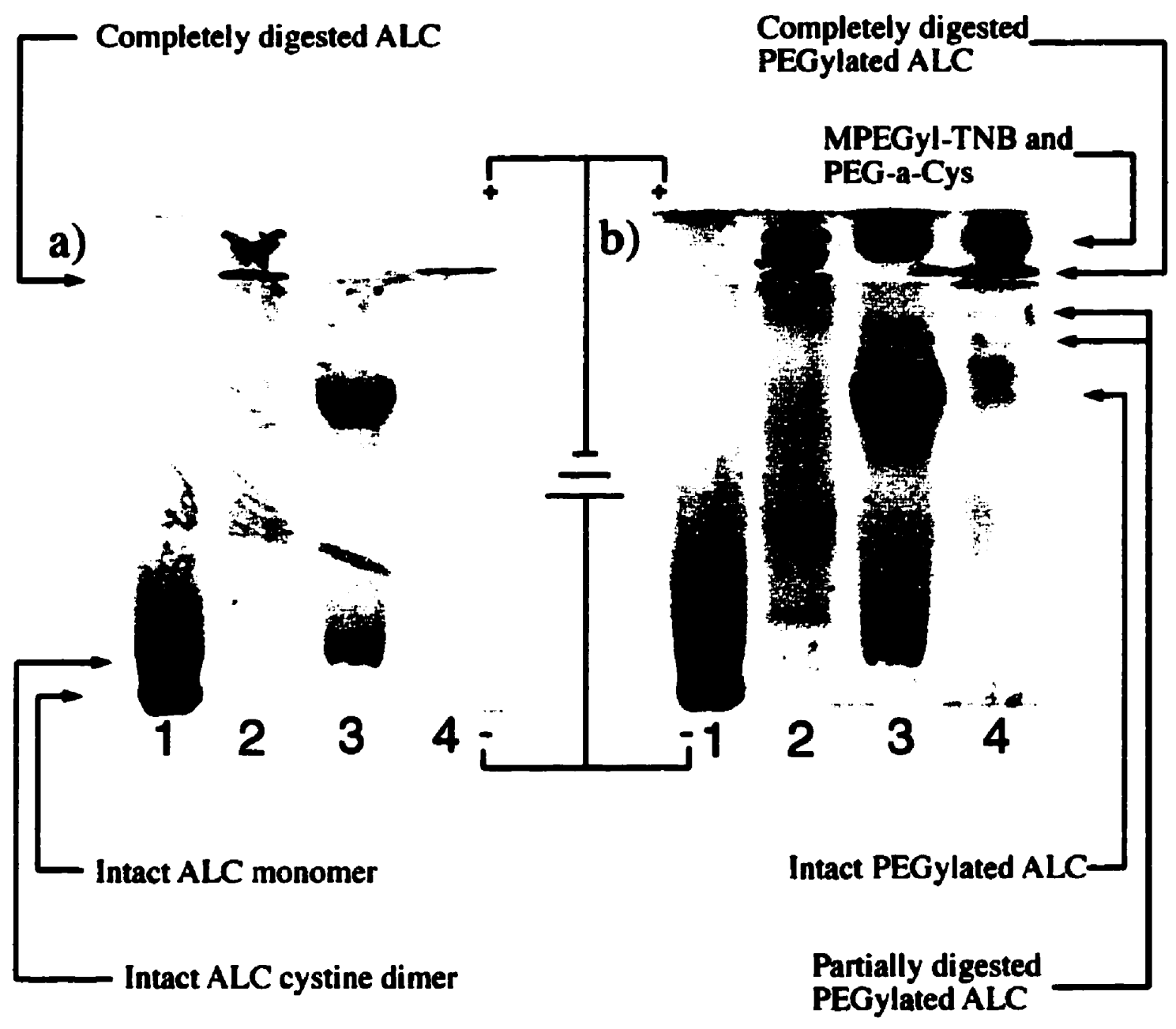

Figure 18: Ultracentrifugation supernatants at 0.1 days: NB-PAGE analysis. (a) Coomassie (peptide) stain. (b) Coomassie + subsequent Kurfurst (PEG) stain. Enzyme digestion of both ALC and PEGylated ALC appeared to have been successful. Although faint bands corresponding to partially digested PEGylated ALC were detected (Lane 4), they were no longer visible by the following day (data not shown).

Lane 1: Intact ALC peptide

Lane 2: Digested ALC peptide

Lane 3: Intact PEGylated ALC peptide

Lane 4: Digested PEGylated ALC peptide 


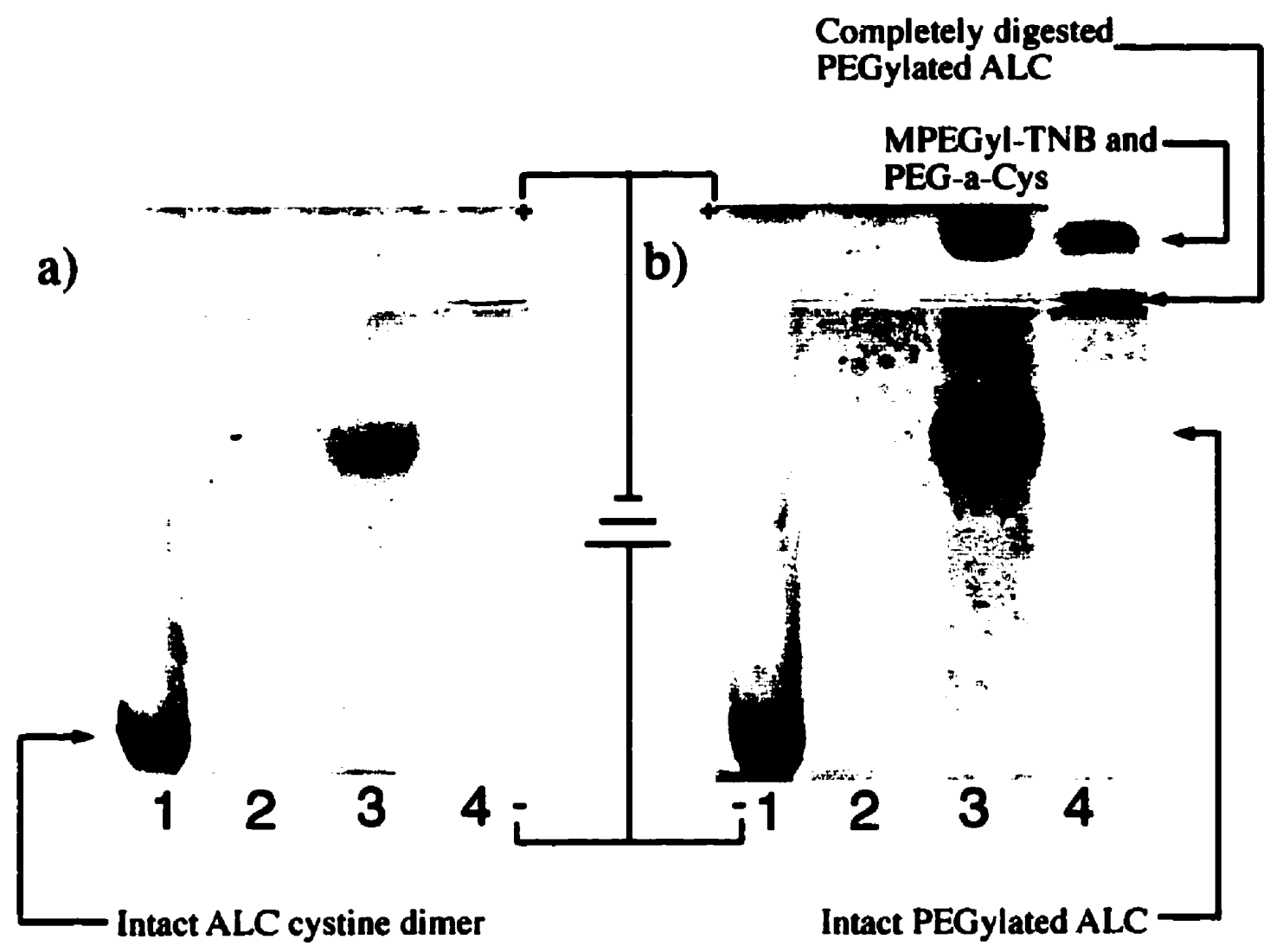

Figure 19: Ultracentrifugation supernatants at 7 days: NB-PAGE analysis.

(a) Coomassie (peptide) stain. (b) Coomassie + subsequent Kurfurst

(PEG) stain. Digested ALC peptide can no longer be visualized on the gel (lane 2).

Digested PEGylated peptide is still visible at the same intensity as it was at the 0.1 day time point (lane 4).

Lane 1: Intact ALC peptide

Lane 2: Digested ALC peptide

Lane 3: Intact PEGylated ALC peptide

Lane 4: Digested PEGylated ALC peptide 


\subsubsection{Free amino acid analysis of digested samples}

The free amino acid analyses of the supernatants of all of the digested unmodified ALC and digested PEGylated ALC samples (Table 2) revealed millimolar concentrations of free Arg. The undigested samples ( 0.1 day supernatants of both unmodified and PEGylated ALC, tested as controls) contained only micromolar concentrations of free Arg. The percent digestion of each sample was calculated by dividing the concentration of free Arg by the product of the number of C-terminal Arg residues in the intact peptide (4) and the nominal initial concentration of ALC (1.0 mM).

Table 2: Free [Arg] and \% digestion of ultracentrifugation supernatants. The results show that the digested ALC and digested PEGylated ALC samples were digested to approximately the same extent $(60-80 \%)$.

\begin{tabular}{|c|c|c|c|}
\hline Sample & Time (days) & {$[\mathrm{Arg}](\mathrm{mM})$} & \% Digestion \\
\hline Unmodified ALC (control) & 0.1 & 0.002 & 0 \\
\hline Digested unmodified ALC & $\begin{array}{l}0.1 \\
1 \\
2 \\
3 \\
5 \\
7\end{array}$ & $\begin{array}{l}2.93 \\
2.71 \\
2.53 \\
2.51 \\
2.35 \\
1.65\end{array}$ & $\begin{array}{l}73 \\
68 \\
63 \\
63 \\
59 \\
41\end{array}$ \\
\hline PEGylated ALC (control) & 0.1 & 0.003 & 0 \\
\hline Digested PEGylated ALC & $\begin{array}{l}0.1 \\
1 \\
2 \\
3 \\
5 \\
7\end{array}$ & $\begin{array}{l}3.46 \\
3.09 \\
2.95 \\
3.00 \\
3.12 \\
3.00\end{array}$ & $\begin{array}{l}87 \\
77 \\
74 \\
75 \\
78 \\
75\end{array}$ \\
\hline
\end{tabular}

Both unmodified and PEGylated ALC were digested to a high degree by the carboxypeptidase enzyme. Unmodified ALC was $73 \%$ digested at 0.1 days; PEGylated ALC was $87 \%$ digested at this time. The free Arg concentrations appeared to drop 
slowly over the course of the experiment, more significantly in the digested unmodified ALC than in the digested PEGylated ALC.

\subsubsection{Structural effects of PEGylation and digestion}

\subsubsection{Structural stability at 1 day}

Circular dichroism spectroscopy was used to probe the structural effects of PEGylation and carboxypeptidase B digestion of ALC after a 1 day $\mathrm{pH} 7.0$ incubation at $20^{\circ} \mathrm{C}$. The spectra of all samples (Figure 20) were similar in shape, with minima at 208 and $222 \mathrm{~nm}$ suggesting partial $\alpha$-helical structure. However, the mean residue ellipticities $(\theta)$ of the samples were of significantly different magnitudes. PEGylated ALC (Figure 20b) showed no alteration from its initial value (not shown). The $\theta_{222}$ magnitude of the digested PEGylated ALC dropped by 25\% (Figure 20b). The $\theta_{222}$ of the unmodified ALC dropped by $50 \%$, while the digested unmodified ALC $\theta_{222}$ decreased by $90 \%$ (Figure 20a). Mean residue ellipticities were calculated based on initial peptide concentrations.

\subsubsection{Structural stability over eight day incubation}

The effects of incubation at $20^{\circ} \mathrm{C}$ on intact unmodified and PEGylated ALC were investigated by circular dichroism spectroscopy. CD spectra were recorded at specific time points during the 8 day incubation. The spectra were superimposed without attempting to correct for the concentrations of peptide. It was observed that by the end of the 8 day incubation, the amplitude of the CD spectrum of intact unmodified ALC was reduced to baseline values (Figure 21a). The amplitude of the intact PEGylated ALC ellipticity at $222 \mathrm{~nm}$ had only dropped by approximately $50 \%$ by this point (Figure 21b). The shapes of the curves altered over the course of the experiment for both samples: the amplitude at $208 \mathrm{~nm}$ dropped more quickly than that at $222 \mathrm{~nm}$. However, evidence of $\alpha$-helix was still observable in the PEGylated ALC spectrum at the 8th day of incubation. 

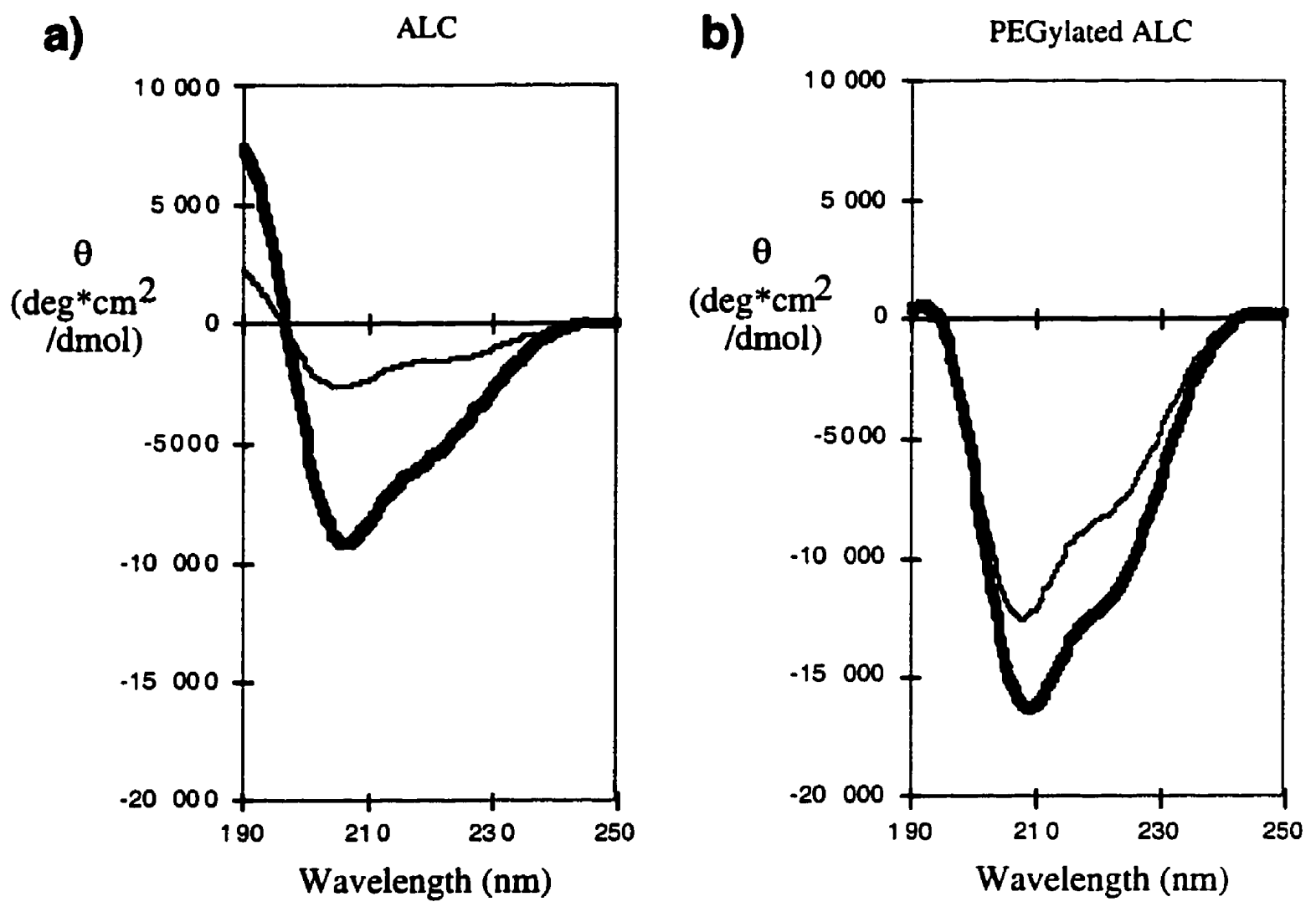

Intact ALC

Digested ALC

Figure 20: Structural effects of PEGylation and digestion of ALC peptide over 1 day: CD spectroscopy. The shapes of all of the spectra were similar, with minima at $208 \mathrm{~nm}$ and $222 \mathrm{~nm}$, suggesting largely $\alpha$-helical structures. However, the amplitudes of the ellipticities varied. (a) ALC peptide. Intact ALC $\theta_{22}$ was $50 \%$ that of its value at 0 days (not shown), while digested ALC $\theta_{222}$ dropped by 90\%. (b) PEGylated ALC. The CD spectrum of intact PEGylated peptide at 1 day was unchanged from its spectrum at 0 days (not shown). The $\theta_{222}$ of digested PEGylated ALC dropped by $25 \%$. All mean residue ellipticity values were calculated based on initial peptide concentrations $(150 \mu \mathrm{M})$. Adapted from (Pomroy \& Deber, 1998). 


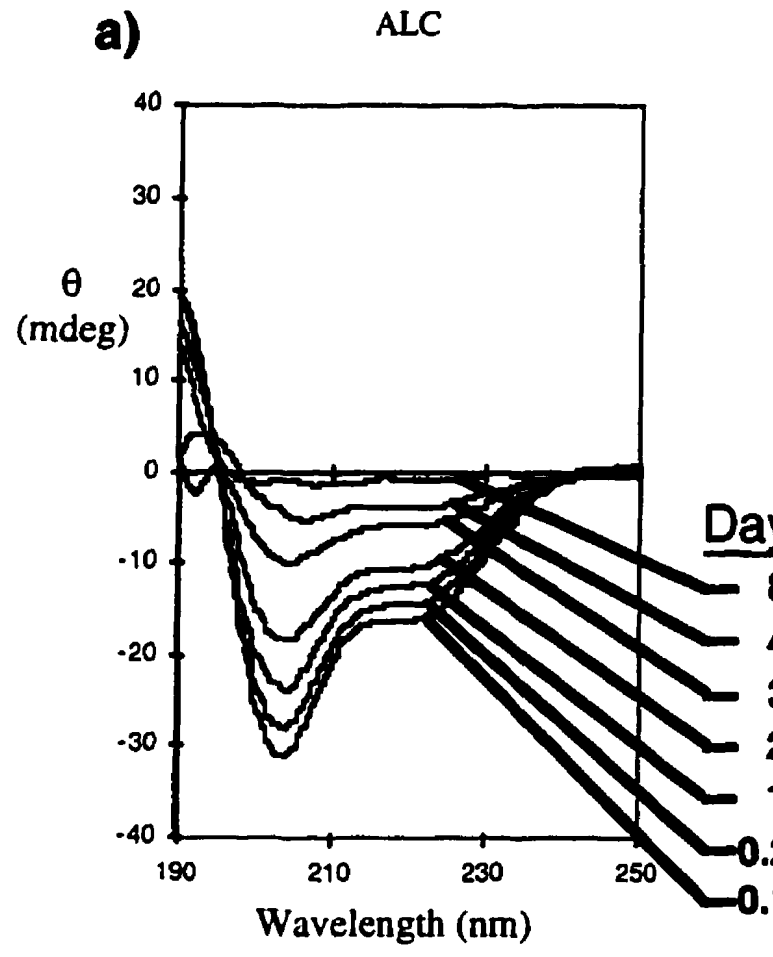

b)

PEGylated ALC

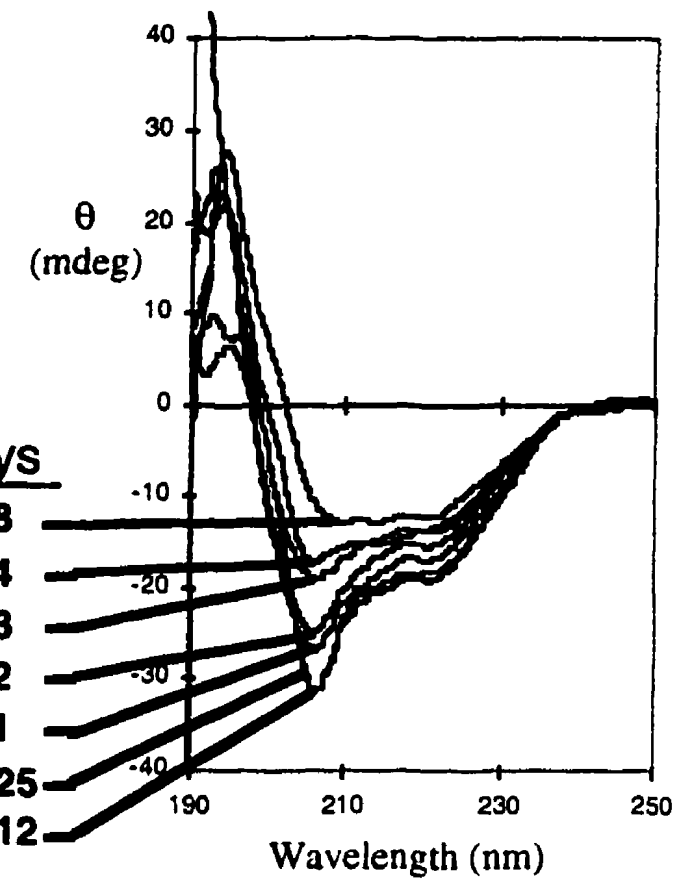

Figure 21: Structural effects of PEGylation of ALC peptide over 8 days: CD spectroscopy. The ordinate axes are listed in absolute ellipticity rather than mean residue ellipticity as the intent was to compare the absolute magnitude of $\theta$ over time. (a) Intact ALC showed a steady decline in $\theta$ over the incubation, reaching a very low signal (<5\% initial value) by the 8th day. (b) Intact PEGylated ALC also showed a decline in $\theta$ though at a much lower rate. By the 8th day, the PEGylated ALC retained $50 \%$ of its $\theta_{22}$. Both spectra changed shape over the incubation, but still showed evidence of $\alpha$-helix (minima at $208 \mathrm{~nm}$ and $222 \mathrm{~nm}$ ) by the 8th day. 


\section{Chapter 4}

\section{Discussion}


PEG-a-Cys reagent was created in order to allow for the reversible attachment of the water-soluble polymer PEG to hydrophobic peptides such as membrane protein TM segments, in order to maintain their aqueous solubility so as to allow their structural characterization (section 1.3.1). The ALC peptide was conceived of as a system for modeling of a fusion protein of a TM segment with a soluble carrier protein (section 1.3.2), as a target with which to test the solubilizing power of PEG-a-Cys.

The PEG-a-Cys reagent was designed for ease of synthesis and of purification (sections 4.1.1 and 4.1.2). The polymeric nature of the reagent required methods of analysis unusual for organic molecules, including gel filtration chromatography (section 4.1.3) and multidimensional NMR as well as UV/Visible spectroscopies (section 4.1.4).

Modifications of the ALC peptide were optimized using a special form of native polyacrylamide gel electrophoresis (section 4.2.1) as an analytical tool. PEGylation of the ALC peptide and reversibility of the disulfide bond formed by PEGylation (section 4.2.2), as well as enzyme digestion of the peptide to a hydrophobic form in order to model the cleavage of a TM segment from a fusion protein (section 4.2.3) were tested in this manner.

The effects of PEGylation and enzyme digestion on the solubility (section 4.2.4) and the secondary structure (section 4.2.5) of the model peptide were investigated to establish the utility of PEG-a-Cys as an aid for the structural characterization of TM segments. 


\subsection{PEG-a-Cys reagent}

\subsubsection{Design considerations: Bis- vs. mono-esterification of PEG to Ellman's reagent}

Each molecule of Ellman's reagent contains two carboxylic acid groups. It was deemed advantageous to esterify with MPEG at both carboxylic acid groups to produce the bisester PEG-a-Cys [bis-monomethoxypoly(ethylene glycol)yl 5,5'-dithiobis(2nitrobenzoate) or 'bis-MPEGyl-DTNB'], rather than attempting to activate only one carboxylic acid group per Ellman's reagent molecule to produce the asymmetric monoesterified product, [monomethoxypoly(ethylene glycol)yl 5,5'-dithiobis(2nitrobenzoate)] or 'MPEGyl-DTNB'. To achieve bis-esterification, two molar equivalents of each of MPEG and the DCC activator were used in relation to Ellman's reagent (see Figure 6, section 2.1.1).

The advantages of bis-esterification are several. The symmetry of the thiolreactive disulfide bond in Ellman's reagent was predicted to result in mixed disulfide formation between target thiols and equal proportions of either half of the reagent. In the bis-esterified product PEG-a-Cys (Figure 22a), both halves of the molecule are attached to a PEG chain and therefore the reaction of target Cys residues with either half would result in PEGylation. In contrast, the monoesterified product MPEGyI-DTNB (Figure 22b) might form mixed disulfides between target Cys residues and the nonesterified TNB half of the reagent. Such mixed disulfide formation between TNB and Cys side chains has been demonstrated to promote cystine formation by disulfide exchange (Holtzer, 1986). The formation of cystine would further reduce the number of free Cys residues available for PEGylation. Bis-esterification of Ellman's reagent was thus necessary in order to produce a reagent that would maximize the PEGylation of target Cys residues and prevent the competitive reaction of TNB-Cys disulfide bond formation.

Bis-esterification to create PEG-a-Cys also simplified gel filtration purification of the product from any unreacted starting materials and/or byproducts (Figure 22). 
PEG-a-Cys (a) is more than twice the molecular weight of the largest starting material, MPEG (c). In contrast, the mono-ester MPEGyl-DTNB (b) is only slightly larger than MPEG. It was much easier to separate PEG-a-Cys from MPEG than it would have been to separate MPEGyl-DTNB from MPEG, due to the molecular weight difference.

The molecular weight range of PEG would complicate the purification of PEG compounds of similar molecular weights. MPEG $^{5000}$ was calculated to be $97 \%$ within the range of $4.0-6.0 \mathrm{kDa}$ by both mole fraction and weight fraction, based on the degree and nature of polymerization of PEG (Flory, 1940). This was extrapolated to conclude that the molecular weight of MPEGyl-DTNB would be $97 \%$ within the range of $4.4-6.4 \mathrm{kDa}$. This distribution overlaps that of $\mathrm{MPEG}^{5000}$. The distribution of PEG-a-Cys molecular weights would range from $8.4-12.4 \mathrm{kDa}$; this range overlaps neither MPEGyl-DTNB nor MPEG ${ }^{5000}$ and reinforces the purification advantage of the bis-esterified reagent. Other reactants and byproducts included Ellman's reagent (Figure 22d), dicyclohexylcarbodiimide (DCC, Figure 22e), dicyclohexylurea (DCU, Figure 22f) and dimethylaminopyradine (DMAP, Figure 22g). These compounds were considered trivial to separate from either PEG-a-Cys or MPEGyl-DTNB by methods based on molecular size as none were in excess of $0.5 \mathrm{kDa}$. 


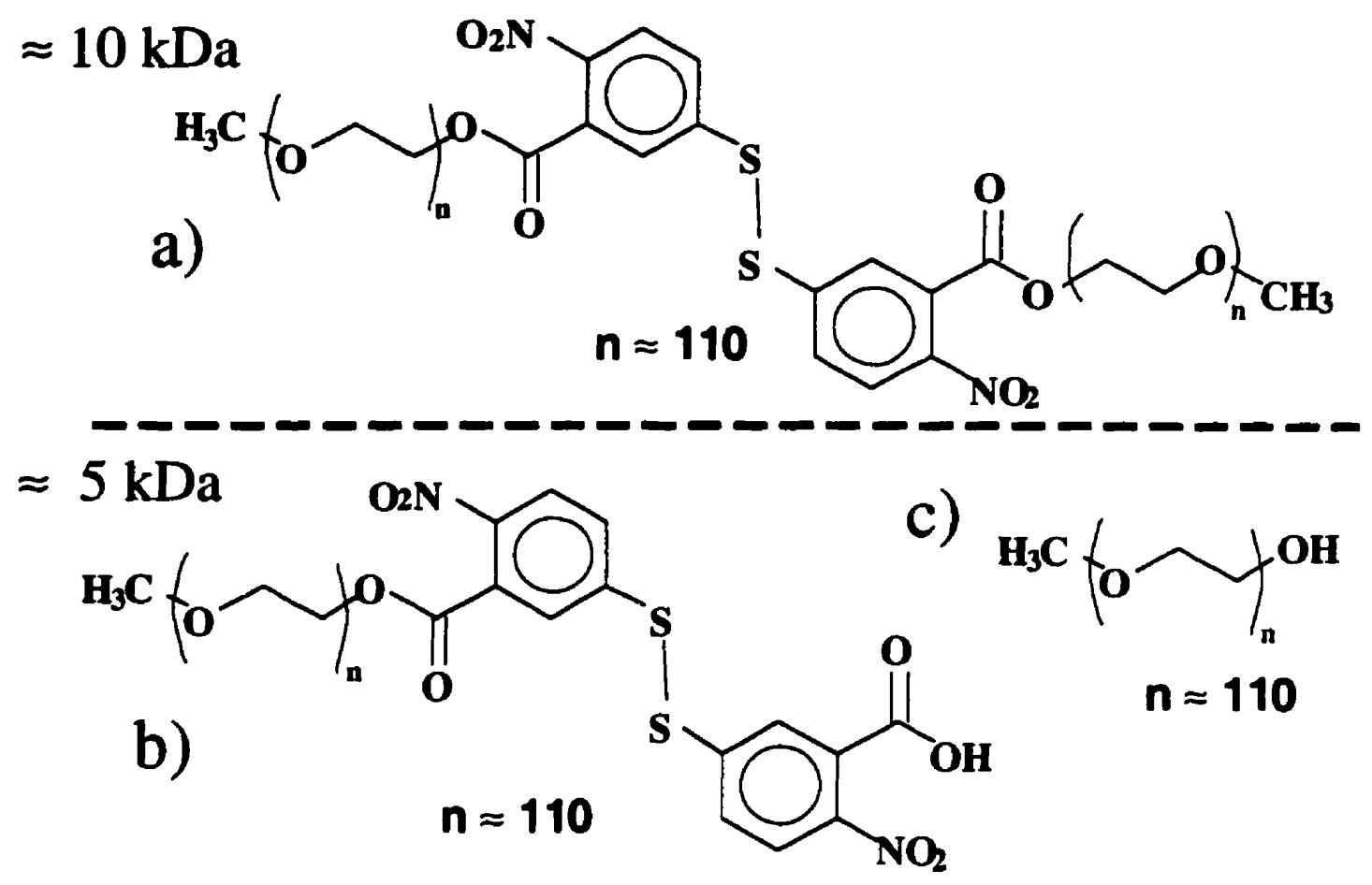<smiles>CN(C)c1ccncc1</smiles>

Figure 22: Molecular weights of the reactants, products and byproducts of PEG-a-Cys synthesis. PEG-a-Cys (a) was designed for facile separation from any unreacted starting materials and synthesis byproducts based on its molecular weight. The average molecular weight of PEG-a-Cys (10.4 kDa) is double that of both putative side product MPEGyl-DTNB (b, $5.4 \mathrm{kDa}$ ) and starting material MPEG $^{5000}(\mathrm{c}, 5.0 \mathrm{kDa})$; it is over $25 \mathrm{x}$ that of any of the small molecules [Ellman's Reagent (d, $0.4 \mathrm{kDa}), \operatorname{DCC}(\mathrm{e}, 0.2 \mathrm{kDa}), \mathrm{DCU}(f, 0.2 \mathrm{kDa})$ or DMAP $(\mathrm{g}, 0.1 \mathrm{kDa})]$. 


\subsubsection{Synthesis}

PEG-a-Cys is based on a polymer, and therefore recrystallizations and certain other methods of small molecule chemistry are not necessarily appropriate nor effective for the post-synthetic processing of the reagent. Unreacted MPEG was expected to coprecipitate from ethanol along with PEG-a-Cys, and it was not surprising that the values calculated for the synthesis yield were quite high.

It was intriguing that the final PEG-a-Cys yield was significantly $(0.46 \mathrm{~g}$, or 5\%) greater than that of the crude product (Table 1). As a well known property of PEG is its ability to bind water molecules (see section 1.2.1), it was surmised that the increase in mass between crude product and PEG-a-Cys was due to adsorption of moisture during the filtration and washing steps. Vacuum desiccation over calcium sulfate was insufficient to remove this water. PEG-a-Cys was not heated to drive off the water, as there was concern that at elevated temperatures the presence of water and possibly trace amounts of DMAP from the synthesis might result in base-catalyzed hydrolysis of the ester or decomposition of the Ellman's reagent portion of the molecule (Riddles et al., 1983). As it was intended that PEG-a-Cys would be dissolved in aqueous solution before reaction with its target peptide, the presence of a small amount of bound water was not deemed to be of great concern.

A major advantage of PEG-a-Cys synthesis was the simplicity of the one step reaction. Multiple reaction steps decrease overall yields and increase the likelihood of side reactions unless care is taken to isolate the desired product at each step. While such separations are simple when working with small molecules, polymeric species with molecular weight distributions such as PEG are not trivial to purify (Powell, 1980). The internal disulfide of Ellman's reagent allowed for esterification to the carboxylic acid groups in a single step, as the disulfide was quite unreactive to the carbodiimide chemistry used and therefore did not require the extra reactions of protection and deprotection (see section 1.2.3.2). The synthesis of PEG-a-Cys is a reaction that can be carried out quickly using inexpensive reagents of low toxicity and with a minimum 
of equipment. The synthesis of PEG-a-Cys is therefore not limited to organic chemistry specialists and should be simple to carry out in laboratories where the focus is protein and peptide research.

\subsubsection{Purification}

Unreacted MPEG was predicted to coprecipitate with PEG-a-Cys from ethanol. Any MPEGyl-DTNB formed was also predicted to coprecipitate. It was therefore necessary to purify PEG-a-Cys from putative coprecipitated PEG species as well as from any trace amounts of small molecule contaminants. The technique of gel filtration chromatography was ideal for the separation of PEG-a-Cys from possible contaminants as the molecular weight of PEG-a-Cys is far greater than any of the other species that might be thought to be present (see section 4.1.1).

Several resins of exclusion limits ranging from 10 to $200 \mathrm{kDa}$ were tested for their ability to purify PEG-a-Cys. The use of the column-relative measure of bed volumes eluted simplified comparisons of the data between runs and between columns of different resins. It had the advantage of eliminating between-run fluctuations in assay incubation time, sample volume and concentration, as well as between-column differences in resin bed volume and flow rate. Normalization of the two assays used with respect to one another permitted superposition of the results of both assays for a single column run, allowing for easy comparison of different resins and column runs and simplifying interpretation.

The exclusion limits of gel filtration resins are represented in terms of molecular weight $(\mathrm{kDa})$ and are based on the behaviour of globular proteins. The solution properties of a linear, highly hydrated and highly mobile polymer such as PEG were predicted to be quite different from those of a globular protein of similar molecular weight. The inability of $\mathrm{G} 10$ sepharose resin (exclusion limit $=10 \mathrm{kDa}$ ) to separate PEG-a-Cys from other PEG species was therefore not surprising even though PEG-aCys at $10.4 \mathrm{kDa}$ average m.w. is above the nominal exclusion limit while PEG at $5 \mathrm{kDa}$ 
is well below it. The best resolution was in fact achieved with $\mathrm{G} 100$ sepharose resin (exclusion limit $=100 \mathrm{kDa})$.

PEG-a-Cys was distinguished from other PEG species by its response to both the TNB and Skoog assays and its elution behaviour. The TNB assay detects any compound containing Ellman's reagent, including PEG-a-Cys and MPEGyl-DTNB. The Skoog assay detects all PEG species, including PEG-a-Cys, MPEGyl-DTNB and MPEG. The gel filtration was predicted to separate PEG-a-Cys (10.4 kDa) from both MPEG (5 kDa) and any MPEGyl-DTNB (5.4 kDa). The elution profile obtained was that of a first peak that responded equivalently to both assays which eluted ahead of a second peak that responded to only the Skoog assay. The second peak was identified as MPEG based on its assay response. The first peak, while it could have been identified as either PEG-a-Cys or MPEGyl-DTNB based on assay response alone, was identified as PEG-a-Cys since it eluted ahead of MPEG and was therefore clearly of a significantly higher molecular weight.

The resolution of the purification was improved by the use of a pressurized FPLC system with a column of sephadex $75 \mathrm{HR}$ resin (exclusion limit $=75 \mathrm{kDa}$ ). This resulted in the near baseline resolution of the two peaks. PEG-a-Cys was collected in the narrow range between 0.42 and 0.44 bed volumes in order to ensure the purity of the collected fraction, at the cost of a low (43\%) recovery.

The absence of a second peak that was detectable by the TNB assay was evidence that no significant amount of MPEGyl-DTNB had formed, and that the synthesis had proceeded as intended to the bis-ester PEG-a-Cys. The only contaminant detected was the inert species MPEG.

The development of the purification strategy was ongoing during the course of the research. Due to this, the inert nature of the only detectable contaminant and the observation that unpurified reagent was effective both in reacting with cysteine (section 3.1.3.3) and reproducibly altering the mobility of the ALC model peptide in a gel shift 
assay (data not shown), unpurified PEG-a-Cys was used for the characterization (section 3.1.3) and circular dichroism experiments (section 3.3.4).

\subsubsection{Characterization}

\subsubsection{NMR spectroscopy}

The detection of a peak in the carbonyl region of the $1 \mathrm{D}-{ }^{13} \mathrm{C}-\mathrm{NMR}$ spectrum of PEG-a-Cys was not sufficient to establish that an ester bond had been formed between MPEG and Ellman's reagent, as the resonance at $164 \mathrm{ppm}$ might have been attributable to an acidic carbonyl as well as an ester carbonyl. Therefore, a $2 \mathrm{D}{ }^{1} \mathrm{H}-{ }^{13} \mathrm{C}$ heteronuclear multiple bond correlation (HMBC) experiment was carried out on PEG-a-Cys. In this experiment, a peak at the intersection of a proton and carbon resonance signifies the covalent attachment of the hydrogen and carbon atoms, either directly through a single bond or indirectly over multiple covalent bonds (Bax \& Summers, 1986).

The relative strength of the $\mathrm{C}_{c}-\mathrm{H} 2$ peak was stronger than the $\mathrm{C}_{c}-\mathrm{H} 5$ or $\mathrm{C}_{c}-\mathrm{H} 6$ peaks due to the more direct connection between the carbonyl carbon and the $\mathrm{H} 2$ hydrogen, which were separated by only 3 covalent bonds. The $\mathrm{H} 5$ and $\mathrm{H} 6$ hydrogens were separated from the carbonyl carbon by 4 and 5 covalent bonds respectively. The intensity of the $\mathrm{C}_{\mathrm{c}}-\mathrm{H}_{\mathrm{p}}$ peak was similar to that of the $\mathrm{C}_{\mathrm{c}}-\mathrm{H} 2$ peak, which suggested an identical distance of three bonds between the Ellman's reagent carbonyl carbon and the carbonyl-proximal $\mathrm{CH}_{2}$ hydrogens of MPEG. The $\mathrm{C}_{\mathrm{c}}$ and $\mathrm{H}_{\mathrm{p}}$ atoms were predicted to be separated in the putative structure of the PEG-a-Cys molecule by the same number (3) of covalent bonds.

The appearance and intensity of the $\mathrm{C}_{c}-\mathrm{H}_{\mathrm{p}}$ peak in the HMBC NMR spectrum indicated that the Ellman's reagent and the MPEG were covalently linked via the carbonyl carbon, confirming that the esterification reaction had been successful. 


\subsubsection{UV/Vis spectroscopy}

In order to characterize the putative PEG-a-Cys, its colourimetric properties upon disulfide reduction were compared with those of the starting materials Ellman's reagent and MPEG ${ }^{5000}$. Reduction of Ellman's reagent and PEG-a-Cys was expected to produce the thiol compounds TNB and MPEGyl-TNB respectively. At a pH of 7 or higher TNB is an anionic chromophore (Ellman, 1959), and MPEGyl-TNB was expected to behave similarly.

Solutions of both PEG-a-Cys and Ellman's reagent, when reduced, became yellow. Each displayed a broad absorbance ranging from approximately $350 \mathrm{~nm}$ in the ultraviolet to $500 \mathrm{~nm}$ in the visible. The absorbance maximum was different for the two compounds, however: Ellman's reagent absorbed maximally at $412 \mathrm{~nm}$, consistent with the literature value (Ellman, 1959), and PEG-a-Cys absorbed maximally at 423 nm.

The difference in absorbance maximum from the starting material was considered evidence that the final product was indeed a new compound with its own unique character. The distinction was attributed to a difference in the electronic contributions from the ester in PEG-a-Cys and the carboxylic acid of Ellman's reagent, both of which are conjugated to the aromatic ring of the anionic chromophore.

It was noted that the amplitude of the maximum absorbance of Ellman's reagent was lower than that of PEG-a-Cys, even though solutions of equal molarity were prepared. This was due to the limited solubility of Ellman's reagent at $\mathrm{pH}$ 7.0. The absorbance of Ellman's reagent is traditionally measured in aqueous solution at $\mathrm{pH} 8.0$ due to the increase in solubility of the compound at higher $\mathrm{pH}$ values (Ellman, 1959). However, the disulfide in Ellman's reagent is susceptible to alkaline hydrolysis with a rate proportional to the concentration of hydroxide ion, which increases at $\mathrm{pH}$ values larger than 7.0 (Riddles et al., 1979). As absorbances were recorded over a large section of the spectrum which took some time for the instrument to scan, use of a pH higher than 7.0 would have risked significant alkaline hydrolysis of the reference 
unreduced reagents. Each spectrum was constructed from the difference between the absorbance of the reduced compound and that of the reference compound. Alkaline hydrolysis of the reference compounds during the course of the wavelength scans would have thus led to incorrect spectra. Therefore, solutions of $\mathrm{pH} 7.0$ were used in spite of the limited solubility of Ellman's reagent.

\subsubsection{Reactivity with cysteine}

Disulfide exchange to form a mixed disulfide between PEG-a-Cys and Cys was predicted to occur spontaneously at $\mathrm{pH} 7$ and result in the release of the MPEGyl-TNB anionic chromophore. PEG-a-Cys solutions did evolve a yellow colour comparable to that of the reduced compound when mixed with $\mathrm{Cys}$ at $\mathrm{pH}$ 7.0. The absorbance of the solutions increased proportionally to the concentration of Cys, saturating at a Cys concentration twice that of PEG-a-Cys. The use of Ser as a control demonstrated that PEG-a-Cys was unreactive to amino, carboxyl and hydroxyl functionalities. Thus, the reactivity of the PEG-a-Cys with thiol groups and its specificity for them was established. 


\subsection{PEGylation and enzyme digestion of ALC}

\subsubsection{Native basic PAGE analysis of proteins}

Native PAGE of basic proteins, referred to as native basic PAGE or NB-PAGE (section 2.3.1.1), was used to analyze the states of PEGylation and digestion of various ALC peptide samples. In NB-PAGE, a buffer of $\mathrm{pH} 4.2$ is used in order to enhance the native net positive charge of basic polypeptides, and no detergents are added. Positively charged basic proteins move towards the cathode rather than the anode as in SDS-PAGE, which necessitates reversing the direction of the electric field in most setups that are intended for SDS-PAGE (Oolson \& Tooke, 1995). While the detergent in SDS-PAGE both denatures the proteins and imparts a uniform ratio of charge to molecular weight, in NB-PAGE proteins migrate a distance proportional to the ratio of their native net (positive) charge to their native hydrodynamic size (Reisfield et al., 1962). This prevents the use of size standards in NB-PAGE, as proteins of similar molecular weight but with different net charges and/or different hydrodynamic shapes can have different mobilities. However, it allows for the separation of peptides that vary in charge but not size, which SDS-PAGE cannot resolve.

NB-PAGE was used instead of SDS-PAGE for the analysis of PEGylated derivatives of ALC peptide for two reasons. First, it was determined that PEGylated ALC bands stained on NB-PAGE with Coomassie brilliant blue were much more easily visualized than on SDS-PAGE. The strong association between PEG and SDS (Moroi, 1992) may have interfered with binding of dye in the SDS-PAGE gels. Second, mobility shifts caused by PEGylation on SDS-PAGE were predicted to be slight, and that mobility shifts caused by removal of 1 to 4 residues by the carboxypeptidase $B$ enzyme would be undetectable by SDS-PAGE. In contrast, NB-PAGE was particularly well-suited to analyze PEGylation and digestion states of ALC. ALC itself is a small highly charged species that displayed high mobility on NB-PAGE. PEGylation increased the size of the peptide without altering its charge, and digestion of the 
carboxyl terminal Arg residues decreased its net positive charge by $25 \%$ per residue while decreasing the mass (and presumably size) of the peptide by only $6 \%$ per residue. Both of these effects lowered the charge to size ratio of the peptide, which resulted in bands of low mobility on NB-PAGE.

The use of the Kurfurst stain (see section 2.3.1.2) subsequent to staining with Coomassie blue allowed the visualization of unreacted PEG-a-Cys as well as allowing differentiation of PEGylated peptide from unmodified peptide. Unreacted PEG-a-Cys was not visualized by Coomassie but was by the Kurfurst stain. The visualization of PEGylated peptide bands was enhanced by the Kurfurst stain in comparison to the Coomassie stain alone. Unmodified peptide was well visualized with Coomassie alone, and showed no enhancement after the Kurfurst stain.

\subsubsection{PEGylation}

PEG-a-Cys was designed to react spontaneously with cysteine residues, releasing the yellow chromophore MPEGyl-TNB (section 1.3.1). The observation of a yellow colour upon mixing of PEG-a-Cys with ALC peptide at $\mathrm{pH} 7.0$ suggested that the reagent had reacted successfully with the target peptide. It was intended that visible spectroscopy could be used to follow the reaction; however, optimization of the reaction conditions necessitated using a buffer free solution at $\mathrm{pH} 5.0$ to prevent the formation of interpeptide disulfide bonds by ALC. At pH 5.0 the reaction product did not exhibit chromophoric behaviour; it was assumed that $\mathrm{pH} 5.0$ was below the $\mathrm{pKa}$ of the MPEGyl-TNB thiol group. Although the option of colourimetric monitoring of the reaction was no longer available, the use of native basic PAGE enabled qualitative assessment of the PEGylation state of the peptide.

Analysis revealed that complete PEGylation of ALC occurred at an equimolar ratio of PEG-a-Cys to peptide (Figure 14, lane 3). The visualization of the low mobility band was adequate with Coomassie stain and was enhanced by the Kurfurst stain, identifying it as PEGylated peptide. The large shift in mobility of PEGylated peptide as 
compared to unmodified ALC was due to the significant increase in hydrodynamic size caused by the conjugation of a 4 - $6 \mathrm{kDa}$ flexible hygroscopic PEG molecule to the 2.6 $\mathrm{kDa}$ peptide. The broadness of the band was considered to be due to the molecular weight distribution (see section 4.1.1) of the PEG in the reagent.

Unmodified ALC (Figure 14, lane 1) ran as two bands that were identified as monomer and cystine dimer based on subsequent experiments with a disulfide-specific reducing agent. However, it was possible to PEGylate all detectable peptide. PEG-aCys was known to react only with thiols, not disulfides (data not shown). It was therefore assumed that the disulfide formed in the unmodified ALC sample was an artifact of the NB-PAGE analysis, in that it formed at some point after the addition of sample buffer, perhaps during the electrophoresis.

The band appearing in the stacking gel (at the top) at the point of sample loading was visualized only with Kurfurst stain and not with Coomassie. It therefore represented an uncharged species of PEG that was not attached to peptide. The band was identified as a mixture of two species: unreacted PEG-a-Cys, since the band became more intense as the concentration of PEG-a-Cys used in the reaction was raised; and the reaction byproduct MPEGyl-TNB, as the band was visible in the lane of equimolar PEG-a-Cys and ALC, where all of the reagent was used for PEGylation of ALC. PEG-a-Cys is an uncharged molecule and MPEGyl-TNB would be predicted to be uncharged at the $\mathrm{pH}$ of the gel (4.2). The staining behaviour and position of the band is therefore consistent with its identification.

\subsubsection{Reversibility of PEGylation}

Unmodified ALC peptide reduced with TCEP-HCl displayed a single high mobility band on NB-PAGE (Figure 15). PEGylated ALC, reduced with TCEP-HCl, ran on NB-PAGE as a single high mobility band indistinguishable from reduced unmodified ALC. It was concluded that the PEGylation of ALC by PEG-a-Cys was reversible by the simple use of a disulfide-specific reducing agent, which released the peptide in monomeric form. 


\subsubsection{Enzyme digestion of C-terminal Arg residues}

The enzyme carboxypeptidase B sequentially removes basic amino acid residues (e.g. Lys, Arg) from the carboxyl termini of peptides and proteins by hydrolysis (Folk et al., 1960). Digestion of ALC with this enzyme was intended to remove the four Cterminal Arg residues, leaving only the hydrophobic core of the peptide and thereby mimicking the enzymatic cleavage of a TM segment from a soluble carrier protein. Complete digestion of all four C-terminal Arg residues would increase the average residue hydrophobicity of the peptide from 0.35 to 1.28 , based on the Kyte-Doolittle hydrophobicity scale (Kyte \& Doolittle, 1982). Even partial digestion of two of the four C-terminal Arg residues would more than double the average residue hydrophobicity of the peptide (Table 3). Increased hydrophobicity was expected to have a profound effect on the aqueous solubilities of the digested forms of ALC.

Table 3: Hydrophobicity of digested states of ALC peptide as determined by the method of Kyte and Doolittle. Complete digestion of all 4 C-terminal Arg residues of ALC increases the average residue hydrophobicity of the peptide by a factor of 3.7 .

\begin{tabular}{|cc|}
\hline \# Arg Residues Digested & Average Residue Hydrophobicity \\
\hline $\begin{array}{c}0 \\
\text { (intact) }\end{array}$ & 0.35 \\
\hline 1 & 0.55 \\
\hline 2 & 0.77 \\
\hline 3 & 1.01 \\
\hline $\begin{array}{c}4 \\
\text { (complete digestion) }\end{array}$ \\
\hline
\end{tabular}

Digestion was performed at $\mathrm{pH} 7.0$ in phosphate buffer to promote enzyme activity. 'Complete' digestion of all four C-terminal Arg residues was expected to result 
in a hydrophobic peptide of very low charge. Since mobility on NB-PAGE is proportional to net positive charge, completely digested ALC peptides were expected to have very low mobility on NB-PAGE gels. A band appearing at the interface of stacking and running gels was postulated to represent completely digested ALC, as the intensity of this band increased proportional to the concentration of enzyme and no bands of lesser mobility were noted at any enzyme concentration (Figure 16). At the extremely low charge of the digested peptide, the difference in size between unmodified and PEGylated peptides had no observable effect on mobility, and both appeared at identical positions (Figure 16, lanes 3 and 6). The digested PEGylated ALC band was distinguishable only by the enhancement of its visibility upon Kurfurst staining (Figure 16, lane 6).

Partial digestion, the removal of between 1 and 3 of the 4 C-terminal Arg residues, was expected to result in peptides of charge states and hence mobilities intermediate between those of intact (undigested) and completely digested peptide. Peptide samples with lower than optimal concentrations of carboxypeptidase B produced such bands of intermediate mobility on NB-PAGE (Figure 16, lanes 2 and 4), providing further evidence that the band appearing at the interface of stacking and running gel represented completely digested peptide with all 4 C-terminal Arg residues removed.

Carboxypeptidase B digestion was concluded to be optimal at an enzyme concentration of $10 \mu \mathrm{g} / \mathrm{mL}$ for a 2 hour digest at the previously optimized conditions of $20^{\circ} \mathrm{C}, \mathrm{pH} 7.0$ (Folk et al., 1960) for both unmodified or PEGylated ALC at peptide concentrations of $1 \mathrm{mM}$.

\subsubsection{Solubility effects of PEGylation}

In order to determine the effectiveness of PEGylation in maintaining the solubility of the hydrophobic peptide released by complete digestion of ALC, samples were incubated for 7 days at $20^{\circ} \mathrm{C}$. Amino acid analysis of the samples to establish 
soluble peptide concentration was preceded by high speed ultracentrifugation (100 000 $\mathrm{X} \mathrm{g}$ ) in an attempt to remove any insoluble species (Mel \& Ross, 1975).

Previous amino acid analyses of samples centrifuged at $14000 \times \mathrm{g}$ suggested that the low speed was not sufficient to remove all insoluble peptide (data not shown). It was therefore considered necessary to resort to high speed ultracentrifugation to ensure the removal of insoluble peptides.

The results of the amino acid analyses clearly demonstrate the solubilizing power of PEG-a-Cys. While the digested unmodified ALC concentration dropped to virtually nil within one day of incubation, the digested PEGylated peptide remained soluble at levels indistinguishable from controls for the entire 7 day experiment. It remained only to establish unequivocally that the digested PEGylated was completely digested by the carboxypeptidase B enzyme.

NB-PAGE analyses of the ultracentrifugation supernatants suggested that complete digestion of both ALC and PEGylated ALC was successful, and also supported the conclusion that digested ALC had precipitated over the course of the experiment while digested PEGylated ALC had not. The analysis of the 0.1 day samples (Figure 18) revealed that all of the detectable unmodified ALC had been completely digested (Figure 18, lane 2). Faint bands corresponding to partially digested PEGylated ALC were visible (Figure 18, lane 4), but most of the peptide appeared to be in the completely digested state. By 1 day of incubation, all of the digested PEGylated ALC appeared to be in the completely digested state (not shown).

Analysis at day 7 of the experiment (Figure 19) of the digested unmodified ALC supernatant showed no detectable bands at all (Figure 19, lane 2), suggesting that no peptide was present. In contrast, the day 7 sample of digested PEGylated ALC (Figure 19 , lane 4) revealed a strong band at the characteristic position of completely digested ALC, suggesting that all of the digested PEGylated ALC was still present in solution. 
To ensure that the digested PEGylated peptide had been digested, concentrations of free amino acids in the ultracentrifugation supernatants were analyzed. Unmodified ALC had been $73 \%$ digested at 0.1 days; digested PEGylated ALC was $80 \%$ digested at that time. The lesser degree of digestion of the unmodified ALC may have been a result of its insolubility; some may in fact have precipitated upon partial digestion, as the average residue hydrophobicity had been calculated to increase dramatically as each single Arg was removed (see Table 3). Any precipitated peptide would not have been available to the enzyme for further digestion. In contrast, the PEGylated ALC, which remained soluble, also remained available as a substrate for the carboxypeptidase.

It is unknown why the levels of free Arg in the digested ALC sample dropped slowly over the course of the experiment. It is possible that the precipitated peptide served to nucleate the precipitation of the free amino acid. A small drop was noted in the digested PEGylated ALC between the 0.1 and 1 day samples, but free Arg levels remained constant between 1 and 7 days.

The free amino acid analysis results support the hypothesis that carboxypeptidase B digestion was successful on both ALC and PEGylated ALC substrates. The observed solubility of the digested PEGylated ALC cannot be rationalized by the argument that the enzyme was unable to digest the PEGylated peptide. Therefore, PEGylation was directly responsible for the maintenance of solubility of the digested PEGylated ALC. PEG-a-Cys was thus proven to be effective at solubilizing a hydrophobic peptide model of a TM segment.

\subsubsection{Structural effects of PEGylation}

PEGylation of proteins has been demonstrated to be possible without alteration of the structure of the target protein. Tethering of two tumour necrosis factor receptor domains to one another has been accomplished using a PEG linker, without disrupting the structure of either domain (Tuma et al., 1995). Ribonuclease A was found to maintain its native conformation upon extensive PEGylation (Caliceti et al., 1990). 
Subtilisin was found to maintain its native conformation upon PEGylation, both in water and in dioxane, a solvent in which the non-PEGylated enzyme is not even soluble (Pasta et al., 1988).

While the structural stability of PEGylated proteins was encouraging, the extrapolation of such results to short peptides such as ALC was not taken for granted. However, some PEGylated peptides have been structurally characterized. Several 44 residue peptides based on the sequence of human growth hormone-releasing factor showed no change in secondary structure upon PEGylation at their carboxyl termini, as evidenced by circular dichroism 'CD' spectroscopy, in both 75\% methanol (aqueous) and $100 \%$ water (Felix, 1997). Although these peptides were larger in size than ALC, their structural stability upon PEGylation was encouraging.

Ideally, PEGylation of hydrophobic peptides would have no discernible effect on their three-dimensional structures. This would allow for the high resolution structural characterization of the PEGylated peptides. However, the reversibility of the disulfide bond formed by PEG-a-Cys reagent was intended to allow easy removal should it be found to affect the structure of a peptide to which it is attached.

The secondary structures of intact and digested forms of unmodified and PEGylated ALC were assessed by circular dichroism spectroscopy. The shapes of all spectra after a 24 hour incubation were unchanged, but the amplitude of the mean residue ellipticities dropped in all but the intact PEGylated ALC sample. The digestion was carried out over a 24 hour period rather than 2 hours in order to lower the concentration of enzyme required, as the enzyme was not separated from the peptides before spectroscopy and there was a concern that detection of the secondary structure of the enzyme would interfere with the $\mathrm{CD}$ spectra.

Differences in mean residue ellipticity of this degree could be thought to indicate significant secondary structure differences between the species, except that such differences would also be expected to result in visibly differing shapes of the spectra 
(Johnson, 1988). Since the spectra were of identical shapes, an alternate explanation was indicated.

The observed spectra could have been produced by samples of identical structure but of differing concentrations, as $\mathrm{CD}$ amplitude is proportional to the concentration of the absorbing species (Johnson, 1988). Researchers have exploited this to use CD spectroscopy as a method of measuring the concentration of a peptide with a known structure (Vitello et al., 1979). The calculations of mean residue ellipticity in this experiment were based on the initial concentrations of peptide used; varying decreases in ALC concentrations during the 24 hour incubation would explain the variance in the amplitudes of the spectra.

In fact, ALC peptide had been designed such that upon digestion by carboxypeptidase B, its hydrophobicity would increase dramatically, with the anticipated effect of aggregation and precipitation of the peptide in aqueous solution. Precipitation of peptide would cause a drop in the concentration of soluble peptide. As only soluble species are able to contribute to CD spectra (Cantor \& Timasheff, 1982), precipitation of insoluble peptide would explain the drop in $\mathrm{CD}$ amplitude observed.

With this reasoning, the $\mathrm{CD}$ results were interpreted as follows. None or little of the PEGylated ALC precipitated over the 24 hour incubation, while ca. $25 \%$ of the digested PEGylated ALC did. About 50\% of the control ALC precipitated as did ca. $90 \%$ of digested control ALC. The constancy of the shapes of the spectra suggested that the secondary structures of the four different species were similar. The results indicated that the secondary structures of the peptides were unaffected by either PEGylation or digestion, but that precipitation had occurred in all but the intact PEGylated sample. The digested unmodified ALC appeared to be $90 \%$ precipitated, the intact unmodified ALC 50\% and the digested PEGylated ALC 25\%. The difference in the proportions of precipitated peptide suggested that PEGylation was effective in slowing the precipitation of both intact and digested ALC. 
CD spectra of intact unmodified and PEGylated ALC samples were recorded over an 8 day incubation to test the long term stability of the peptides' secondary structures. The shapes of the spectra for both samples changed during the experiment, the amplitude at $208 \mathrm{~nm}$ dropping more quickly than that at $222 \mathrm{~nm}$. The intact unmodified ALC spectrum was indistinguishable from the baseline by the 8th day; its shape was therefore not discernible. The shape of the PEGylated ALC spectrum altered significantly by the 8 th day of incubation (Figure $21 \mathrm{~b}$ ). However, the sample still showed evidence of $\alpha$-helical structure in that minima at 208 and $222 \mathrm{~nm}$ were visible. These results suggested that the concentration of peptide had dropped in both samples over the course of the incubation, but less so in the intact PEGylated ALC than in the intact ALC. This implied that PEGylation was effective in slowing the precipitation of intact ALC peptide. The secondary structures of the PEGylated peptide did undergo some alteration, but remained largely $\alpha$-helical.

It was surprising that the $\mathrm{CD}$ spectra suggested the precipitation of intact unmodified ALC as well as both intact and digested PEGylated ALC, since these peptides were demonstrated by the ultracentrifugation experiment to be soluble for at least 5 and 7 days respectively. A possible explanation is that the sample preparation for the $\mathrm{CD}$ spectroscopy experiments differed from the procedures used for the other experiments detailed in this document: PEG-a-Cys that was not FPLC-purified was used, the concentrations of ALC and enzyme used were altered, and reducing agent was included in the samples to reduce interpeptide disulfide bonds. It is important to note that even under these conditions, PEGylation with PEG-a-Cys appeared to slow the precipitation of both intact and digested peptides and caused no substantial transition of secondary structure. 


\subsection{Conclusion}

PEG-a-Cys, a novel poly(ethylene glycol) derivative, was demonstrated to be capable of spontaneously reacting with a cysteine-containing model peptide, resulting in the attachment of PEG to the peptide via a chemically reversible disulfide bond. PEGylation maintained the solubility of the hydrophobic peptide for 7 days after it was enzymatically cleaved from its charged C-terminal residues in a manner modeling the cleavage of a TM segment from a soluble carrier protein, while the unmodified peptide precipitated within I day of such treatment. Attachment of PEG caused no major structural transitions in aqueous solution.

These results have clear and important implications for the field of membrane protein research. The difficulty in obtaining high resolution three dimensional structures of the hydrophobic TM domains of integral membrane proteins (see section 1.1.3) can be attributed in part to the insolubility of these domains (Garavito et al., 1996; Opella, 1997). The structures of membrane proteins whose TM domains are recalcitrant to characterization can be investigated by chemical or biological synthesis of individual segments of these domains (Deber \& Li, 1995; Peng et al., 1998). However, the extreme hydrophobicity of these segments does create obstacles to their characterization.

The ability, demonstrated by this research, to maintain the solubility of a hydrophobic peptide after its cleavage from solubilizing charged terminal groups (in the case of chemically synthesized peptides), or in an analogous manner from a soluble carrier protein (in the case of biologically synthesized peptides), will aid in the structural characterization of these peptides. The insight gained into the structures and interactions amongst these segments will aid in elucidation of the relationships between integral membrane protein TM domain structure and function. 


\subsection{Future perspectives}

The ability of PEG-a-Cys to PEGylate and thereby prevent the precipitation of the hydrophobic digested ALC peptide has been demonstrated. The effect should be applicable in the general case of hydrophobic peptides; however, the repetition of the solubility tests on PEGylated versions of other hydrophobic peptides would confirm this conjecture. PEGylation of longer or more hydrophobic peptides might establish the limit, if any, of effectiveness.

PEG-a-Cys reagents could be constructed with various sizes of MPEG, from $0.75 \mathrm{kDa}$ to $8 \mathrm{kDa}$ or larger. The smaller PEG-a-Cys reagents would have to be tested on peptides of varying lengths and hydrophobicities to ensure that they were able to prevent precipitation. The use of smaller sizes would minimize complications with techniques such as NMR spectroscopy. Smaller PEG-a-Cys reagents might be easier to separate after reduction-based removal from membrane-inserted peptides, for example by dialysis. Longer or branched PEG-a-Cys reagents might be able to solubilize larger and more hydrophobic peptides. Hydrophobic peptides that are completely insoluble in aqueous solution should be able to be PEGylated by reaction with PEG-a-Cys reagents in an organic solvent such as methylene chloride.

The effects of PEGylation on the secondary structure of short peptides such as ALC should be investigated in a rigorous and complete manner at a variety of peptide concentrations. Purified PEG-a-Cys reagent should be used for these experiments in order to rule out effects of trace contaminants in the unpurified material.

The application of PEG-a-Cys to a genuine fusion protein of a TM segment would confirm and extend its utility. Such a fusion protein could be engineered with a 'Cys-tag' between the enzyme cleavage site and the TM segment to provide a site for PEGylation. The optimum point during the recovery of the expressed protein for reaction with PEG-2-Cys should be determined. Enzyme cleavage of the TMPEGylated fusion protein in the absence of detergent should be compared to the 
cleavage of the unmodified fusion protein in terms of the solubility of the resulting TM peptides over time.

The advantages of keeping hydrophobic peptides such as TM segments soluble over time should be exploited. Purification systems that are interfered with by detergents (e.g., methods of affinity chromatography in which the ligand is sensitive to denaturation by detergents) should be investigated to determine whether PEGylation of the peptides is preferable. This would simplify purification of TM peptides.

A purified PEGylated TM peptide could be reconstituted in a membrane-mimetic system suitable for structural characterization, such as micelles of a specific detergent, vesicles, or liposomes. PEGylation at one end of such a peptide might be exploited to fix the orientation of the peptide with respect to a pre-formed vesicle or liposome, as PEG molecules larger than $1 \mathrm{kDa}$ are known to be unable to cross bilayers. This would allow the construction of a population of peptides inserted with particular orientations within the bilayer. Chemically attached soluble proteins have been used to fix the orientation of hydrophobic peptides with respect to lipid vesicles in this manner (Moll \& Thompson, 1994).

The non-proteinaceous nature of PEG would be unlikely to interfere with many methods of analyzing protein structure, and it is possible that a high resolution NMR structure might be obtained using PEGylated isotopically-labelled TM segments. Should the size of the PEG be too large to allow NMR spectroscopy, the PEG could be removed after membrane insertion of the peptides, by simple chemical reduction. Although a method would have to be developed to separate the cleaved PEG from the peptide/membrane solution, the high resolution structure of the isolated TM segments in a membrane-mimetic environment would ultimately be obtainable. 
Chapter 5

References 
Abuchowski, A., Kazo, G. M., Verhoest, C. R., Jr., Van Es, T., Kafkewitz, D., Nucci, M. L., Viau, A. T., et al. (1984). Cancer therapy with chemically modified enzymes. I. Antitumor properties of polyethylene glycol-asparaginase conjugates. Cancer Biochem Biophys, 7(2), 175-86.

Abuchowski, A., van Es, T., Palczuk, N. C., \& Davis, F. F. (1977). Alteration of immunological properties of bovine serum albumin by covalent attachment of polyethylene glycol. J Biol Chem , 252(11), 3578-81.

Akabas, M. H., Cheung, M., \& Guinamard, R. (1997). Probing the structural and functional domains of the CFTR chloride channel. J Bioenerg Biomembr, 29(5), 453-63.

Antonsen, K. P. \& Hoffman, A. S. (1992). Water Structure of PEG by Differential Scanning Calorimetry Measurements. In J. M. Harris (Ed.), Poly(Ethylene Glycol) Chemistry: Biotechnical and Biomedical Applications, (pp. 15-28). New York: Plenum Press.

Bax, A. \& Summers, M. F. (1986). ${ }^{1} \mathrm{H}$ and ${ }^{13} \mathrm{C}$ assignments from sensitivity-enhanced detection of heteronuclear multiple-bond connectivity by 2D multiple quantum NMR. J. Am. Chem. Soc. , 108, 2093-2094.

Beauchamp, C. O., Gonias, S. L., Menapace, D. P., \& Pizzo, S. V. (1983). A new procedure for the synthesis of polyethylene glycol-protein adducts; effects on function, receptor recognition, and clearance of superoxide dismutase, lactoferrin, and alpha 2-macroglobulin. Anal Biochem, 131(1), 25-33.

Bergstrom, K., Osterberg, E., Holmberg, K., Hoffman, A. S., Schuman, T. P., Kozlowski, A., \& Harris, J. H. (1994). Effects of branching and molecular weight of surface-bound poly(ethylene oxide) on protein rejection. J Biomater Sci Polym Ed, 6(2), 123-32.

Bruin, G. J., Huisden, R., Kraak, J. C., \& Poppe, H. (1989). Performance of carbohydrate-modified fused-silica capillaries for the separation of proteins by zone electrophoresis. J Chromatogr , 480(3), 339-49.

Caliceti, P., Schiavon, O., Veronese, F. M., \& Chaiken, I. M. (1990). Effects of monomethoxypoly(ethylene glycol) modification of ribonuclease on antibody recognition, substrate accessibility and conformational stability. J Mol Recognit , 3(2), 89-93.

Campbell, R. M., Heimer, E. P., Ahmad, H. G., Eisenbeis, T. J., Lambros, Y., Lee, R. W., Miller, P. R., et al. (1997). Pegylated peptides V: Carboxy-terminal PEGylated analogs of growth hormone-releasing factor (GRF) display enhanced duration of biological activity in vivo. Journal of Peptide Research, 49, 527-537.

Cantor, C. \& Timasheff, S. N. (1982). . In H. Neurath (Ed.), The Proteins, (3rd ed., Vol. V, pp. 145). New York: Academic Press.

Chou, P. Y. \& Fasman, G. D. (1978). Empirical predictions of protein conformation. Annu Rev Biochem , 47(3), 251-76.

Chung, L. A. \& Thompson, T. E. (1996). Design of Membrane-Inserting Peptides: Spectroscopic Characterization with and without Lipid Bilayers. Biochemistry, 35(35), 11343-11354. 
Clore, G. M. \& Gronenborn, A. M. (1998). Determining the structures of large proteins and protein complexes by NMR. Trends Biotechnol , 16(1), 22-34.

Cowan, S. W., Schirmer, T., Rummel, G., Steiert, M., Ghosh, R., Pauptit, R. A., Jansonius, J. N., et al. (1992). Crystal structures explain functional properties of two E. coli porins. Nature , 358(6389), 727-33.

Cserhati, T. \& Szogyi, M. (1994). Interaction of Phospholipids with Proteins and Peptides. New Advances IV. Int. J. Biochem. , 26(1), 1-18.

Deber, C. M. \& Goto, N. K. (1997). Conformational Properties of Amino Acids in Transmembrane Helices. In G. von Heijne (Ed.), Membrane Protein Assembly, (pp. 25-38). Georgetown: R.G. Landes Company.

Deber, C. M. \& Li, S. C. (1995). Peptides in membranes: helicity and hydrophobicity. Biopolymers, 37(5), 295-318.

Delgado, C., Francis, G. E., \& Fisher, D. (1992). The Uses and Properties of PEGLinked Proteins. Critical Reviews in Therapeutic Drug Carrier Systems , 9(3,4), 249-304.

Desjarlais, J. R. \& Handel, T. M. (1995). New strategies in protein design. Curr Opin Biotechnol , 6(4), 460-6.

Dill, K. A. (1990). Dominant forces in protein folding. Biochemistry , 29(31), 713355.

Dong, M., Baggetto, L. G., Falson, P., Le Maire, M., \& Penin, F. (1997). Complete removal and exchange of sodium dodecyl sulfate bound to soluble and membrane proteins and restoration of their activities, using ceramic hydroxyapatite chromatography. Anal Biochem, 247(2), 333-41.

Dougherty, D. A. (1996). Cation-pi interactions in chemistry and biology: a new view of benzene, Phe, Tyr, and Trp. Science, 271(5246), 163-8.

Doyle, D. A., Cabral, J. M., Pfuetzner, R. A., Kuo, A., Gulbis, J. M., Cohen, S. L., Chait, B. T., et al. (1998). The structure of the potassium channel: molecular basis of $\mathrm{K}+$ conduction and selectivity [see comments]. Science , 280(5360), 69-77.

Ellman, G. L. (1959). Tissue Sulfhydryl Groups. Archives of Biochemistry and Biophysics , 82, 70.

Felix, A. M. (1997). Site-Specific Poly(ethylene glycol)ylation of Peptides. In J. M. Harris \& S. Zalipsky (Eds.), Poly(ethylene glycol): Chemistry and Biological Applications, (pp. 218-38). Washington, D.C.: American Chemical Society.

Flanagan, S. D. \& Barondes, S. H. (1975). Affinity partitioning. A method for purification of proteins using specific polymer-ligands in aqueous polymer twophase systems. J Biol Chem , 250(4), 1484-9.

Flory, P. J. (1940). Molecular size distribution in ethylene oxide polymers. J. Am. Chem. Soc. , 62, 1561.

Folk, J. E., Piez, K. A., Carroll, W. R., \& Gladner, J. A. (1960). Carboxypeptidase B IV. Purification and Characterization of the Porcine Enzyme. The Journal of Biological Chemistry, 235(8), 2272-2277. 
Fontana, A. (1991). Analysis and modulation of protein stability. Curr Opin Biotechnol , 2(4), 551-60.

Frishman, D. \& Mewes, H. W. (1997). Protein structural classes in five complete genomes [letter]. Nat Struct Biol , 4(8), 626-8.

Gaertner, H. F. \& Puigserver, A. J. (1992). Increased activity and stability of poly(ethylene glycol)-modified trypsin. Enzyme Microb Technol , 14(2), 1505.

Garavito, R. M., Picot, D., \& Loll, P. J. (1996). Strategies for crystallizing membrane proteins. J Bioenerg Biomembr, 28(1), 13-27.

Gish, D. (1970). Peptide synthesis. Mol Biol Biochem Biophys , 8(3-4), 276-335.

Glass, J. D., Silver, L., Sondheimer, J., Pande, C. S., \& Coderre, J. (1979). 4Phenoxy-3,5-dinitrobenzoylpolyethyleneglycol: reversible attachment of cysteine-containing polypeptides to polymers in aqueous solution. Biopolymers , 18, 383-392.

Gombotz, W. R., Wang, G. H., Horbett, T. A., \& Hoffman, A. S. (1991). Protein adsorption to poly(ethylene oxide) surfaces. J Biomed Mater Re: 25(12), 1547-62.

Gouaux, E. (1998). alpha-Hemolysin from Staphylococcus aureus: an archetype of beta- barrel, channel-forming toxins. J Struct Biol , 121(2), 110-22.

Grisshammer, R. \& Tate, C. G. (1995). Overexpression of integral membrane proteins for structural studies. $Q$ Rev Biophys , 28(3), 315-422.

Henry, G. D. \& Sykes, B. D. (1994). Methods to study membrane protein structure in solution. [Review] [59 refs]. Methods Enzymol, 239, 515-35.

Heymann, J. B., Muller, D. J., Mitsuoka, K., \& Engel, A. (1997). Electron and atomic force microscopy of membrane proteins. Curr Opin Struct Biol , 7(4), 543-9.

Holtzer, A. (1986). Phenomenological Analysis of the Kinetics of the Production of Interchain Disulfide Cross-Links in Two-Chain, Coiled-Coil Proteins by Reaction with 5,5'-Dithiobis(2-nitrobenzoate). Biochemistry, 25(10), 30083012.

Jahnig, F. \& Surrey, T. (1997). Folding and Insertion of Proteins into Membranes In Vitro. In G. von Heijne (Ed.), Membrane Protein Assembly, (pp. 83-98). Georgetown: R.G. Landes Company.

Jencks, W. P. (1969). Catalysis in Chemistry and Enzymology. New York: McGrawHill.

Johansson, G. (1992). Affinity Partitioning in PEG-Containing Two-Phase Systems. In J. M. Harris (Ed.), Poly(Ethylene Glycol) Chemistry: Biotechnical and Biomedical Applications, (pp. 73-84). New York: Plenum Press.

Johnson, W. C., Jr. (1988). Secondary structure of proteins through circular dichroism spectroscopy. Annu Rev Biophys Biophys Chem , 17, 145-66. 
Johnson, W. C., Jr. (1990). Protein secondary structure and circular dichroism: a practical guide. Proteins , 7(3), 205-14.

Jones, E. Y. (1996). Three-dimensional structure of cell adhesion molecules. Curr Opin Cell Biol, 8(5), 602-8.

Kelly, P. A., Goujon, L., Sotiropoulos, A., Dinerstein, H., Esposito, N., Edery, M., Finidori, J., et al. (1994). The GH receptor and signal transduction. Horm Res , 42(4-5), 133-9.

Kiefer, H., Krieger, J., Olszewski, J. D., Von Heijne, G., Prestwich, G. D., \& Breer, H. (1996). Expression of an olfactory receptor in Escherichia coli: purification, reconstitution, and ligand binding. Biochemistry, 35(50), 16077-84.

Kurfurst, M. M. (1992). Detection and Molecular Weight Determination of Polyethylene Glycol-Modified Hirudin by Staining after Sodium Dodecyl Sulfate-Polyacrylamide Gel Electrophoresis. Analytical Biochemistry , 200, 244-248.

Kyte, J. \& Doolittle, R. F. (1982). A simple method for displaying the hydropathic character of a protein. J Mol Biol , 157(1), 105-32.

Ladd, D. L. \& Snow, R. A. (1993). Reagents for the Preparation of Chromophorically Labeled Polyethylene Glycol-Protein Conjugates. Analytical Biochemistry, 210, 258-263.

Lantz, M. S. \& Ciborowski, P. (1994). Zymographic techniques for detection and characterization of microbial proteases. Methods Enzymol, 235, 563-94.

Lehrer, S. S. (1975). Intramolecular crosslinking of tropomyosin via disulfide bond formation: evidence for chain register. Proc Natl Acad Sci U S A , 72(9), 337781 .

Lehrer, S. S. (1978). Effects of an interchain disulfide bond on tropomyosin structure: intrinsic fluorescence and circular dichroism studies. $J$ Mol Biol , 118(2), 209 26.

Lemmon, M. A. \& Engelman, D. M. (1994). Specificity and promiscuity in membrane helix interactions. $Q$ Rev Biophys, 27(2), 157-218.

Liu, L.-P., Li, S.-C., Goto, N. K., \& Deber, C. M. (1996). Threshold Hydrophobicity Dictates Helical Conformations of Peptides in Membrane Environments. Biopolymers , 39, 465-470.

Lu, Y.-A. \& Felix, A. M. (1993). Pegylated Peptides I: Solid-Phase Synthesis of Nalpha-Pegylated Peptides Using Fmoc Strategy. Peptide Research , 6(3), 140146.

Marsh, D. (1996). Peptide models for membrane channels. Biochem J, 315(Pt 2), 345-61.

Matsushima, A., Okada, M., \& Inada, Y. (1984). Chymotrypsin modified with polyethylene glycol catalyzes peptide synthesis reaction in benzene. FEBS Lett , 178(2), 275-7.

Mel, H. C. \& Ross, D. W. (1975). Biophysics of cell separations. [Review] [49 refs]. $Q$ Rev Biophys , 8(3), 421-38. 
Mingarro, I., von Heijne, G., \& Whitley, P. (1997). Membrane-protein engineering. Trends Biotechnol, 15(10), 432-7.

Miroux, B. \& Walker, J. E. (1996). Over-production of proteins in Escherichia coli: mutant hosts that allow synthesis of some membrane proteins and globular proteins at high levels. J Mol Biol , 260(3), 289-98.

Moll, T. S. \& Thompson, T. E. (1994). Semisynthetic Proteins: Model Systems for the Study of the Insertion of Hydrophobic Peptides into Preformed Lipid Bilayers. Biochemistry, 33(51), 15469-15482.

Montal, M. (1990). Molecular anatomy and molecular design of channel proteins. Faseb J , 4(9), 2623-35.

Mori, S., Nakata, Y., \& Endo, H. (1992). Biosynthesis of cholesterol linoleate by polyethylene glycol-modified cholesterol esterase in organic solvents. Biotechnol Appl Biochem , 15(3), 278-82.

Moroi, Y. (1992). Micelles: theoretical and applied aspects. New York: Plenum Press.

Morpurgo, M., Veronese, F. M., Kachensky, D., \& Harris, J. M. (1996). Preparation of characterization of poly(ethylene glycol) vinyl sulfone. Bioconjug Chem, 7(3), 363-8.

Musu, T., Azarkan, M., Brygier, J., Paul, C., Vincentelli, J., Baeyens-Volant, D., Guermant, C., et al. (1996). Reversible Modification of Thiol-Containing Polypeptides with Poly(ethylene glycol) Through Formation of Mixed Disulfide Bonds. Applied Biochemisty and Biotechnology , 56, 243-263.

Oolson, I. \& Tooke, N. E. (1995). PAGE of basic proteins, Phastsystem TM User Manual, (Application File No. 300). Sweden: Pharmacia Biotech.

Opella, S. J. (1997). NMR and membrane proteins. Nat Struct Biol, 4(5), 845-8.

Osterberg, E., Bergstrom, K., Holmberg, K., Schuman, T. P., Riggs, J. A., Burns, N. L., Van Alstine, J. M., et al. (1995). Protein-rejecting ability of surfacebound dextran in end-on and side- on configurations: comparison to PEG. $J$ Biomed Mater Res , 29(6), 741-7.

Pasta, P., Riva, S., \& Carrea, G. (1988). Circular dichroism and fluorescence of polyethylene glycol-subtilisin in organic solvents. FEBS Lett, 236(2), 329-32.

Peng, S., Liu, L. P., Emili, A. Q., \& Deber, C. M. (1998). Cystic fibrosis transmembrane conductance regulator: expression and helicity of a double membrane-spanning segment. FEBS Lett , 431(1), 29-33.

Pollack, A. \& Whitesides, G. M. (1976). Organic Synthesis Using Enzymes in TwoPhase Aqueous Ternary Polymer Systems. Journal of the American Chemical Society , 98(1), 289-291.

Pomroy, N. C. \& Deber, C. M. (1998). Solubilization of hydrophobic peptides by reversible cysteine PEGylation. Biochem Biophys Res Commun , 245(2), 61821 .

Popot, J. L. \& Saraste, M. (1995). Engineering membrane proteins. Curr Opin Biotechnol, 6(4), 394-402. 
Powell, G. M. I. (1980). Polyethylene Glycol. In R. L. Davidson (Ed.), Handbook of Water-Soluble Gums and Resins, . Toronto: McGraw-Hill Book Company.

Preusch, P. C., Norvell, J. C., Cassatt, J. C., \& Cassman, M. (1998). Progress away from 'no crystals, no grant' [letter]. Nat Struct Biol , 5(1), 12-4.

Ray, W. J., Jr. (1992). Effect of polyethylene glycol-400 at low concentrations on long-term growth of muscle phosphoglucomutase crystals from concentrated salt solutions. Proteins, 14(2), 300-8.

Reisfield, R. A., Lewis, U. J., \& Williams, D. E. (1962). Disc electrophoresis of basic proteins and peptides on polyacrylamide gels. Nature , 195, 281-283.

Riddles, P. W., Blakeley, R. L., \& Zerner, B. (1979). Ellman's Reagent: 5,5'Dithiobis(2-nitrobenzoic Acid) -- a Reexamination. Analytical Biochemistry, 94, 75-81.

Riddles, P. W., Blakeley, R. L., \& Zerner, B. (1983). Reassessment of Ellman's Reagent. Methods in Enzymology, 91, 49-60.

Shai, Y. (1995). Molecular recognition between membrane-spanning polypeptides. Trends Biochem Sci , 20(11), 460-4.

Sirokman, G. \& Fasman, G. D. (1993). Refolding and Proton Pumping Activity of a Polyethylene glycol-Bacteriorhodopsin Water-Soluble Conjugate. Protein Science , 2, 1161-1170.

Skoog, B. (1979). Determination of Polyethylene Glycols 4000 and 6000 in Plasma Protein Preparations. Vox Sang , 37, 345-349.

Sliwkowski, M. X. \& Levine, R. L. (1985). Labeling of cysteine-containing peptides with 2-nitro-5-thiobenzoic acid. Anal Biochem, 147(2), 369-73.

Smith, A. J. (1997). Amino acid analysis. Methods Enzymol , 289, 419-26.

Snider, J., Neville, C., Yuan, L. C., \& Bullock, J. (1992). Characterization of the heterogeneity of polyethylene glycol-modified superoxide dismutase by chromatographic and electrophoretic techniques.J Chromatogr, 599(1-2), 141-55.

Takeda, K., Shigemura, A., Hamada, S., Gu, W., Fang, D., Sasa, K., \& Hachiya, K. (1992). Dependence of Reaction Rate of 5,5'-Dithiobis-(2-Nitrobenzoic Acid) to Free Sulfhydryl Groups of Bovine Serum Albumin and Ovalbumin on the Protein Conformations. Journal of Protein Chemistry , 11(2), 187-192.

Tjerneld, F. \& Johansson, G. (1990). Aqueous two-phase systems for biotechnical use. Bioseparation , 1(3-4), 255-63.

Tomich, J. M., Carson, L. W., Kanes, K. J., Vogelaar, N. J., Emerling, M. R., \& Richards, J. H. (1988). Prevention of aggregation of synthetic membranespanning peptides by addition of detergent. Anal Biochem, 174(1), 197-203.

Traxler, B., Boyd, D., \& Beckwith, J. (1993). The topological analysis of integral cytoplasmic membrane proteins. J Membr Biol , 132(1), 1-11. 
Tuma, R., Russell, M., Rosendahl, M., \& Thomas, G. J. J. (1995). Solution Conformation of the Extracellular Domain of the Human Tumor Necrosis Factor Receptor Probed by Raman and UV-Resonance Raman Spectroscopy: Structural Effects of an Engineered PEG Linker. Biochemistry, 34, $15150-15156$.

Veronese, F. M., Largajolli, R., Boccu, E., Benassi, C. A., \& Schiavon, O. (1985). Surface modification of proteins. Activation of monomethoxy-polyethylene giycols by phenylchloroformates and modification of ribonuclease and superoxide dismutase. Appl Biochem Biotechnol, 11(2), 141-52.

Vitello, L., Kresheck, G. C., Albers, R. J., Erman, J. E., \& Vanderkooi, G. (1979). Block Poly(Ala)-Poly(Lys): A Water-Soluble Model for Intrinsic Membrane Proteins? Biochimica et Biophysica Acta , 557, 331-339.

Wagner, G. (1997). An account of NMR in structural biology. Nat Struct Biol , 4 Suppl., 841-4.

Walmsley, T. A., Abernethy, M. H., \& Fitzgerald, H. P. (1987). Effect of Daylight on the Reaction of Thiols with Ellman's Reagent, 5,5'-Dithiobis(2-Nitrobenzoic acid). Clinical Chemistry, 33(10), 1928-1931.

Wei, J. \& Fasman, G. D. (1995). A Poly(Ethylene Glycol) Water-soluble Conjugate of Porin: Refolding to the Native State. Biochemistry, 34(19), 6408-6415.

Wu, N. Z., Da, D., Rudoll, T. L., Needham, D., Whorton, A. R., \& Dewhirst, M. W. (1993). Increased microvascular permeability contributes to preferential accumulation of Stealth liposomes in tumor tissue. Cancer Res , 53(16), 376570.

Zalipsky, S. \& Lee, C. (1992). Use of Functionalized Poly(Ethylene Glycol)s for Modification of Polypeptides. In J. M. Harris (Ed.), Poly(Ethylene Glycol) Chemistry: Biotechnical and Biomedical Applications, . New York: Plenum Press.

Zalipsky, S., Seltzer, R., \& Menon-Rudolph, S. (1992). Evaluation of a New Reagent for Covalent Attachment of Polyethylene Glycol to Proteins. Biotechnology and Applied Biochemistry , 15, 100-114. 